FINAL REPORT

\title{
A CERCLA-BASED DECISION MODEL TO SUPPORT REMEDY SELECTION FOR AN UNCERTAIN VOLUME OF CONTAMINANTS AT A DOE FACILITY
}

Christine E. Kerschus

\section{AFIT/GEE/GOR/97D-01}

Approved for public release; distribution unlimited 
AFIT/GEE/GOR/97D-01

\begin{abstract}
A CERCLA-BASED DECISION MODEL TO SUPPORT REMEDY SELECTION FOR AN UNCERTAIN VOLUME OF CONTAMINANTS AT A DOE FACILITY
\end{abstract}

\title{
THESIS
}

Presented to the Faculty of the Graduate School of Engineering of the Air Force Institute of Technology

\author{
Air University \\ In Partial Fulfillment of the \\ Requirements for the Degree of \\ Master of Science in Engineering and Environmental Management
}

Christine E. Kerschus

December, 1997

Approved for public release; distribution unlimited 


\section{THESIS APPROVAL}

STUDENT: Christine E. Kerschus

CLASS: GEE-97D

THESIS TITLE: A CERCLA-Based Decision Model to Support Remedy Selection for an Uncertain Volume of Contaminants at a DOE Facility

DEFENSE DATE: 24 November 1997

COMMITTEE： NAME/TITLE/DEPARTMENT

SIGNATURE

Advisor

Jack M: Kloeber Jr., Lieutenant Colonel, USA

Assistant Professor of Operations Research

Department of Operational Sciences

Reader

Jack A. Jackson Jr., Lieutenant Colonel, USAF

Assistant Professor of Operations Research

Department of Operational Sciences

Reader Richard F. Deckro, DBA

Professor of Operations Research

Department of Operational Sciences

Reader Mark N. Goltz, PhD

Associate Professor of Eng \& Env

Department of Eng \& Env Management 


\section{Acknowledgments}

This effort would not have been possible without the guidance, patience, and experience of LTC Jack Kloeber. His enthusiasm for educating has greatly enhanced my AFIT education and has forever impacted the way I will make decisions. I would also like to thank the other members of my committee: Lt Col Jack Jackson, who taught me to try to keep things focused, Dr. Richard Deckro, who helped me see the "big picture", and Dr. Goltz, who was the lone environmental member attempting to keep us all straight!

In addition I would also like to thank the entire WAG 6 Team (Jacobs, LMES, MSE, VCU, DOE). Their assistance and kindness made this experience all the more worthwhile.

My deepest gratitude is extended to my family and friends: my AFIT friends, who commiserated with me (Thanks Debbie and Helene!); my Mom and Dad, who always encouraged and believed in me; and my loving fiancé Sean O'Brien, who supported me beyond belief and after all of this-still wants to marry me! Finally, a hearty Mahalo! is extended to Mr. William Barry, the supervisor who made this life changing, AFIT experience possible. God bless you all. 


\section{Table of Contents}

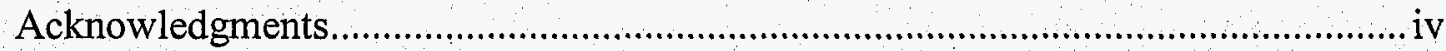

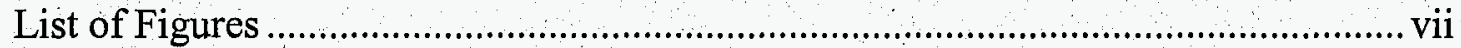

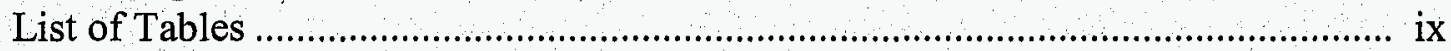

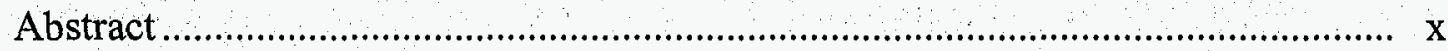

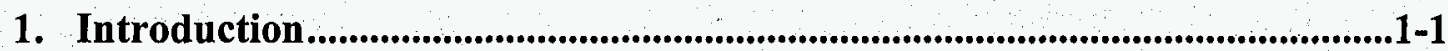

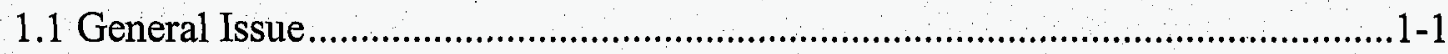

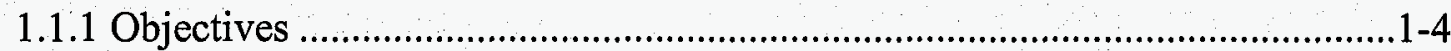

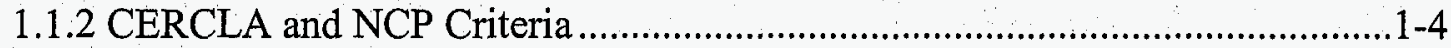

1.1.2.1 Threshold Criteria ............................................................................. 1-7

1.1.2.2 Modifying Criteria ............................................................................... $1-8$

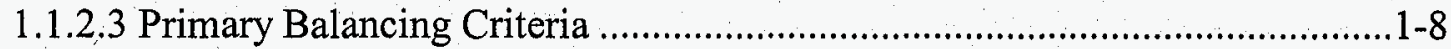

1.1.3 Remediation Technologies and Technology Trains..................................... 1-11

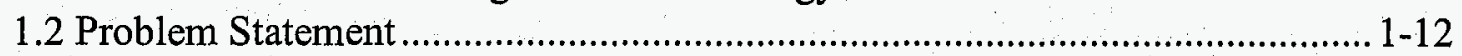

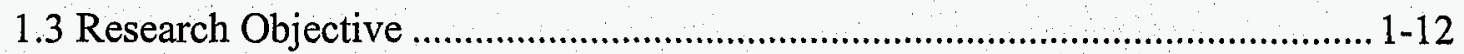

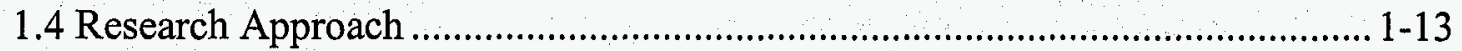

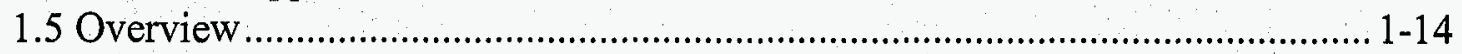

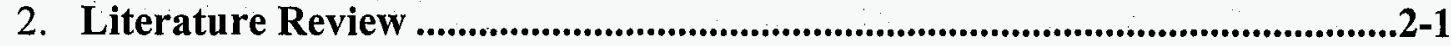

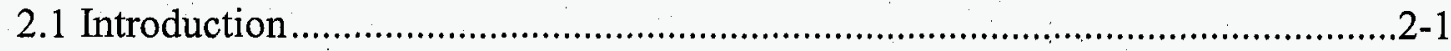

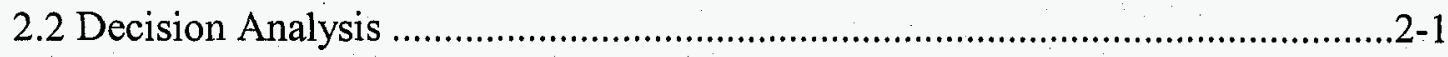

2.2.1 Identifying Decision Opportunities \& Understanding Objectives ....................2-2

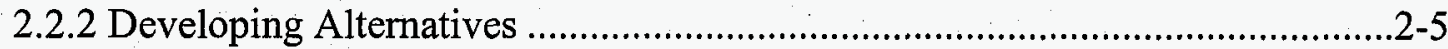

2.2.3 Decompose and Model the Decision Opportunity ..........................................2-7

2.2.3.1 Value Hierarchies.................................................................................2. $2-7$

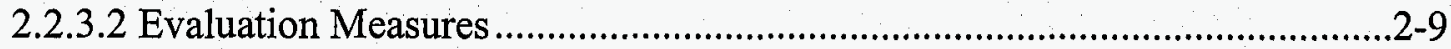

2.2.3.3 Multiattribute Preference Theory............................................................. 2-10

2.2.3.4 Assessing Weights ............................................................................... 2-14

2.2.3.5 Overall Value Function and the Power-Additive Utility Function .............. 2-15

2.2.4 The Final Four..................................................................................... 2-17

2.3 Decision Analysis (DA) Applications in the CERCLA Arena ........................ 2-18

2.4 DA Applications in the Technology Selection Process at DOE Facilities......... 2-20

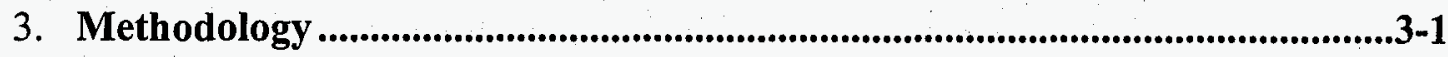

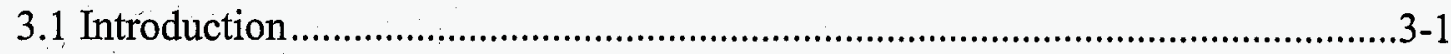

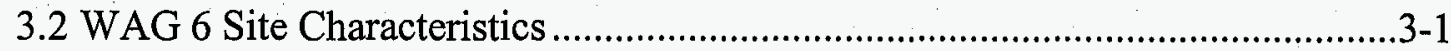

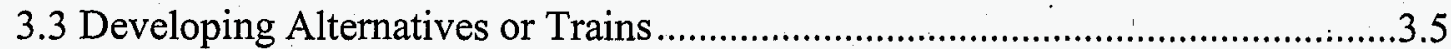

3.4 WAG 6 CERCLA Value Hierarchy .................................................................

3.5 Evaluation Measures, Scores, and Single Dimensional Value Functions.......... 3-10

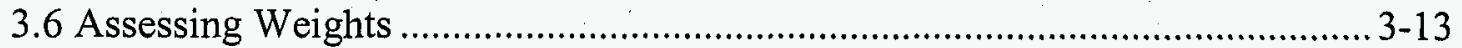

3.7 Application of Additive Value and Power-Additive Utility Functions ............. 3-15 
3.7.1 Uncertainty.....

3.8 The Decision Models: Deterministic and Probabilistic ....................................3-19

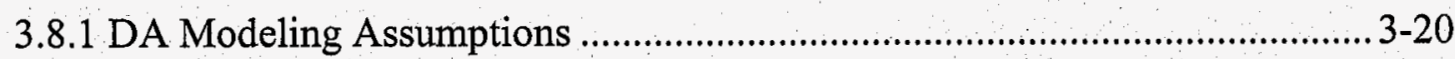

3.8.2 Life Cycle Cost Modeling Assumptions ........................................................ 3-22

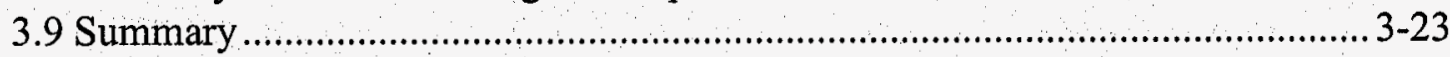

4. Results and Analysis .............................................................................................4-1

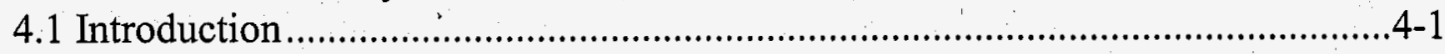

4.2 Deterministic Results ..............................................................................

4.3 Required CERCLA Analysis ……..................................................................

4.4 Criteria Weight Sensitivity Analysis.................................................................. 4-11

4.5 Discussion of Train Rankings as Affected by Volume......................................... 4-13

4.6 Probabilistic Analysis ............................................................................... 4-14

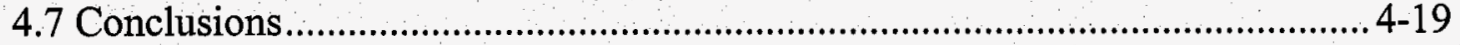

5. Findings, Conclusions, and Recommendations ....................................................5-1

5.1 Summary of Analysis and Results ................................................................

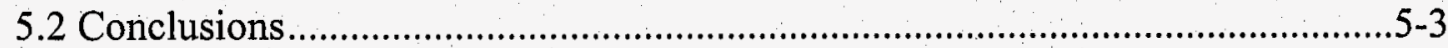

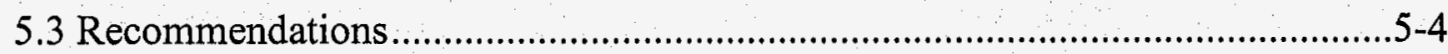

\section{Appendices:}

Appendix A: Spill Volume Distribution................................................................ A-1

Appendix B: WAG 6 CERCLA Hierarchy, Evaluation Measures and Weights .... B-1

Appendix C: Technology Descriptions ............................................................

Appendix D: Scoring Packet......................................................................

Appendix E: Expected CERCLA Values/Utilities for All Trains \& All Volumes. E-1

Appendix F: Sensitivity Analysis of the Multiattribute Risk Tolerance Factor..... F-1

Appendix G: Technology Performance Calculations for Tc-99 ……………….........

Appendix H: Deterministic Models ...................................................................... H-1

Appendix I: Probabilistic Models .........................................................................

Appendix J: Deterministic Results .......................................................................... J-1

Appendix K: Criteria Weight Sensitivity Analysis .................................................. K-1

Appendix L: Probabilistic Results ........................................................................ L-1

Appendix M: MSE Life Cycle Cost Data .................................................................

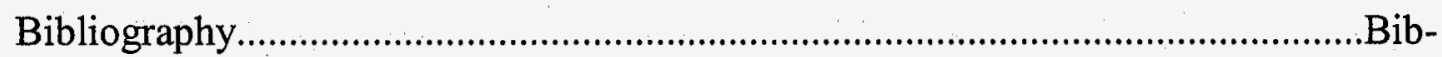




\section{List of Figures}

Figure 1.1 CERCLA criteria hierarchy [EPA/540/G-89/004,1989:6-7] ................1-7

Figure 2.1 Modified decision analysis process flowchart [Clemen, 1996:6] ............2-2

Figure 2.2 Short-Term effectiveness hierarchy [40 CFR S300.430(e)(9)(iii)(E)] ....2-9

Figure 2.3 Example of a monotonically increasing function ...............................2-13

Figure 2.4 Example of a monotonically decreasing function............................... 2-14

Figure 3.1 Cumulative probability distribution of TCE spill volume......................3-2

Figure 3.2 Conceptual spill model of the TCE contaminant plume..........................3-4

Figure 3.3 CERCLA criteria and sub-criteria hierarchy .......................................

Figure 3.4 WAG 6's CERCLA based criteria and sub-criteria...............................3-9

Figure 3.5 WAG 6 hierarchy showing balancing criteria weights ....................... 3-13

Figure 3.6 Long-Term effectiveness hierarchy and weights 3-14

Figure 3.7 Decision and risk methodology used for train selection....................... 3-24

Figure 4.1 Overall CERCLA ranking for 50,000 gallon spill.................................4-2

Figure 4.2 Overall CERCLA ranking for 500,000 gallon spill .................................4-4

Figure 4.3 Overall CERCLA ranking for 100,000 gallon spill................................4-5

Figure 4.4 Net present cost rankings only (100,000 gallon spill) ..........................4-6

Figure 4.5 Short-Term effectiveness rankings only (100,000 gallon spill) ..............4-7

Figure 4.6 Net present cost vs. overall effectiveness (at 100,000 gallons) ...............4-9

Figure 4.7 Net present cost vs. overall CERCLA value (at 100,000 gallons) ........4-10

Figure 4.8 Weight sensitivity analysis at 100,000 gallons...................................4-11

Figure 4.9 Train rankings for differing spill volumes......................................... 4-14

Figure 4.10 Risk profile of overall CERCLA utility............................................ 4-16

Figure 4.11 Risk profile of net present cost ..................................................... 4-17

Figure 4.12 Risk profile for time ................................................................. 4-19

Figure A.1 Spill volume distribution .......................................................... A-1

Figure A.2 Probability density function ........................................................

Figure B.1 CERCLA value hierarchy and associated weights............................ B-1

Figure B.2 Long-term effectiveness and permanence hierarchy......................... B-3

Figure B.3 Evaluation measure for residual risk from hazardous materials ........... B-5

Figure B.4 Evaluation measure for residual risk from TCE ............................... B-6

Figure B.5 Evaluation measure for residual risk from Tc-99 ............................. B-7

Figure B.6 Evaluation Measure for adequacy and reliability of controls................ B-8

Figure B.7 Reduction of toxicity, mobility, or volume hierarchy .......................... B-9

Figure B.8 Evaluation measure for treatment employed and materials treated .....B-11

Figure B.9 Evaluation measure for TCE destroyed, treated or recycled.................. 12

Figure B.10 Evaluation measure for TC-99 destroyed, treated, or recycled ...........B-13

Figure B.11 Evaluation measure for reduction in toxicity .................................14

Figure B-12 Evaluation measure for reduction of mobility of TCE ...................... 15

Figure B.13 Evaluation measure for reduction of mobility of Tc-99.......................15

Figure B.14 Evaluation measure for the reduction of volume of TCE zone............B-16 
Figure B.15 Evaluation measure for the reduction' of volume of the Tc-99 zone...B-17

Figure B.16 Evaluation measure for irreversible treatment of TCE ........................B-17

Figure B.17 Evaluation measure for irreversible treatment of TC-99 ......................B-18

Figure B.18 Short-term effectiveness hierarchy ...............................................19

Figure B.19 Evaluation measure for risks posed to the community ........................... 20

Figure B.20 Evaluation measure for potential impact on workers.............................. 21

Figure B.21 Evaluation measure for potential surface releases ................................ B-22

Figure B.22 Evaluation measure for potential subsurface injection of materials ...B-23

Figure B.23 Evaluation measure for time until protection is achieved.....................

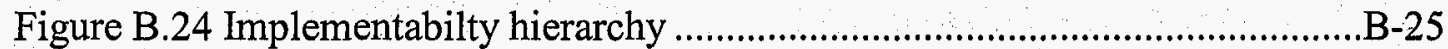

Figure B.25 Evaluation measure for unknowns associated with construction.........B-27

Figure B.26 Evaluation measure for tech. diff's. assoc. w/construction and ops. ..B-28

Figure B.27 Evaluation measure for reliability of the technology .............................

Figure B.28 Evaluation measure for the ease of undertaking future remediation...B-30

Figure B.29 Evaluation measure for monitoring effectiveness of remedy...............B-31

Figure B.30 Evaluation measure for administrative feasibility................................... B-32

Figure B.31 Evaluation measure for availability of off site treatment, etc..............B-33

Figure B.32 Evaluation measure for availability of necessary equipment and spec.

Figure B.33 Cost hierarchy

Figure B.34 Evaluation measure for net present cost ............................................

Figure F.1 Varying shapes of the multi-attribute risk tolerance factor .......................F-1

Figure H.1 Long-term effectiveness and permanence hierarchy............................... H-1

Figure H.2 Reduction of toxicity, mobility, or volume hierarchy.............................

Figure H.3 Short-term effectiveness hierarchy .................................................. H-3

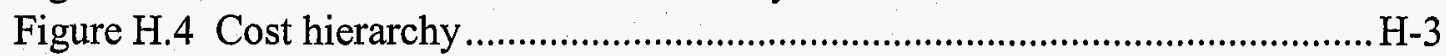

Figure H.5 Implementability hierarchy ...............................................................

Figure I.1 DPL decision tree for overall CERCLA value .............................................-2

Figure I.2 DPL decision tree for net present cost..........................................................-3

Figure I.3 DPL decision tree for time to remediate......................................................-4

Figure J.1 Long-term effectiveness and permanence rankings at 100,000 Gal .........J-7

Figure J.2 Reduction of TMV rankings at 100,000 gallons......................................

Figure J.3 Implementability rankings at 100,000 gallons ........................................

Figure K.1 Sensitivity of long-term effectiveness weight...................................... K-2

Figure K.2 Sensitivity of reduction of TMV weight............................................. K-2

Figure K.3 Sensitivity of short-term effectiveness weight...................................... K-3

Figure K.4 Sensitivity of implementability weight.............................................. K-3

Figure K.5 Sensitivity of cost weight.................................................................. K-4

\section{List of Tables}

Table 2.1 Example strategy generation table for technology trains ............................2-6

Table 2.2 DA models used in CERCLA applications...........................................2-18

Table 3.1 Discrete probabilities assessed for TCE spill volumes................................3-1 
Table 3.2 Example strategy generation table for technology trains ............................

Table 3.3 Technology trains evaluated ........................................................................ 3-6

Table 3.4 WAG 6 CERCLA criteria/sub-criteria and evaluation measures ............ 3-10

Table 4.1 Overall CERCLA \& balancing criteria values for all trains $(50,000) \ldots \ldots . .4-3$

Table 4.2 Sensitivity of train 9 to adjustments in criteria weights.......................... 4-12

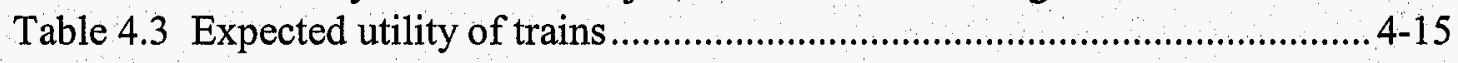

Table 4.4 Summary of top four train rankings............................................... 4-20

Table 5.2 Description of top four trains.................................................................5-2

Table 5.2 Expected CERCLA value/utility of top trains .............................................5-3

Table F.1 Sensitivity of trains to variance in $\rho(\mathrm{m})$...................................................F-2

Table G.2 Tc-99 Concentration for UVB, oxidation, and the no action alt............ G-2

Table H.1 Evaluation measures and single dimensional value function.................. H-5

Table H.2 Varying evaluation measure scores $(50,000$ gallon spill) ......................... H-8

Table H.3 Varying evaluation measures $(50,000$ gallon spill).................................. H-8

Table H.4 Constant evaluation measures and scores ..................................................-10

Table H.5 Constant evaluation measures and scores ..............................................

Table J.1 Overall CERCLA and balancing criteria value at 50,000 gallons..............J-1

Table J.2 Overall CERCLA and balancing criteria value at 100,000 gallons............J-2

Table J.3 Overall CERCLA and balancing criteria value at 200,000 gallons.............-3

Table J.4 Overall CERCLA and balancing criteria value at 300,000 gallons............. J-4

Table J.5 Overall CERCLA and balancing criteria value at 400,000 gallons............. -5

Table J.6 Overall CERCLA and balancing criteria value at 500,000 gallons............J-6

Table J.7 Train rankings at all spill volumes ......................................................... J-10

Table L.1 Expected CERCLA utility for top four trains.............................................-1

Table L.2 Expected net present cost for top four trains ..............................................

Table L-3 Expected time until protection achieved ....................................................-1 


\begin{abstract}
The Paducah Gaseous Diffusion Plant (PGDP) operated by the Department of Energy is challenged with selecting the appropriate remediation technology to cleanup contaminants at Waste Area Group (WAG) 6. This research utilizes value-focused thinking and multiattribute preference theory concepts to produce a decision analysis model designed to aid the decision makers in their selection process. The model is based on CERCLA's five primary balancing criteria, tailored specifically to WAG 6 and the contaminants of concern, utilizes expert opinion and the best available engineering, cost, and performance data, and accounts for uncertainty in contaminant volume. The model ranks 23 remediation technologies (trains) in their ability to achieve the CERCLA criteria at various contaminant volumes. A sensitivity analysis is performed to examine the effects of changes in expert opinion and uncertainty in volume. Further analysis reveals how volume uncertainty is expected to affect technology cost, time and ability to meet the CERCLA criteria. The model provides the decision makers with a CERCLA-based decision analysis methodology that is . objective, traceable, and robust to support the WAG 6 Feasibility Study. In addition, the model can be adjusted to address other DOE contaminated sites.
\end{abstract}




\section{A CERCLA Based Decision Model to Support Remedy Selection for an Uncertain Volume of Contaminants at a DOE Facility}

\section{Introduction}

\subsection{General Issue}

The Department of Energy (DOE) and its predecessor agencies have been involved in the research, production and testing of nuclear weapons since the 1940s. During that time, numerous facilities, both government and privately-owned, were constructed or leased across the country to support these efforts. These facilities generated large quantities of radioactive and hazardous materials which, unfortunately, contaminated many of the facilities and surrounding areas. The DOE's Oak Ridge Operations Office, which is responsible for four such facilities, estimates that it will take from $\$ 8.9$ to $\$ 9.6$ billion to cleanup the four facilities in their area of responsibility by 2015 [http:www.em.doe.gov/add2006/ores.html: June 1997]. One such facility is the Paducah Gaseous Diffusion Plant.

The Department of Energy owns an active uranium enrichment facility in Paducah, Kentucky, known as the Paducah Gaseous Diffusion Plant (PGDP). The PGDP is located 10 miles west of Paducah, a city of approximately 31,000 , and 3.5 miles south of the Ohio river. The Paducah facility was constructed in 1951 and began operation in 1952 . The plant enriches the most abundant isotope of uranium,

${ }^{238} \mathrm{U}$, to ${ }^{235} \mathrm{U}$, a more fissile material. The enrichment process is complicated. It begins by converting naturally occurring uranium to uranium hexafluoride $\left(\mathrm{UF}_{6}\right)$ gas. 
The $\mathrm{UF}_{6}$ feedstock is then pumped through micropores in a series of membranes to facilitate separation of the two isotopes, ${ }^{238} \mathrm{U}$ and ${ }^{235} \mathrm{U}$. Diffusion through the micropores is mass dependent; however, because the difference in mass is so small, it takes a large number of separation membranes (over 1000) arranged in a cascade to capture a ${ }^{235} \mathrm{U}$ enrichment of several percent [DOE/OR/07-1243\&D4, 1997: 4-4].

Most of the $\mathrm{UF}_{6}$ was produced from feedstock, which came from the PGDP feed plant that processed both natural uranium and uranium from reactor tails. The uranium from the reactor tails included uranium that had been returned for reenrichment from the plutonium production reactors at the DOE Hanford and Savannah River plants. The reactor tails received after 1975 were placed in storage rather than being processed and contained technetium-99 (Tc-99). These tails are believed to be the sole source of the Tc-99 that has been released into the environment at PGDP [DOE/OR/07-1243\&D4, 1997: 4-4].

Since the plant's construction, trichloroethylene (TCE) has been used as a cleaning solvent to decontaminate equipment and waste material before disposal. TCE is a Dense Non-Aqueous Phase Liquid (DNAPL), an immiscible fluid with a density greater than water. TCE currently ranks $13^{\text {th }}$ on the Agency for Toxic Substances and Disease Registry (ATSDR)/Environmental Protection Agency's Top 20 Hazardous Substances 1995 list [http://atsdr1.atsdr.cdc.gov:8080/cxcx3.html Note that this list is updated periodically by ATSDR and EPA to meet the requirements of the Comprehensive Environmental Response Compensation and Liability Act section 104]. Although TCE is not currently recognized as a cancer 
causing chemical, a partially degraded product originating from TCE, known as vinyl chloride, is carcinogenic and ranks number four on ATSDR's top 20 list. The use of TCE as a degreaser at PGDP ceased on July 1, 1993 [DOE/OR/07-1243\&D4, 1997:

4-4]; however, it is unclear how much TCE was released to the environment over the years of its use at PGDP. Estimated spill volumes range anywhere from a minimum of 2,000 to a maximum of 500,000 gallons of TCE [Papatyi, 1997: 3-3].

Effective May 31, 1994, the PGDP was placed on the National Priorities List (NPL) by the U.S. Environmental Protection Agency (EPA). The Paducah Site Baseline Summary projects that as much as $\$ 255.714$ million will be spent in remediation efforts from 1997 through 2006 and an additional \$363.212 million will be spent from 2007 through remediation completion. This expected short term funding level totals $\$ 618.926$ million, and assumes DOE receives the funds necessary for cleanup when needed [EI00000-0197]. The DOE's EM50 Subsurface Contaminants Focus Area has requested an analysis that will assist in the selection of remediation technologies, or groups of technologies, known as technology trains for their Waste Area Group (WAG) 6 site at PGDP. These technology trains can be used to remediate or clean up and control the level of contamination, such that the protection of human health and the environment will not be compromised by the principal contaminants of concern (PCOCs) at WAG 6, henceforth to be defined as TCE and Tc-99.

\subsubsection{DOE Objectives}


The primary objective of the DOE is to work with the EPA and Kentucky Department for Environmental Protection through a negotiated Federal Facilities Agreement (FFA). The draft FFA sets forth requirements to address releases of hazardous or radioactive substances by investigating solid waste management units (SWMUs) and areas of concern through an integrated remedial investigation/feasibility study process (RI/FS). Five SWMUs have been combined into a single Waste Area Grouping known as WAG 6. The objectives of the integrated RL/FS for WAG 6 at PGDP are to collect sufficient information on each SWMU, to evaluate the risk-based impact to human health and the environment, determine the nature and extent of contamination, and collect data for the support of the feasibility study (FS) [DOE/OR/07-1243\&D4, 1997: ES-1]. In order to meet these objectives and ultimately determine whether the site remediation is possible, the decision makers turned to the Comprehensive Environmental Response, Compensation and Liability Act (CERCLA) and the nine technology performance criteria specified in the RI/FS processes described in the National Contingency Plan (NCP) [DOE/OR/07-1243\&D4, 1997:1-11].

\subsubsection{CERCLA and NCP Criteria}

The Comprehensive Environmental Response, Compensation and Liability Act, commonly referred to as "CERCLA" or "Superfund", was enacted by Congress in 1980. CERCLA's enactment stemmed from an emerging realization, most directly associated with the Love Canal tragedy, that inactive hazardous waste sites presented great risk to public health as well as the environment, and that there were no existing 
regulations to address abandoned sites. CERCLA's primary intent was to address the past disposal of hazardous substances at these sites. CERCLA defines "hazardous substances" as those substances that are listed or designated under other environmental statutes; for example "hazardous wastes" under the Resource Conservation and Recovery Act (RCRA), "hazardous substances" under the Clean Water Act, "toxic pollutants" under the Clean Air Act, and "imminently hazardous chemical substances or mixtures" under the Toxic Substances Control Act (TSCA) [Lee, 1995: 227].

CERCLA requires the EPA to develop a ranking of the most hazardous waste sites across the nation. This ranking is known as the National Priorities List (NPL) and is updated yearly. In order to determine which sites belonged on the NPL, a hazardous ranking system was developed to score the sites. Once a site is placed on the NPL, it is subject to public comment and review.

In 1986, CERCLA was extensively amended with the Superfund Amendments and Reauthorization Act (SARA). In part, these amendments reflected Congress' great concern for federal facilities meeting the requirements of CERCLA, so they created an entire section, section 120, devoted to federal facility cleanup [Lee, 1995: 276]. Section 120 dictates that any federal facility that manages hazardous waste or has potential hazardous waste problems be scored under the hazardous ranking system to determine whether it should be placed on the NPL. If placed on the NPL, the facility must begin a remedial investigation/feasibility study (RI/FS) within six months of its listing. While the RI/FS is underway, the federal agency responsible for 
the site must work with the EPA and state where the site is located to ensure the RI/FS process is as complete and focused as possible [Lee, 1995: 276].

In order to accomplish the cleanup of hazardous waste sites, CERCLA refers to the methodology prescribed in the National Contingency Plan (NCP). When performing a CERCLA based response action or cleanup, the procedures set forth in the NCP must be followed by the EPA and the federal facility. The NCP establishes criteria for determining the appropriate environmental response by outlining the procedures to be followed in performing cleanups, remedial actions or removal actions. However, the guidance is often vague, and many times unclear, with numerous redundancies. Because the NCP fails to specify the type of remediation technology to employ at each type of hazardous waste site, technology selection is often a subject of intense debate in CERCLA proceedings [Lee, 1995: 232].

According to CERCLA and the NCP, there are nine performance criteria to be considered when comparing and selecting remediation technologies or technology trains. The nine criteria are divided into the following three distinct groups: Modifying Criteria, Threshold Criteria, and Primary Balancing Criteria and are presented in Figure 1.1[40 CFR S300.430(e)(9)(iii)]: 


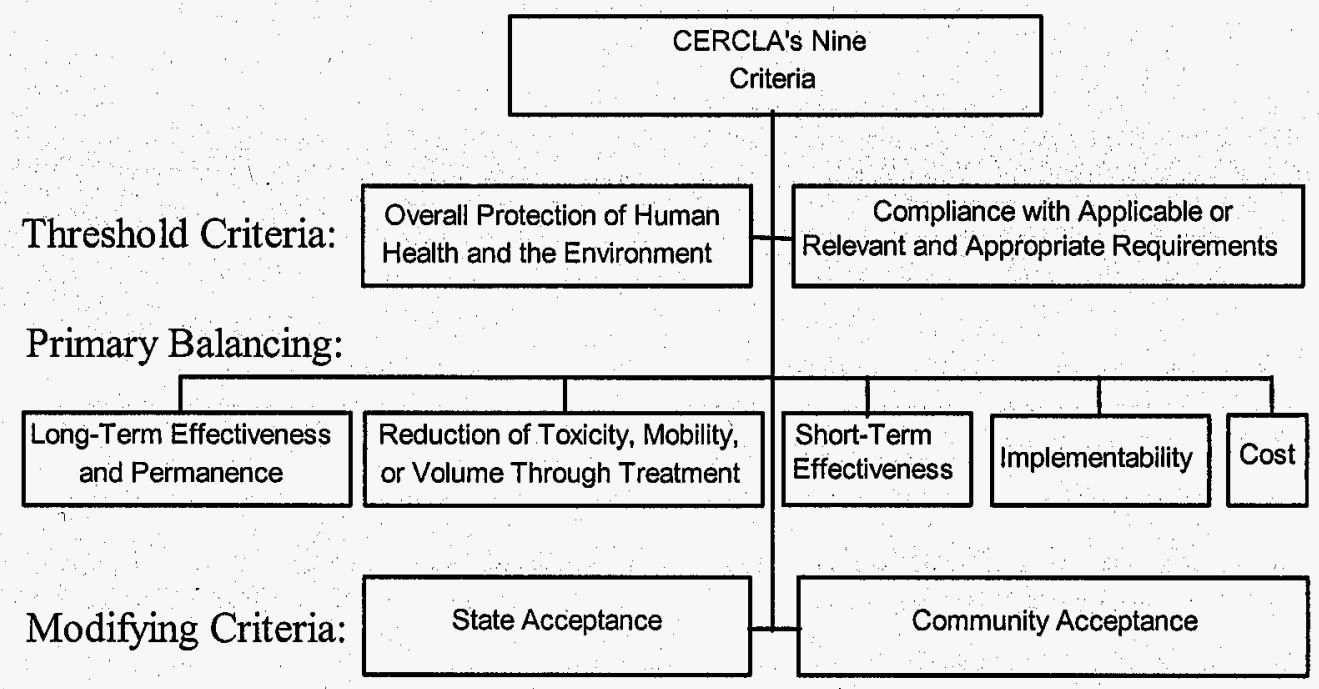

Figure 1.1 CERCLA criteria hierarchy [EPA/540/G-89/004, 1989: 6-7]

\subsubsection{Threshold Criteria}

The Threshold Criteria, consisting of the Overall Protection of Human Health and the Environment and Compliance with Applicable or Relevant and Appropriate Requirements (ARARs), are criteria that all remediation technologies considered must meet in order to be eligible for selection.

The Overall Protection of Human Health and the Environment criterion draws on the assessments conducted under other evaluation criteria, especially long-term effectiveness and permanence, short-term effectiveness, (both are primary balancing criteria) and compliance with ARARs. Compliance with ARARs mandates strict observance of all federal and state laws that have been identified earlier in the RI/FS process. When it is not possible to meet an ARAR, either the remediation technology/train is rejected (which is what was done at the site in this study) or 
allowable waivers can be obtained under the CERCLA process [EPA/540/G-89-004, 1989:6-6].

The Threshold Criteria serve to screen the candidate technologies/trains, as they are the first criteria considered. Therefore, in order for a remediation technology/train to even be considered for application, the technology/train must meet the Threshold Criteria.

\subsubsection{Modifying Criteria}

The Modifying Criteria, State and Community Acceptance, are considered after the remedial technology, or technology train, has been selected by the decision makers. These criteria encompass the review of the Remedial Investigation/ Feasibility Study (RI/FS) report and Proposed Plan, which details the remedial technology/train selected and proposes how it will be implemented. Both the public and the state, have the opportunity to review and comment on the report and the plan, prior to finalization. Once finalized, the remediation plan is known as the Record of Decision (ROD). The Modifying Criteria are the last criteria to be considered in the evaluation process, after the technological approach has been proposed, and thus will not be addressed in this research effort.

\subsubsection{Primary Balancing Criteria}

The five primary balancing criteria are grouped together because they represent the primary criteria upon which the analysis for selecting a remedial technology/train is based [EPA/540/G-89-004, 1989:6-6]. The approach taken in this research effort focuses specifically on these five criteria. 


\subsection{Long-Term Effectiveness and Permanence}

The evaluation of remediation technologies under this criterion addresses the longterm effectiveness and permanence the technology can achieve. In addition, it evaluates the success of the technology/train in terms of reducing the remaining risk at the site after response objectives have been met. This criterion also focuses on the adequacy and reliability of controls necessary to manage treatment residuals or untreated wastes [EPA/540/G-89-004, 1989:6-8].

\subsection{Reduction of Toxicity, Mobility, or Volume Through Treatment}

The degree to which technologies employ recycling or treatment that reduces toxicity, mobility, or volume shall be assessed, including how treatment is used to address the principal threats posed by the site, is considered under this criterion [40CFR S300.430(e)(9)(iii)(D)]. This criterion is applied to each technology/train and considers the following factors [EPA/540/G-89-004, 1989:6-8]:

- The treatment processes the technology train will employ and the materials that will be treated.

- The amount of hazardous materials that will be destroyed or treated, including how the principal threat(s) will be addressed.

- The degree of expected reduction in toxicity, mobility, or volume measured as a percentage of reduction (or order of magnitude).

- The degree to which the treatment will be irreversible.

- The type and quantity of treatment residuals that will remain following treatment.

- Whether the alternative would satisfy the statutory preference for treatment as a principal element. 


\subsection{Short-Term Effectiveness}

This criterion addresses the effects of a chosen technology during the construction and implementation phase until the remedial response (or cleanup) objectives are met. This criterion should be evaluated with respect to a technology/train's effect on human health and the environment during implementation of the remedial (or cleanup) action. Consideration should be lent to the following, applicable factors [EPA/540/G-89-004, 1989:6-9]:

- Protection of the community during remedial actions.

- Protection of workers during remedial actions.

- Environmental impacts.

- Time until remedial response objectives are achieved.

\subsection{Implementability}

This criterion assesses the technical and administrative feasibility of implementing a remediation technology/train as well as the availability of various services and materials required for its implementation [EPA/540/G-89-004, 1989:6-9].

\subsection{Cost}

The final balancing criterion assesses the cost of a remedial technology. Costs are expressed in net present cost and are broken into two categories: capital costs and operation and maintenance (O\&M) costs. Capital costs include direct costs, such as construction and equipment costs, and indirect costs, such as permit or startup costs. O\&M costs are post-construction costs that are required to execute the remedial action. Some examples of O\&M costs are maintenance materials, disposal of residues, and operating labor costs. 
Present worth analysis is used to evaluate cost outlays or expenditures, which occur over different time periods, by discounting future costs to a common base year. This allows the cost of all technologies to be compared on the basis of a single cost that represents the amount of money, if invested in the base year and distributed as required, would be sufficient to cover all costs associated with the remedial technology over its planned life [EPA/540/G-89-004, 1989:6-11,12].

\subsubsection{Remediation Technologies and Technology Trains}

The WAG 6 team, including the hydrogeologist, decided to attack the contamination by using three hydrogeologic zones: the unsaturated zone, saturated zone, and the aquifer. The decision makers decided that the remediation technologies/trains evaluated in this study will be designed to aggressively treat or remove the PCOCs (TCE and Tc-99) in all three zones. The mere containment of PCOCs is not considered an aggressive treatment and therefore containment is not considered a remedial option. Some technologies are designed to operate in only one zone. It is therefore sometimes necessary to implement more than one remediation technology so all three zones are treated. "Technology trains", or simply trains, are used to describe such a combination, where one remediation technology will treat both the saturated zone and aquifer, such as Pump and Treat, and another remediation technology will treat the zone, such as 6 Phase Heating. For consistency, the term technology train will be applied to all technologies or groups of technologies that are

designed to treat three zones. In addition to evaluating technology trains, selected by the decision makers, this research effort also evaluates the no action alternative, that 
requires no aggressive action towards cleanup. The no action alternative, while not satisfying the Threshold Criteria, is used as a baseline in this study from which other alternatives or technology trains are compared.

\subsection{Problem Statement}

The DOE site manager must incorporate the criteria established in CERCLA and the NCP as part of the RI/FS process to select a remedy for a site contaminated with an uncertain volume of PCOCs. Challenges at the site include: an operational building located on top of the site, complicated hydrogeology, uncertain remediation technology performance, and uncertain volume of PCOCs.

\subsection{Research Objective}

The primary objective of this research is to provide the DOE and the Paducah decision makers with a decision analysis methodology that will provide insight into selecting a technology train that is being considered for remediating WAG 6 , which is contaminated with TCE and Tc-99. A decision analysis model will be developed to quantify how well each technology train is expected to meet the CERCLA criteria. This model will also incorporate the uncertainties associated with volume; and hence, cost, time, and other affected measures used to quantify the overall utility of the technology trains.

\subsection{Research Approach}

This research effort begins by utilizing fundamental decision analysis principles of value-focused thinking and multiattribute preference theory, and employs such decision analysis tools as a value hierarchy, single dimensional value functions, the 
power-additive utility function, and sensitivity analysis. These principles and tools are all used with the aim of providing the best analysis possible of potential combinations of remediation technologies based on the CERCLA criteria. Valuefocused thinking techniques are used to assist the decision makers in creating a CERCLA based, but site and PCOC specific, value hierarchy. Once this value hierarchy is created, evaluation measures can be identified and single dimensional value functions defined. Weights, or preferences, are elicited from the decision makers. Each technology train or alternative is scored against each measure, which ultimately allows for the quantification of the decision makers' values. This information is incorporated into a decision analysis model, along with life cycle costs and technology performance data. The model will rank the remediation technology trains based on their expected utility. A sensitivity analysis of model variables, including criteria weights, completes the research effort by providing the decision makers with additional information about the top technology trains.

The model created is a combined effort between MSE Technology Applications Inc.(MSE), Virginia Commonwealth University (VCU) and the Air Force Institute of Technology (AFIT). MSE is responsible for generating remediation technologies' life cycle costs and performance data for variable amounts (spill volume) of TCE. Cost and performance data were obtained from previous or current applications of remediation technologies and expert opinion was incorporated to tailor the data specifically to WAG 6 .

\subsection{Overview}


Chapter 2 reviews the fundamentals of decision analysis and provides a brief discussion of the current literature related to the topic. Chapter 3 builds on the information in Chapter 2, by providing the decision makers' value hierarchy with associated weights, the single dimensional utility functions, and the decision analysis model. Chapter 4 discusses the results obtained from the model and provides a sensitivity analysis of the model. Chapter 5 concludes the research effort with recommendations that can be drawn from the analysis and suggests follow-on work at WAG 6. Detailed appendices are provided to facilitate communication of the entire process and exemplify the finer points of the research effort. 


\section{Literature Review}

\subsection{Introduction}

There are three main objectives to this literature review. The first is to provide the reader with a brief introduction to decision analysis, including relevant concepts and theories that apply directly to this research. The second objective is to provide examples from the literature that demonstrate decision analysis techniques applied in the CERCLA arena. The final objective is to cite specific research that utilizes decision analysis techniques in the selection process of remediation technologies.

\subsection{Decision Analysis}

Decision analysis is a process which aids decision makers in structuring complex decisions, in identifying sources of uncertainty and representing that uncertainty in a systematic way, and in providing a framework, models and tools for handling decisions where there are multiple, and sometimes conflicting objectives [Clemen 1996: 4]. The flowchart, given in Figure 2.1 on the following page, exemplifies the typical decision analysis process. Note that the decision analysis process is iterative, allowing for continuous improvement. After insight is gained from the first run through the process, it is then possible to revisit the objectives, alternatives, and model that define the decision opportunity. The remaining portion of this section will provide a detailed review of this process, drawing directly on examples and suggestions for implementation from the literature. 


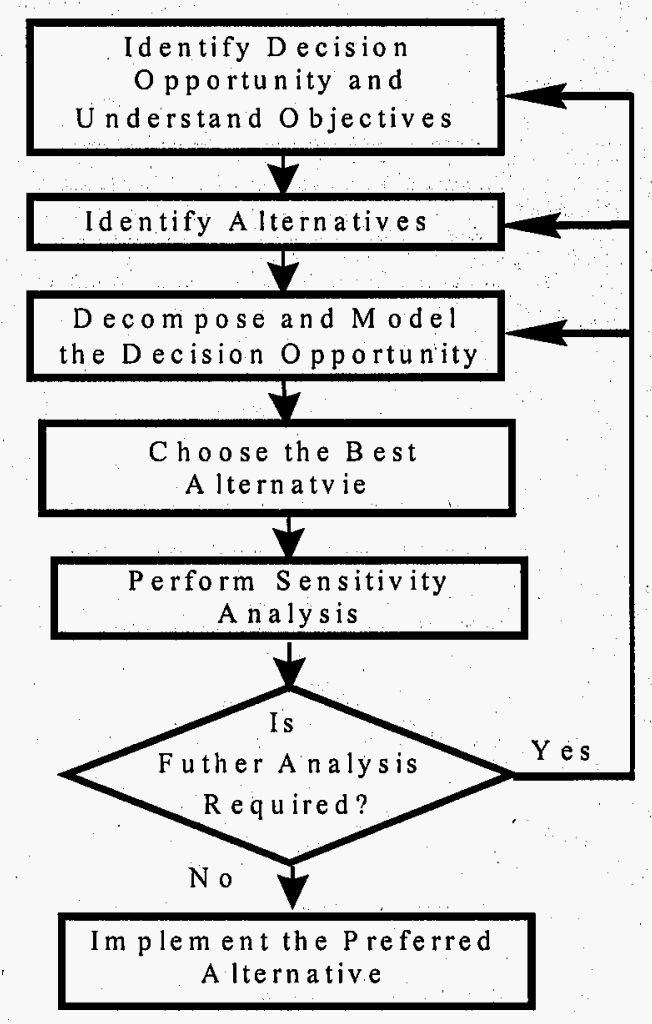

Figure 2.1 Modified Decision Analysis Process Flowchart [Clemen, 1996: 6]

\subsubsection{Identifying Decision Opportunities and Understanding Objectives}

The literature supports two trends of thinking in regards to identifying decision opportunities and defining objectives. The first approach is the standard or conventional approach to decision making. The focus of this approach is on generating alternatives and then considering objectives, criteria, or values to evaluate the alternatives. This traditional approach is termed "alternative-focused thinking" by Keeney, who claims this approach is "reactive, not proactive. Furthermore, it is backward; it puts the cart of identifying alternatives before the horse of articulating values" [Keeney, 1994: 33]. Another disadvantage to the traditional approach is in understanding the decision maker's objectives. Identifying and structuring objectives 
is a difficult task, and this approach fails to clearly specify how to perform that task, nor does it suggest how the objectives can be used to guide the decision maker's thinking [Keeney, 1992: 4].

The second approach is called "value-focused thinking", where leaderships' values are the primary focus of decision making, not alternative generation [Keeney, 1994: 33]. Value-focused thinking challenges the decision maker to consider why they are making the decision to begin with. Decisions are made with the intent of generating the most positive outcome. By using value-focused thinking, the decision maker's values are structured such that it is possible to construct a decision analysis model capable of identifying the alternatives that provide the greatest value to the decision maker.

There are numerous advantages to value-focused thinking. Value-focused thinking uncovers hidden objectives by exposing objectives not yet conceived. It leads to more productive information gathering, improves communication among decision makers, facilitates involvement of multiple stakeholders, enhances the coordination of interconnected decisions, generates better alternatives, and identifies more appealing decision opportunities [Keeney, 1994: 33]. One of the greatest benefits of value-focused thinking is that it includes a process for developing the decision makers' objectives. The process usually involves discussions with the primary decision maker(s), where Keeney's eight suggestions for identifying the objectives can be applied [Keeney, 1994: 35]: develop a wish list; identify alternatives; consider problems and shortcomings; predict consequences; identify 
goals, constraints, and guidelines; consider different perspectives; determine strategic objectives; and determine generic objectives.

Once a list of objectives has been generated, it is important to distinguish between fundamental or end objectives and means objectives. According to Clemen, means objectives help achieve other objectives while fundamental objectives are those that are important because they reflect what the decision maker really wants to accomplish [Clemen, 1996: 44]. To assist in identifying objectives, Keeney suggests implementing the "WITI test or Why Is That Important? test", where each objective is examined by asking that question. If the answer is that the objective is important only because of how it impacts some other objective, then it is a means objective. If the answer is that the objective is one of the reasons for interest in the decision opportunity, then it is a fundamental objective [Keeney, 1994: 34].

Fundamental objectives should be essential, controllable, complete, measurable, operational, decomposable, nonredundant, concise, and understandable. If they do not meet all of the above mentioned criteria, the objective should be defined differently or it could be considered a means objective [Keeney, 1992: 82].

Fundamental objectives can then be organized into value hierarchies, where the upper levels represent more general objectives or values and lower levels further define or describe the upper levels. It is very important to properly structure these value hierarchies because the lowest levels will be the basis from which various evaluation measures will be constructed to score or evaluate alternatives.

\subsubsection{Developing Alternatives}


A value hierarchy can provide a basis for designing good alternatives for the decision opportunity [Kirkwood, 1997: 23], because it is comprised of the fundamental objectives the decision maker is trying to accomplish. Understanding the objectives produces better alternatives, or to restate Keeney's earlier analogy [22], the horse is being placed in front of the cart. Specifically, alternatives should be designed that best achieve the values identified for the decision opportunity. There are a number of methods that are used in designing alternatives.

Keeney suggests thinking about how to better achieve fundamental objectives as a good start to developing alternatives. He recommends focusing on one objective and thinking of alternatives that might be very valuable if that were the only objective in the decision opportunity. This process is then repeated for every objective, after which there should be a broad range of potential alternatives. Next, consider two objectives at a time and try to generate alternatives that satisfy both, and then consider three objectives, and so on until all objectives are considered together. Examine the alternatives generated to see if it is possible to combine any into a single alternative [Keeney, 1994: 39].

Howard states that the most important method for creating alternatives is the strategy generation table [Howard, 1988: 684]. Strategy generation tables show how a total strategy can be specified by selecting among decisions in each of many areas, which could be thought of as individual decision variable settings. The table is constructed by listing all the alternatives (rows) under a specific objective (which represents the column). By combining all the columns, the table is formed and a 
strategy can then be mapped out across the columns. Strategy generation tables are especially useful when a structured procedure is needed to sort out reasonable alternatives to consider in more detail [Kirkwood, 1997:48]. In earlier work at WAG 6, a strategy generation table was constructed where the objectives are the cleanup of a particular hydrogeologic zone or zones (shown by the columns in Table 2.1) and the alternatives are the various technologies that work in the given zone (shown as the rows in Table 2.1) [Papatyi, 1997: 3-9]. A strategy or technology train is the combination of any given technology for one zone matched with any given technology from another zone. From Table 2.1, a valid technology train would be 2 Phase - 6 Phase - Pump \& Treat (P\&T) - Biological Polisher (Bio), and the maximum number of trains that could be formed would be the eight shown.

Table 2.1 Example Strategy Generation Table for Technology Trains

\begin{tabular}{|c|c|c|c|c|}
\hline $\begin{array}{c}\text { Unsaturated } \\
\text { Hydrogeologic Zone } \\
\text { Technologies }\end{array}$ & $\begin{array}{c}\text { Saturated and } \\
\text { Aquifer Zone } \\
\text { Technologies }\end{array}$ & Combinations or Trains \\
\hline SVE & none & P \& T & Bio & SVE - P\&T - Bio \\
\hline & & & & SVE - P\&T - none \\
\hline 2 Phase & none & P \& T & none & 2 Phase - P\&T - Bio \\
\hline 2 Phase & RF Heating & & & 2 Phase - P\&T - none \\
\hline 2 Phase & 6 Phase & & & 2 Phase - RF Heating - P\&T - Bio \\
\hline & & & & 2 Phase - RF Heating - P\&T -none \\
\hline & & & & 2 Phase - 6 Phase - P\&T - Bio \\
\hline & & & & 2 Phase - 6Phase - P\&T - Bio \\
\hline
\end{tabular}

Keeney also suggests maximizing all objectives within a decision opportunity to reach the ideal alternative. Once this ideal has been identified, it can then be analyzed 
to determine which constraints are holding one back from this preferred alternative [Keeney, 1992:221].

Clemen suggests creativity techniques such as fluent and flexible thinking, idea checklists, brainstorming, and metaphorical thinking to enhance alternative generation [Clemen, 1996: 203-206]. The essence of his discussion is that creativity is essential in alternative development because the alternatives themselves ultimately determine the boundaries of the decision opportunity.

\subsubsection{Decompose and Model the Decision Opportunity}

The decomposition and modeling of the decision opportunity can be accomplished a variety of ways. Influence diagrams or decision trees can be used to represent or model the decision opportunity. Probability can be used to model the uncertainty inherent in the decision and hierarchical models can be used to understand the relationships among multiple objectives. Since these models are mathematical, they can be subjected to analysis, which can greatly enhance the decisionmaking opportunity. The following subsections highlight specific steps in the construction of a decision analysis model; they are also the steps that were employed in this research effort and their specific application to the WAG 6 site at the PGDP will be presented in Chapter 3.

\subsubsection{Value Hierarchies}

As stated previously, value hierarchies should reflect the fundamental objectives of the decision opportunity. The upper levels of a value hierarchy represent the more general objective or values of the decision maker(s). The lower levels further 
decompose the general objectives until they reach a level where they can be evaluated through an evaluation measure. Thus, the general idea of a value hierarchy is to ensure that each objective is measured through one or more evaluation measures.

According to Kirkwood, value hierarchies should be complete, nonredundant, decomposable, operable and small in size [Kirkwood, 1997; 16]. A value hierarchy is complete when each tier (or level), taken together as a group, covers all the concerns necessary to evaluate the overall objective of the decision. Nonredundancy means that no two lower level objectives, or evaluation measures can overlap by their definition. Taken together, these two properties are often expressed as "collectively exhaustive and mutually exclusive" [Kirkwood, 1997; 17]. Decomposability or independence ensures that the preference for the score of one evaluation measure does not depend on the score of any other evaluation measure. Operable refers to the value hierarchy being understood by the user and small in size conveys the point that a smaller value hierarchy is more easily communicated.

Consider the following example from CERCLA, where a fundamental objective is for a remediation technology/alternative to achieve Short-Term Effectiveness [40 CFR S300.430(e)(9)(iii)(E)]. CERCLA continues to decompose this fundamental objective into four lower-level, fundamental objectives or "subcriteria"; as depicted by the single, solid lined boxes in Figure 2.2, which demonstrates the Short-Term Effectiveness hierarchy. CERCLA stops at this point, allowing the decision makers and stakeholders the flexibility to design their own, unique evaluation measures of these objectives. The evaluation measures, in the 
dashed boxes, and weights are those that were derived as part of Grelk's research effort for Idaho's National Engineering Laboratory [Grelk; 1997: 3-3].

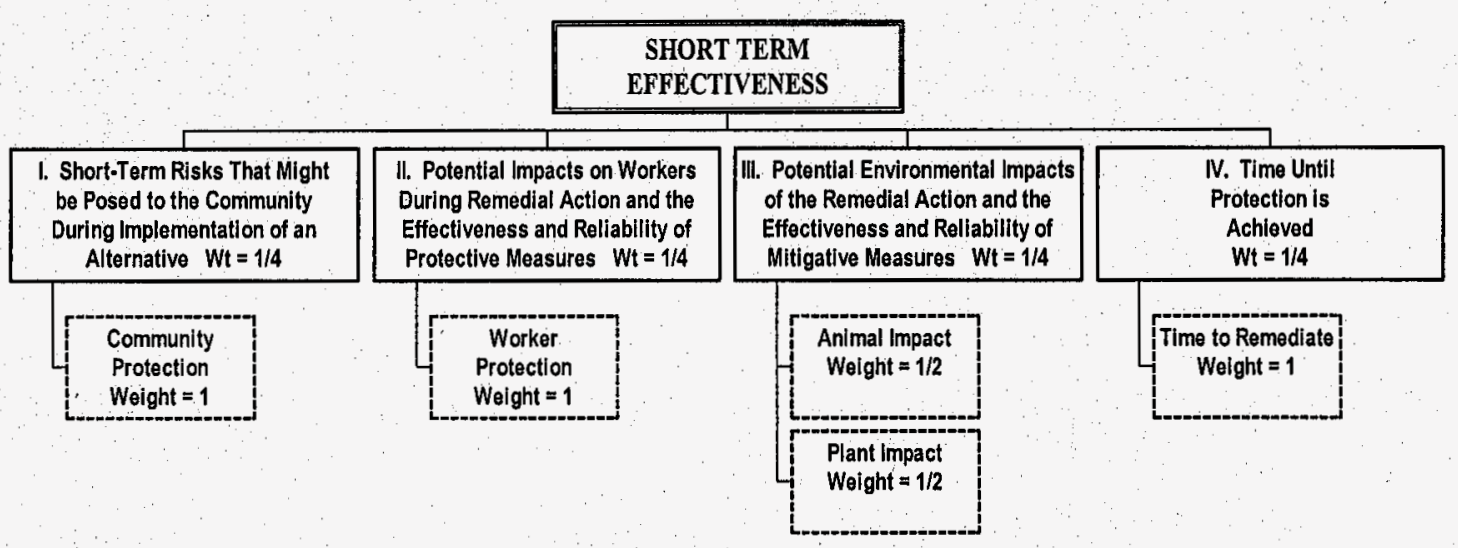

Figure 2.2 Short-Term Effectiveness Hierarchy

\subsubsection{Evaluation Measures}

Evaluation measures allow the qualitative nature of the value hierarchy to be transformed into a quantitative tool capable of determining how well an alternative does with respect to each objective considered within the decision opportunity. Evaluation measure scales can be classified as natural or constructed and either direct or proxy [Kirkwood, 1997: 24]. A natural scale is one that is used widely and commonly interpreted by all. Profit is a natural scale that is widely used in business decisions. Constructed scales are those developed for a particular decision opportunity that measures the degree of attainment of an objective. Direct scales directly measure the degree of attainment of an objective; again, profit is a good example. A proxy scale reflects the degree of attainment of its associated objective, but does not directly measure the objective itself. The Gross National Product (GNP) 
is an example of a proxy scale for the economic state of our nation [Kirkwood, 1997: 24]. The type of scale used can depend on the preference of the decision makers and stakeholders. The most critical factor in scale construction is that it must be precise, specific, and pass the "clarity test" [Howard, 1988: 688]. The clarity test asks whether a clairvoyant, who was capable of foreseeing the future, would be able to determine, unequivocally, what the score or outcome would be for each evaluation measure. No interpretation or judgment should be required of the clairvoyant [Clemen, 1996: 75]. The tradeoff lies in the effort spent to develop the scales, ease of assessing each alternative against the scale, and then communicating the results obtained.

\subsubsection{Multiattribute Preference Theory}

Once these evaluation measures have been created, combining their scores becomes the next issue. It is impossible to combine scores with different units of measure. For example, consider Figure 2.2, where one evaluation measure was the Time to Remediate. The natural, direct scale for this evaluation measure would be time, with units of measure as years. Another evaluation measure from Figure 2.2 is Community Protection, which represents how a remediation alternative affects the surrounding community. Community Protection is a constructed, proxy scale, with units of measure being the action taken at the site (containment, "in situ" treatment, excavation, etc.) [Grelk, 1997: B-11]. How could these two incommensurate evaluation measures ever be combined or even compared? By placing a unitless, dimensionless function over each evaluation measure, known as a single dimensional 
value or utility function, the scores can be transformed into either values or utilities, both of which are unitless. Once the scores have been converted to either values or utilities, they can be combined and compared against one another, hence the significance of multiattribute preference theory.

Multiattribute preference theory addresses decisions where there are multiple objectives, which may be competing, by quantifying the objectives through evaluation measures; developing weights for the objectives, which in turn assigns weight to each of the evaluation measures; and translating the objective evaluation measure scores into common, dimensionless units of measure, such as values. These values are then combined through an overall value function, to generate a single, overall value for an alternative or technology train, which represents how well that alternative meets the decision maker's objectives [Grelk, 1997: 2-12].

Multiattribute preference theory provides the decision maker an opportunity to examine and compare alternatives against competing objectives. Consider the five competing objectives listed as CERCLA balancing criteria in Figure 1.1: long-term effectiveness and permanence, reduction of toxicity, mobility, and volume, short-term effectiveness, implementability, and cost. Any remediation technology train considered for implementation at any CERCLA site must be evaluated against these competing criteria [40 CFR S300.430(e)(9)(iii)]. CERCLA also leaves the relative importance, weighing, or balancing of each criteria up to the decision makers, providing only that "The balancing shall emphasize long-term effectiveness and 
reduction of toxicity, mobility, or volume through treatment" [ 40 CFR S300.430(f)(1)(ii)(E)].

According to multiattribute preference theory, transforming the evaluation measures' scores into dimensionless units requires the use of single dimensional value or utility functions. Single dimensional utility functions are derived from the decision maker through a series of lottery questions where uncertainty and probability are addressed. Because estimates of probabilities are subjective in nature, it is often difficult to assess utilities with a group of decision makers. Single dimensional value functions are also derived from the decision maker(s), but do not incorporate uncertainty or probability and hence are easier to assess. The purpose of a single dimensional value function is to transform scores from evaluation measures into unitless, dimensionless numbers that can ultimately be combined and compared. There are two basic types of single dimensional value functions: monotonically increasing or monotonically decreasing.

Grelk's work presents some examples of single dimensional value functions that were used in environmental remediation technology selection. Figure 2.3 represents a monotonically increasing value function because as The Percent of Principal Threat $\mathrm{i}$ Mass Treated (the actual evaluation measure's score) increases, so does the value to the decision maker, thereby demonstrating a positive slope [Grelk, 1997, B-19]. In other words, if there is no treatment of principal threat i's mass, then there is no value gained for the decision maker. If $100 \%$ of the principal threat is treated, then that corresponds to the greatest value the decision maker could gain which would be ten in 
this example A monotonically increasing function need not be linear, like the one shown in Figure 2.3, nor continuous, but must exhibit a positive

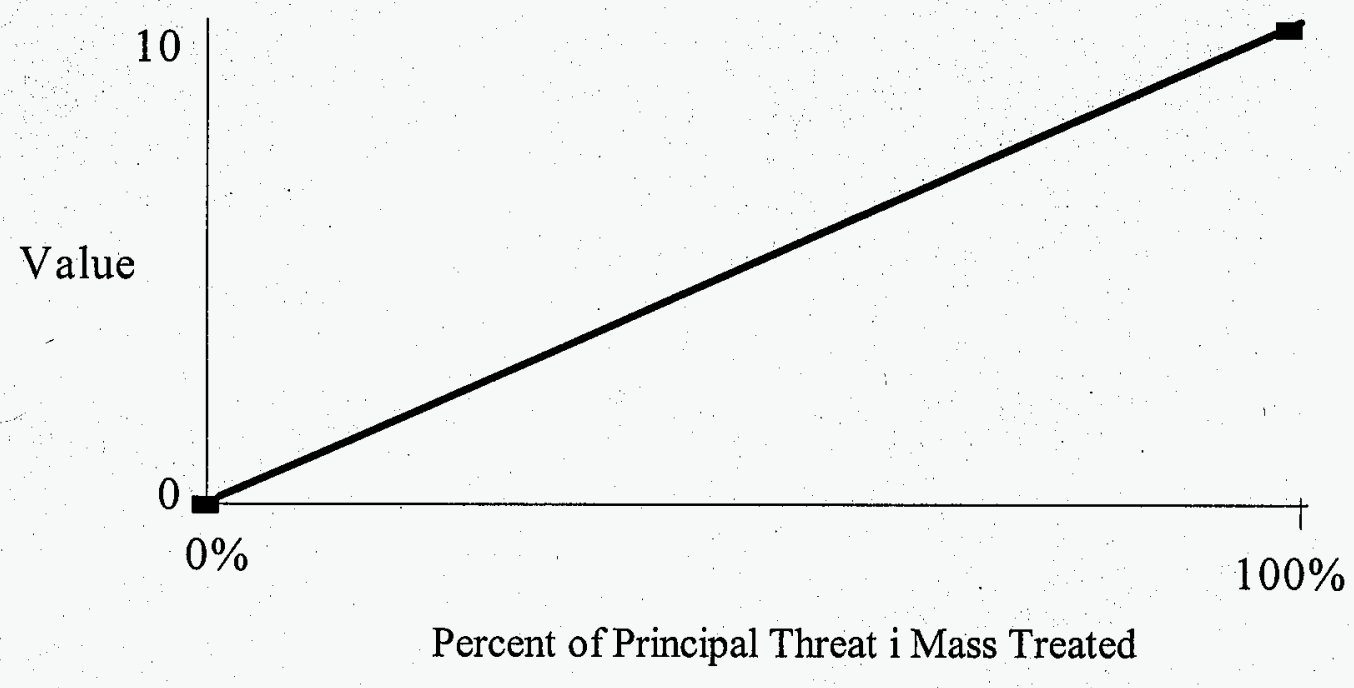

Figure 2.3 Example of a Monotonically Increasing Function

slope, or "trend". The only requirements are that the function assigns the worst score on an evaluation measure a value of zero, the best score on an evaluation measure a value of ten, and the function accurately conveys the decision makers' attitudes.

The other type of value function is the monotonically decreasing function which accounts for the "more is not always better" situation. Consider the evaluation measure depicted in Figure 2.4, where the Number of Major System Components is a proxy measure for how complicated a system is to construct and operate [Grelk1997, B-4]. In this case, the larger the evaluation measure score, the lower the value for the decision maker, thereby the negative slope or "trend" in value. A monotonically decreasing function need not be linear, as shown in Figure 2.4, nor continuous, but 
must exhibit a negative slope, or trend. The only requirements are that the function anchors the worst score on an evaluation measure at a value of zero, the best score on

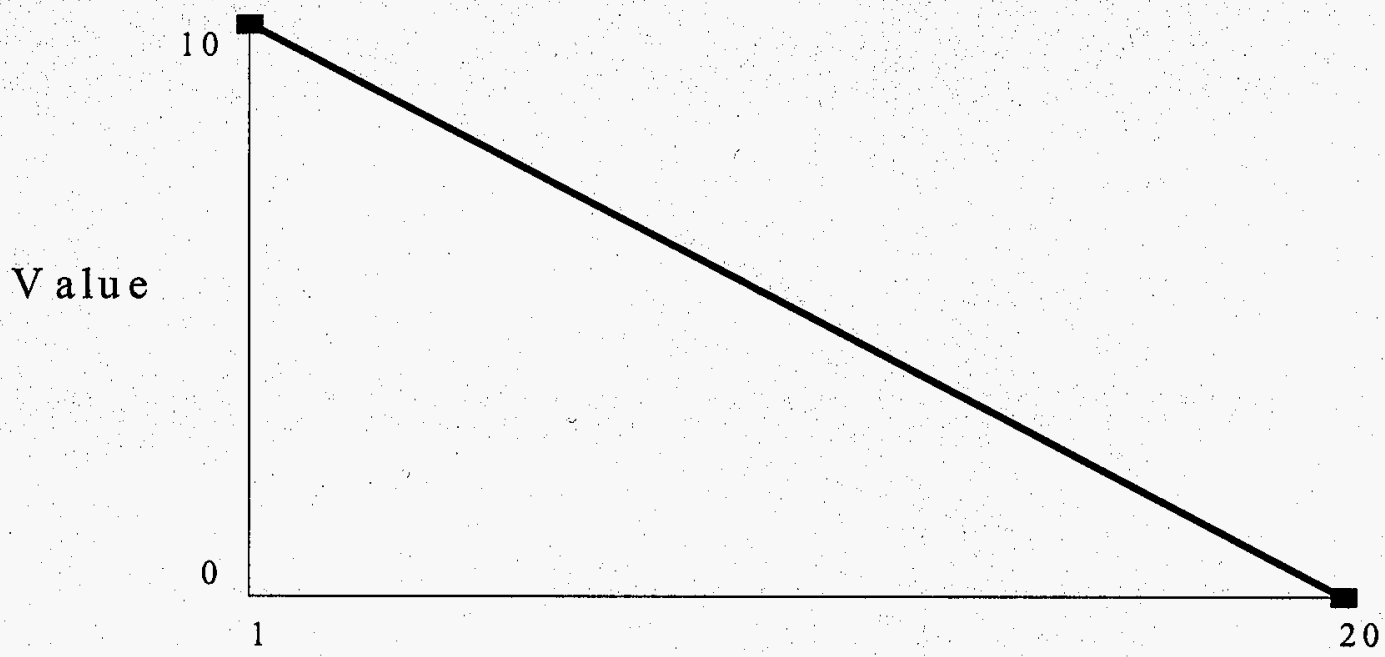

$\mathrm{Number}$ of Major System Components

Figure 2.4 Example of Monotonically Decreasing Function

an evaluation measure at a value of ten, and the function accurately conveys the decision makers' attitudes.

\subsubsection{Assessing Weights}

Assigning weights in a multiple objective analysis is necessary if the decision makers feel that some objectives are more important than others, which is often the case. Weights are assigned to each level of the value hierarchy, where the sum of all the weights for any particular level must equal one. Consider Figure 2.2 where the subcriteria weights (horizontally) sum to one and the evaluation measures' weights (vertically) sum to one under each subcriteria. This restraint forces the decision maker to make tradeoffs between the objectives; if one objective is to have more 
weight, it must come at the expense of at least one other objective's weight. There are a variety of ways to determine weights; such as direct assessment, pricing out, swing weighting, and lottery comparison techniques [Clemen 1996: 546].

The direct assessment of weights requires the decision makers to assign weights to each objective based on their own personal judgment, previously established organizational policy, or law. This method requires consensus among the decision makers and is recommended only when there is sufficient guidance or there are decision "rules" that can be referenced or agreed upon. As mentioned previously, CERCLA does not provide much assistance in this area, so this research effort solicited weights directly from the decision makers, who were able to develop some basic decision rules to assist them in consistently applying weights to their value hierarchy.

\subsubsection{Overall Value Function and the Power Additive Utility Function}

An overall value function combines the values from the multiple evaluation measures into a single measure of the overall value of each alternative [Kirkwood, 1997: 53]. There are various forms that can be used for the overall value function; however, it is important that the form chosen adequately reflect the decision maker's preferences, and can be easily understood by the decision maker [Grelk 1997: 2-27]. The value function form that has been generally used in practice is the additive form [Kirkwood, 1997: 230]. The additive value function is a weighted average of the single dimensional value functions assigned to each evaluation measure and is presented on the following page [Kirkwood, 1997: 230]: 


$$
\mathrm{v}(\mathrm{x})=\sum_{\mathrm{i}=1}^{\mathrm{n}} \lambda_{\mathrm{i}} \mathrm{v}_{\mathrm{i}}\left(\mathrm{x}_{\mathrm{i}}\right)
$$

where the total value is represented by $v(x), i=1$ to the $n^{\text {th }}$ single dimensional value function, and $\lambda_{i}$ represents the weights to the corresponding single dimensional value functions, $\mathrm{v}_{\mathrm{i}}\left(\mathrm{x}_{\mathrm{i}}\right)$. A critical assumption is made in using this function: the objectives must be mutual preferential independent [Kirkwood, 1997:238]. Mutual preferential independence implies that a decision maker's preferences associated with one objective are independent of the preferences associated with all the other objectives. Applying the additive value function allows for the combination of values obtained from the evaluation measures and produces one overall value for each alternative, which allows comparison between alternatives and ranks alternatives as to how well they meet the objectives.

Combining the single dimensional values with their associated weights through an additive value function produces a deterministic ranking of alternatives that does not account for uncertainty or risk. By utilizing the power-additive utility function, it is possible to convert values calculated using a multiattribute value function into utilities, which captures the decision maker's attitude toward risk through the use of a multiattribute risk tolerance factor $\left(\rho_{\mathrm{m}}\right)$. The power-additive utility function is expressed as [Kirkwood, 1997: 161]:

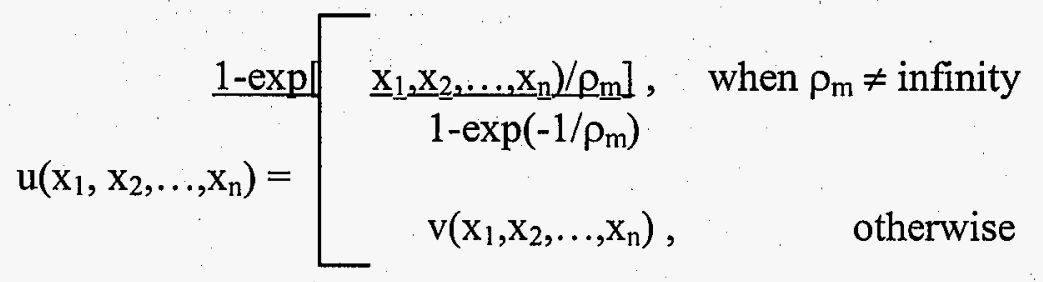


where $\mathrm{u}\left(\mathrm{x}_{1}, \mathrm{x}_{2}, \ldots, \mathrm{x}_{\mathrm{n}}\right)$ is the overall utility for the evaluation measures $\mathrm{x}_{1}, \mathrm{x}_{2}, \ldots, \mathrm{x}_{\mathrm{n}}$, $\mathrm{v}\left(\mathrm{x}_{1}, \mathrm{x}_{2}, \ldots, \mathrm{x}_{\mathrm{n}}\right)$ is an additive value function and must be less than or equal to one, and $\rho_{\mathrm{m}}$ is the multiattribute risk tolerance factor.

The multiattribute risk tolerance factor quantifies the decision maker's degree of aversion to taking risks [Kirkwood, 1997: 162]. Kirkwood assures that the exact value of $\rho_{\mathrm{m}}$ rarely impacts the ranking of alternatives. In fact, he suggests conducting a sensitivity analysis for $\rho_{m}$ that covers the range from 0.2 up to infinity. If the ranking of alternatives does not change over this range, then " ... you should not need to consider the multiattribute risk tolerance any further, and hence you do not have to assess the specific value of $\rho_{\mathrm{m}}$ " [Kirkwood, 1997: 162]. In other words, from

Equation 2.2 above, values convert directly to utilities. If the alternative rankings do change, then an assessment of $\rho_{\mathrm{m}}$ must be made in order to conduct an expected utility analysis.

\subsubsection{The Final Four}

The first of the final four steps in Figure 2.1 is choose the best alternative, which is the alternative with the greatest utility or expected value, calculated from the analysis. The second step is to perform a sensitivity analysis to answer "what if" questions (e.g."If we change this weight, does the model recalculate a different optimal alternative?") [Clemen, 1996: 7]. The third step asks the question "Is further analysis required?", reinforcing the iterative nature of the process. Clemen suggests that a better term for the entire process might be a "decision-analysis cycle" because often 
many iterations are needed. The final step is simply to implement the best alternative generated from the analysis [Clemen, 1996: 7].

\subsection{Decision Analysis Applications in the CERCLA Arena}

Decision analysis (DA) is well developed in disciplines such as military science, medicine, business, and engineering, but with respect to CERCLA, it is more difficult to identify DA applications. Most modeling applications tend to concentrate on the prediction of a variable like contamination concentrations rather than on participation in the decision making process [Jennings, 1994: 1133]. The table below briefly describes the specialized DA models developed over the past fifteen years in reference to CERCLA and is primarily based on the work by Jennings as arranged by Papatyi [Papatyi, 1997: A-1]:

Table 2.2 Models Used in CERCLA Applications

\begin{tabular}{|c|c|c|c|}
\hline Model & Agency & Objective & References \\
\hline $\begin{array}{l}\text { HRS (Hazardous } \\
\text { Ranking System) } \\
\end{array}$ & EPA & $\begin{array}{l}\text { Model used to determine National } \\
\text { Priority Listing of a site. }\end{array}$ & $\begin{array}{l}\text { Wu \& Hilger, } \\
\text { 1984: 797-807 }\end{array}$ \\
\hline $\begin{array}{l}\text { MEPAS } \\
\text { (Multimedia } \\
\text { Environmental } \\
\text { Pollutant } \\
\text { Assessment } \\
\text { System) }\end{array}$ & DOE & $\begin{array}{l}\text { Model used to assess wildlife } \\
\text { endangerment issues at DOE sites }\end{array}$ & $\begin{array}{l}\text { Harz \& } \\
\text { Whelan, 1988: } \\
295-299 \\
\text { Droppo \& } \\
\text { Hopes, 1990: } \\
\text { 193-205 }\end{array}$ \\
\hline $\begin{array}{l}\text { RAAS } \\
\text { (Remedial } \\
\text { Action } \\
\text { Assessment } \\
\text { System) }\end{array}$ & DOE & $\begin{array}{l}\text { Model used for Feasibility Study } \\
\text { to provide alternatives guidance }\end{array}$ & $\begin{array}{l}\text { Hartz \& } \\
\text { Whelan, 1988: } \\
\text { 295-299 }\end{array}$ \\
\hline
\end{tabular}




\begin{tabular}{|c|c|c|c|}
\hline Model & Agency & Objective & References \\
\hline HAZRISK & $\mathrm{DOE}$ & $\begin{array}{l}\text { Model used in cost estimate } \\
\text { development and scheduling } \\
\text { for hazardous waste cleanup } \\
\text { projects }\end{array}$ & $\begin{array}{l}\text { Hudson \& } \\
\text { Shangraw, } \\
\text { 1990: } 241-244\end{array}$ \\
\hline $\begin{array}{l}\text { POS (Program } \\
\text { Optimization } \\
\text { System) }\end{array}$ & DOE & $\begin{array}{l}\text { Model used to optimize } \\
\text { distribution of remediation } \\
\text { budgetary resources }\end{array}$ & $\begin{array}{l}\text { Merkhofer, } \\
\text { Cotton, Longo, } \\
\text { 1988: } 39-43\end{array}$ \\
\hline $\begin{array}{l}\text { DPM (Defense } \\
\text { Priority Model) }\end{array}$ & $\begin{array}{l}\text { Department } \\
\text { of Defense }\end{array}$ & $\begin{array}{l}\text { Model used to estimate the } \\
\text { risk to human health and the } \\
\text { environment and assess } \\
\text { funding priority }\end{array}$ & Expert, 1997 \\
\hline $\begin{array}{l}\text { HARM (Hazard } \\
\text { Assessment Risk } \\
\text { Model) }\end{array}$ & US Air Force & $\begin{array}{l}\text { Model used as a predecessor } \\
\text { to DPM }\end{array}$ & $\begin{array}{l}\text { Hushon, 1990: } \\
\text { 206-216 }\end{array}$ \\
\hline $\begin{array}{l}\text { ENVEST/ } \\
\text { RACER }\end{array}$ & US Air Force & $\begin{array}{l}\text { Model used to estimate cost of } \\
\text { remediation projects }\end{array}$ & Expert, 1997 \\
\hline $\begin{array}{l}\text { FLEX (Flexible } \\
\text { Linear Expert) }\end{array}$ & & $\begin{array}{l}\text { Model used to evaluate } \\
\text { chemical compatibility of } \\
\text { liners }\end{array}$ & $\begin{array}{l}\text { Rossman \& } \\
\text { Siller, 1987: } \\
113-127 \\
\end{array}$ \\
\hline $\begin{array}{l}\text { HERPM (Human } \\
\text { Exposure } \\
\text { Potential Ranking } \\
\text { Model) } \\
\end{array}$ & $\begin{array}{l}\text { NY Dept of } \\
\text { Health }\end{array}$ & $\begin{array}{l}\text { Model used as a ranking tool } \\
\text { that establishes relative } \\
\text { priorities for investigation and } \\
\text { remediation of sites }\end{array}$ & $\begin{array}{l}\text { Smith, Patrick, } \\
\text { \& Hudson, } \\
\text { 1987: 158-161 }\end{array}$ \\
\hline $\begin{array}{l}\text { DRASTIC } \\
\text { (Depth, Recharge, } \\
\text { Aquifer, Soil, } \\
\text { Topography, } \\
\text { Impact, } \\
\text { Conductivity) }\end{array}$ & EPA & $\begin{array}{l}\text { Model used to preliminary } \\
\text { assess hazardous waste sites, } \\
\text { acronym -Depth to water, net } \\
\text { Recharge, Aquifer media, Soil } \\
\text { media, Topography, Impact of } \\
\text { the vadose zone media, and } \\
\text { hydraulic conductivity }\end{array}$ & $\begin{array}{l}\text { Allert, Bennet, } \\
\text { Lehr, Petty, \& } \\
\text { Hackett, } 1987\end{array}$ \\
\hline $\begin{array}{l}\text { CORA (Cost of } \\
\text { Remedial Action) }\end{array}$ & EPA & $\begin{array}{l}\text { Model used as a costing tool } \\
\text { for remedial actions }\end{array}$ & $\begin{array}{l}\text { Chenu \& } \\
\text { Crenca, 1990: } \\
\text { 162-175 }\end{array}$ \\
\hline $\begin{array}{l}\text { PAST (Potential } \\
\text { ARAR's } \\
\text { Selection Tool) }\end{array}$ & & $\begin{array}{l}\text { Model used to assist in the } \\
\text { development of ARARs }\end{array}$ & $\begin{array}{l}\text { Greathouse \& } \\
\text { Clements, } 1991\end{array}$ \\
\hline
\end{tabular}




\subsection{DA Applications in the Technology Selection Process at DOE Facilities}

Upon review of the current literature, the Department of Energy appears to have the lead in utilizing decision analysis techniques when making decisions regarding remediation technology selection.

In 1994, Evans Duffield, Massman, Freeze, Stephenson, and Buss, completed a DA effort that incorporated a risk-cost based economic model, hydrogeological uncertainty model, and hydrogeological simulation model for the DOE's Savannah River site. The fundamental objective of their research was to determine the lowest cost remediation alternative and determine the largest cost contributors to the remediation of the site. They examined six technologies and concluded that the lowest cost technology was pump and treat. They also concluded that operation and maintenance costs were the largest cost contributor due inpart to the sheer volume of ground water that had to be treated [Evans Duffield, Massman, Freeze, Stephenson, and Buss, 1994].

In 1995, Timm used a rather simplistic approach to remediation technology selection at the DOE Rocky Flats facility, where cost and schedule, tempered with some regulatory requirements and future land use considerations, comprised the fundamental objectives of the value hierarchy. No weights were assigned. Alternatives were generated based on their ability to be implemented and included probabilistic data regarding the amount of time required for implementation. Each alternative was screened for technical feasibility and ability to meet time schedules. The alternatives that remained after screening were then evaluated based on: critical 
elements that could potentially lead to significant changes in either cost or schedule and life cycle costs and their variability. "The results enabled the DOE to select and defend a remediation alternative that saved million of dollars" [Timm, 1995: 46].

Early in 1995, the MSE/AFIT/VCU team formed and began producing Life Cycle Cost modeling, remedial technology selection, and risk analysis using DA models for the DOE. Two very applicable works to this research effort are summarized as follows:

Grelk completed a notable example of DA applied research in remediation technology selection in his 1997 AFIT thesis for the Department of Energy's Idaho National Environmental Laboratory. The DA process followed by Grelk is similar to the one described in Section 2.2, only it was deterministic, which means it did not account for any uncertainties or probabilities. The results of the analysis presented a ranking of 28 remediation technology trains along with a sensitivity analysis, which provided further information for the decision makers to consider when selecting a technology train. Perhaps the greatest contribution of Grelk's work was the development of a set of CERCLA based evaluation measures complete with their corresponding single dimensional value functions [Grelk, 1997: 5-5].

Concurrent to Grelk's work, Papatyi also completed DA research in remediation technology selection in his 1997 AFIT thesis for the Department of Energy's Paducah Gaseous Diffusion Plant. Papatyi's work focused on evaluating 58 technology trains considered for remediating the WAG 6 site. He used three evaluation measures: total net present value, year finished with remediation, and percent contaminant removed 
and then developed single dimensional utility functions for each evaluation measure. Basing his initial analysis on dominance and utility, he screened down the 58 trains to 7. From the 7, he selected the top three trains based upon total utility; which were Dynamic Underground Stripping, 2Phase and Oxidation, and LASAGNA and Oxidation.

As Papatyi himself noted, his research was limited by using only three evaluation measures, and not the CERCLA criteria. He also noted that the uncertainty regarding the spill volume at the site should be reflected in the performance data, making it scalable [Papatyi, 1997: 5-5]. It is the intent of this research effort to address these concerns by establishing a CERCLA based value hierarchy for WAG 6 and using scalable performance data based upon a probability distribution of spill volume to identify the best remediation technology or train for the site. 


\section{Methodology}

\subsection{Introduction}

After reviewing the techniques applied in the literature review, value-focused thinking and multiattribute preference theory constitute the best approaches for creating a decision analysis model for remediation technology selection at WAG 6 . The advantage of value-focused thinking is that it incorporates the decision makers' preferences so that the resulting ranking of alternatives (trains) is based completely on their values. Multiattribute preference theory provides the decision maker an opportunity to evaluate and compare alternatives against competing objectives, which is very applicable when addressing CERCLA's balancing criteria.

This chapter begins by reviewing WAG 6 site specific data, continues with the developing of alternatives or trains, building of the WAG 6 CERCLA value hierarchy, constructing the evaluation measures and single dimensional value functions, assessing weights, applying the additive value function and power-additive utility function, and concluding with a brief description of the modeling assumptions.

\subsection{WAG 6 Site Characteristics}

As mentioned previously, the Paducah Gaseous Diffusion Plant (PGDP) was placed on the National Priorities List on May 31, 1994. Because of this listing, PGDP is subject to CERCLA criteria for cleaning up or remediating its hazardous waste sites. The principal contaminants of concern (PCOCs) at Waste Area Group (WAG) 
6 , which is located primarily around and under the C- 400 building, are trichloroethylene (TCE) and technetium-99 (Tc-99).

Unfortunately, there is a lack of information regarding the actual quantity of these contaminants. TCE spill estimates range from 2,000 to 500,000 gallons [Papatyi, 1997: 3-3]. The highest known concentration of TCE in the groundwater at the site is $890,000 \mathrm{ppb}$; the current regulatory limit is $5 \mathrm{ppb}$ [DOE/OR/07-1234\&D4, 1997: 5-20]. The activity of the Tc-99 ranges from $0 \mathrm{piC} / \mathrm{L}$ to $43,922 \mathrm{piC} / \mathrm{L}$; the current regulatory limit is $900 \mathrm{piC} / \mathrm{L}$ but this may be relaxed to $3,900 \mathrm{piC} / \mathrm{L}$ [Davis, 1997].

Based on limited field data, historical records, and interviews with past site workers, a cumulative probability distribution of the volume of TCE spilled was generated and is shown in Figure 3.1.

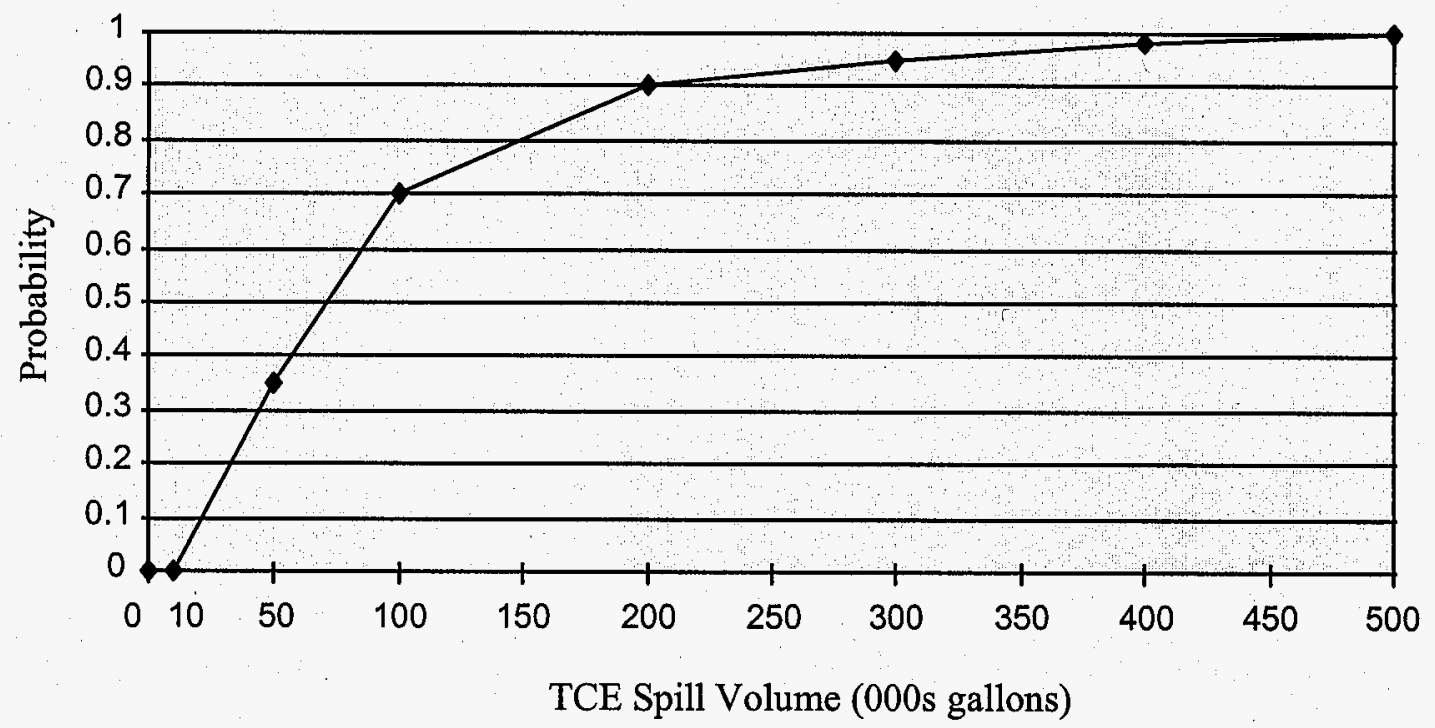

Figure 3.1 Cumulative probability distribution of TCE spill Volume 
From this distribution, through discretization, discrete probabilities were calculated for spill volumes of $50,000,100,000,200,000,300,000,400,000$, and 500,000 gallons and used by MSE for calculating cost and performance data. Appendix A details the mathematical/statistical procedure of discretizing a continuous distribution through moment matching. The results obtained from the analysis in Appendix A are summarized in Table 3.1. The expected value or mean of this spill distribution is 98,750 gallons.

The probabilities in Table 3.1 are used in the decision analysis models and their application will be further discussed at that point.

Table 3.1 Discrete Probabilities Assessed for TCE Spill Volumes

\begin{tabular}{|c|c|}
\hline TCE Spill Volume (gallons) & Probability \\
\hline 50,000 & 0.74 \\
\hline 200,000 & 0.20 \\
\hline 300,000 & 0.03 \\
\hline 400,000 & 0.02 \\
\hline 500,000 & 0.01 \\
\hline
\end{tabular}

"Understanding the geology and hydrology of a hazardous waste site is the crucial first step in accurately identifying and selecting an efficient remedial technology" [Barry, 1997]. Figure 3.2 is a conceptual spill model, created by Papatyi, which exemplifies the geologic complexity of the WAG 6 site [Papatyi, 1997: 3-4]. 


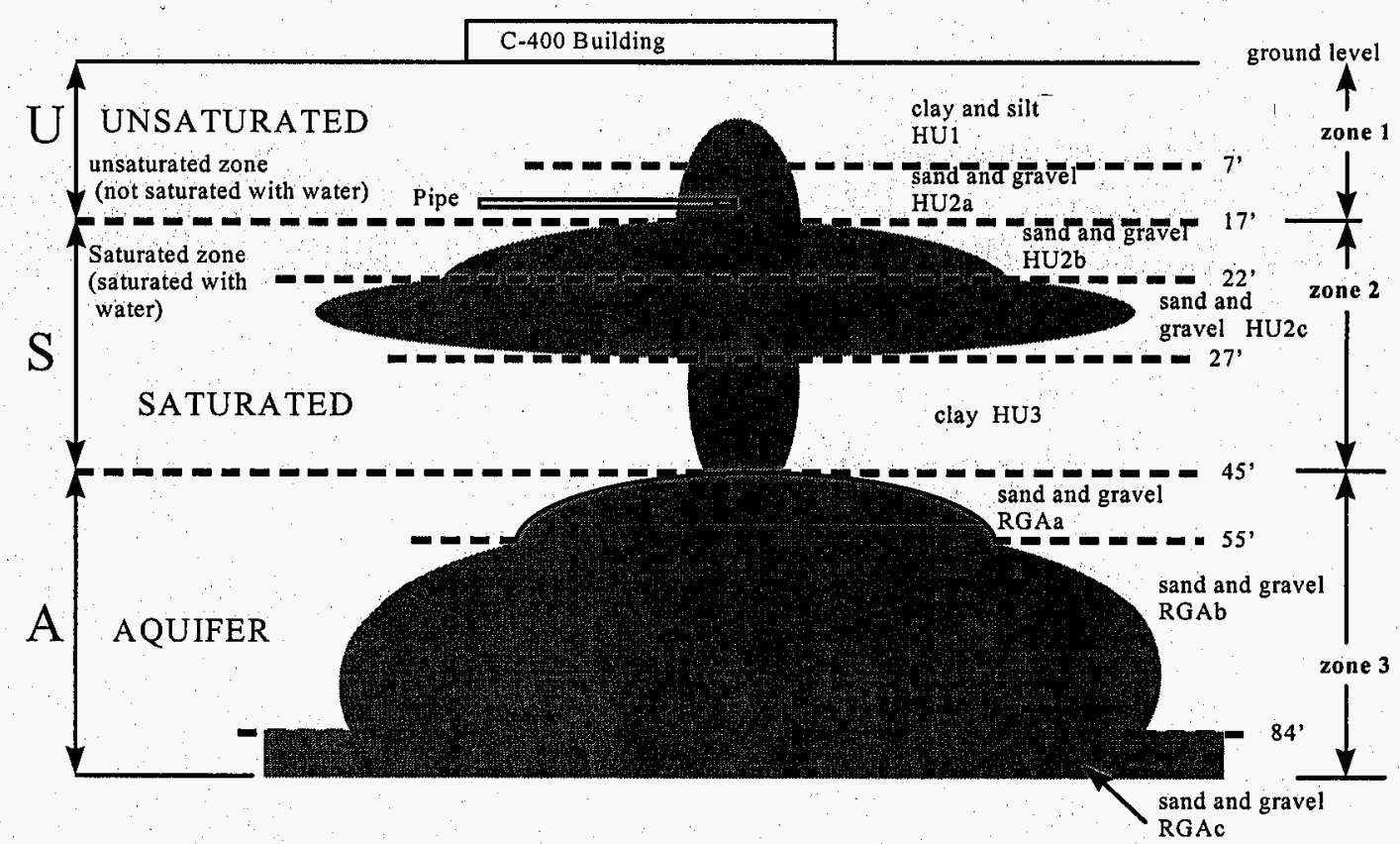

Figure 3.2 Conceptual Spill Model of the TCE Contaminant Plume

Notice there are eight hydrologic units (HU1, HU2a, RGAa, etc.), each representing nonhomogeneity (differing soil compositions) in the subsurface. These differing soil compositions promote nonhomogeneous contaminant migration through the subsurface. Figure 3.1 is a conceptual visualization of this concept; where, for example, the HU3 clay hydrologic unit tends to retard the spill, forcing it to pond on top of the clay unit, because clay is rather impermeable. The spill only passes through the clay unit when there are fractures or nonhomogeneities in the clay's composition.

The decision makers decided to combine the eight hydrologic zones presented in Figure 3.1 into three operational zones: the unsaturated (U) - zone 1, the saturated (S) - zone 2, and aquifer (A) - zone 3. Recent discussions with the site geologist have supported this hydrogeologic simplification and categorization. He described the saturated zone as the zone where pore volumes are saturated with water, but the 
hydraulic conductivity is too low for the region to serve as a water supply [Davis, 1997].

As the site characterization/remedial investigation continues at WAG 6, new data are collected, improving the understanding of the subsurface composition of the site. Recent geologic corings have shown that the clay layer (HU3) may not be 18 feet thick as originally estimated, but rather insignificant or nonexistent, thus providing little or no buffer for the aquifer. This new information seems to better explain how ground water samples from zone 3 became so contaminated [Davis, 1997].

\subsection{Developing Alternatives or Trains}

The decision makers decided to evaluate only aggressive technologies capable of remediating both TCE and Tc-99; no "containment only" technologies are considered in this analysis. Because of the geologic complexity of the site, only three technologies were found that could remediate all the contamination affecting all three zones: Dynamic Underground Stripping (DUS), Dual Phase, and UnterdruckVerdampfer-Brunnen (UVB). However, there are three technologies that could work in the unsaturated and saturated zones and there are six potential technologies that could work in the aquifer. By combining these two groupings, a train, capable of remediating all three zones could be formed. Table 3.2, on the following page, demonstrates how the 18 trains are formed. 
Table 3.2 Example Strategy Generation Table for Technology Trains

\begin{tabular}{|c|c|c|}
\hline $\begin{array}{c}\text { Unsaturated \&Saturated } \\
\text { Hydrogeologic Zone } \\
\text { Technologies } \\
\text { (Zones 1\&2) }\end{array}$ & $\begin{array}{c}\text { Aquifer Zone } \\
\text { Technologies } \\
\text { (Zone 3) }\end{array}$ & $\begin{array}{c}\text { Number of } \\
\text { Combinations or } \\
\text { Trains }\end{array}$ \\
\hline 2 Phase & Pump and Treat & 2Phase \& Pump \& Treat \\
\hline 6 Phase & Permeable Treatment Zone & 2Phase \& Surfactants \\
\hline LASAGNA & Cosolvents & etc. \\
\hline & Surfactants & \\
\hline & Redox & $3 * 6=18$ \\
\hline & Oxidation & 3 \\
\hline
\end{tabular}

In addition to the 18 trains developed above, the decision makers wanted to consider one specific train of Radio Frequency Heating in zones 1 and 2, and Oxidation in zone 3 as well as the No Action Alternative, when there is no remedial technology employed at the site. The No Action Alternative is used as a benchmark in this analysis. Table 3.3 lists all the trains evaluated in this analysis. In addition, Appendix $\mathrm{C}$ gives a brief description of how each of the candidate technologies works.

Table 3.3 Technology Trains Evaluated

\begin{tabular}{|c|l|}
\hline $\begin{array}{c}\text { Train } \\
\text { Number }\end{array}$ & \multicolumn{1}{c|}{ Train Description } \\
\hline 1 & DUS \\
\hline 2 & UVB \\
\hline 3 & Dual Phase \\
\hline 4 & 2 Phase and Pump \& Treat \\
\hline 5 & 2 Phase and Permeable Treatment Zones \\
\hline 6 & 2 Phase and Cosolvents \\
\hline 7 & 2 Phase and Surfactants \\
\hline 8 & 2 Phase and Redox \\
\hline 9 & 2 Phase and Oxidation \\
\hline
\end{tabular}




\begin{tabular}{|c|l|}
\hline 10 & 6 Phase and Pump \& Treat \\
\hline 11 & 6 Phase and Permeable Treatment Zones \\
\hline 12 & 6 Phase and Cosolvents \\
\hline Train & \multicolumn{1}{c|}{ Train Description } \\
\hline Number & \\
\hline 13 & 6 Phase and Surfactants \\
\hline 14 & 6 Phase and Redox \\
\hline 15 & 6 Phase and Oxidation \\
\hline 16 & LASAGNA and Pump \& Treat \\
\hline 17 & LASAGNA and Permeable Treatment Zones \\
\hline 18 & LASAGNA and Cosolvents \\
\hline 19 & LASAGNA and Surfactants \\
\hline 20 & LASAGNA and Redox \\
\hline 21 & LASAGNA and Oxidation \\
\hline 22 & Radio Frequency Heating and Oxidation \\
\hline
\end{tabular}

\subsection{WAG 6 CERCLA Value Hierarchy}

Because WAG 6 is on the NPL, the remedial technology selection process must address the criteria established in CERCLA. The CERCLA criteria are divided into the following three distinct groups: Modifying Criteria, Threshold Criteria, and Primary Balancing Criteria [40 CFR S300.430(f)(1)]. The Modifying Criteria, State and Community Acceptance, are not included in this analysis, because they should be considered after the Record of Decision (ROD) has been released to the public for review. The Threshold Criteria, consisting of the Overall Protection of Human Health and the Environment and Compliance with Applicable or Relevant and Appropriate Requirements (ARARs) are threshold objectives that all evaluated remediation trains must meet in order to be eligible for selection. Therefore, in order for a remediation 
train to be considered and used in this analysis, it will have already been examined to ensure it has met the Threshold Criteria.

A primary intent of this research effort is to describe the five Balancing Criteria of CERCLA in the context of WAG 6 and determine which subcriteria and evaluation measures ensure that these criteria are met. Figure 3.3 identifies the five CERCLA primary balancing criteria, denoted by the bolded boxes, and associated subcriteria as expressed in the Code of Federal Regulations (CFR). However, some of these subcriteria may not directly apply to WAG 6 or may not be mutually preferentially independent from one criteria or subcriteria to the next. 


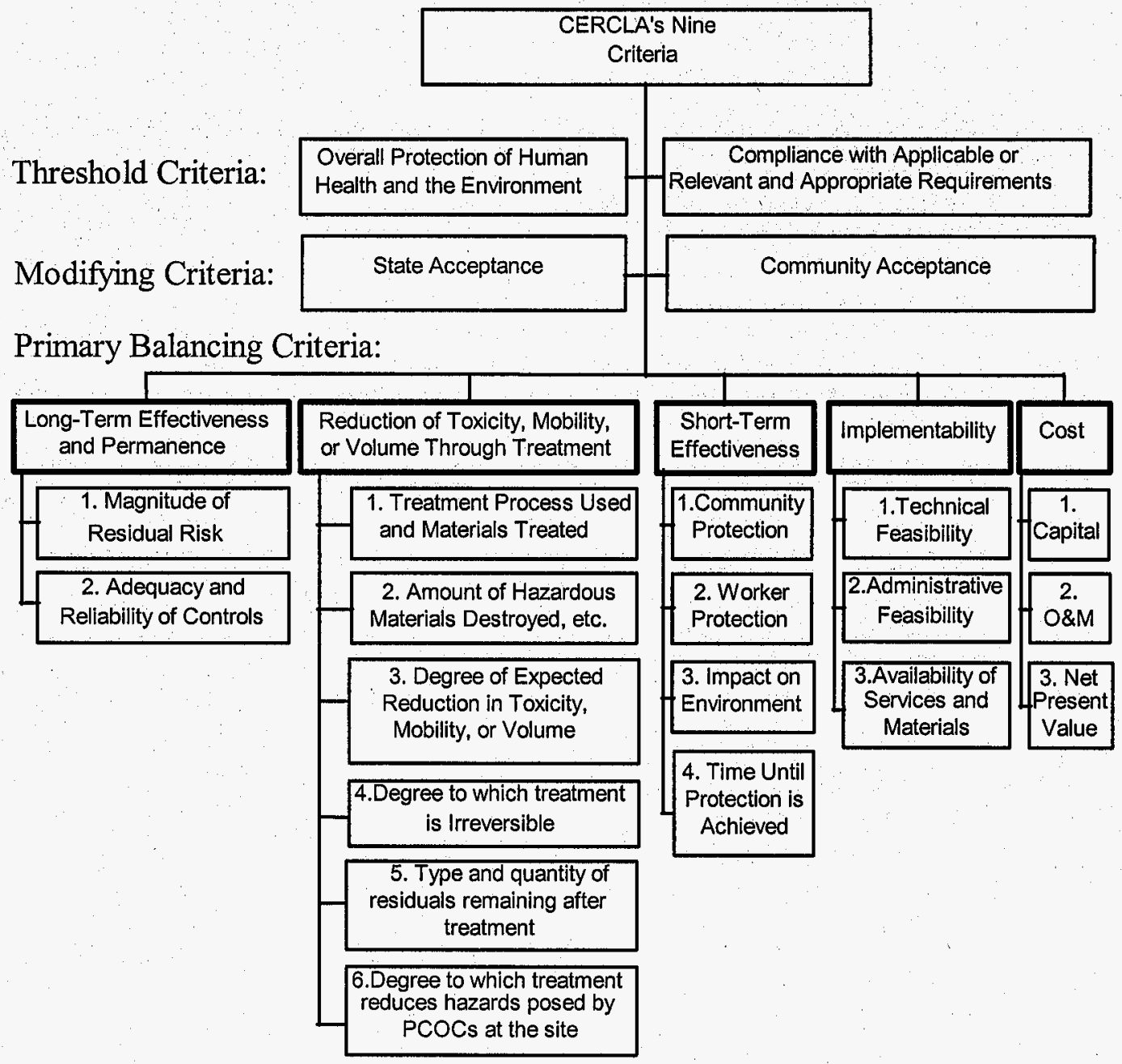

Figure 3.3 CERCLA criteria and subcriteria hierarchy [40CFR S300.430(e)(9)]

The WAG 6 team analyzed the CERCLA subcriteria of the five primary balancing criteria in reference to WAG 6, assured mutual preferential independence among the criteria as described in section 2.2.3.5, used EPA guidance for clarification [EPA/540/G-89/004], and developed evaluation measures and single dimensional value functions for each of those subcriteria which directly apply to WAG 6. Figure 3.4 depicts the WAG 6 CERCLA criteria and subcriteria hierarchy. 


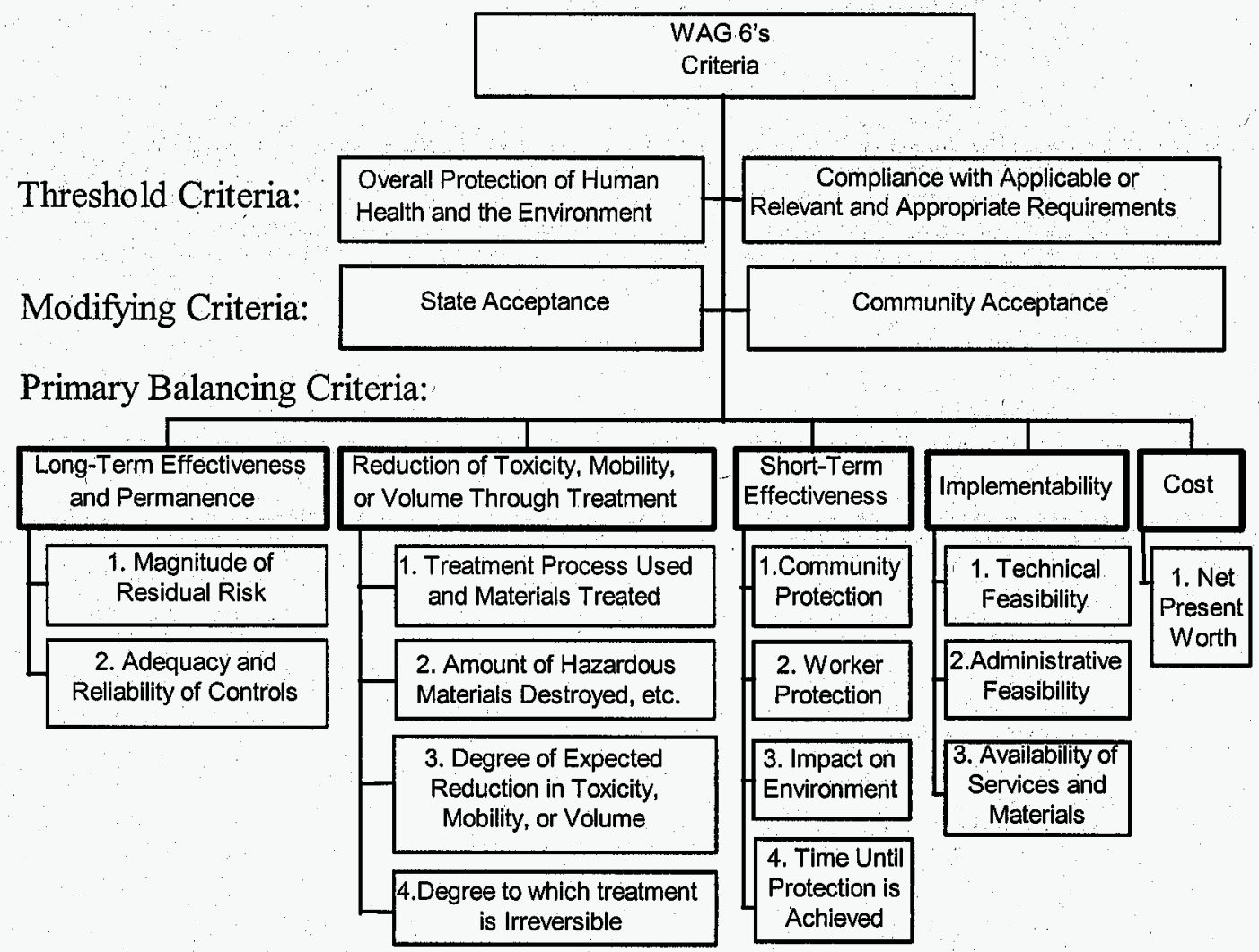

Figure 3.4 WAG 6's CERCLA based criteria and subcriteria

The two hierarchies (Figures 3.3 and 3.4) are predominantly the same. There is a slight difference in the cost subcriteria, where the WAG 6 hierarchy combines the subcriteria into one, net present cost. The WAG 6 team defines net present cost as the discounted sum of capital costs and annual O\&M costs. Another distinction between the two hierarchies is that the WAG 6 hierarchy has only four subcriteria under the Reduction of Toxicity, Mobility, or Volume Through Treatment (TMV) criterion. The WAG 6 team thought subcriterion 5 under TMV (Figure 3.3) is redundant with what was addressed with subcriterion 1 under the Long-Term Effectiveness and Permanence criterion and they wanted to ensure mutual preferential independence. In 
the same way, they thought that subcriterion 6 under TMV (Figure 3.3) is redundant with subcriterion 3 under TMV, which already addressed the reduction of hazards.

\subsection{Evaluation Measures, Scores, and Single Dimensional Value Functions}

CERCLA provides limited guidance on the development of evaluation

measures. It suggests whether high or low scores associated with an evaluation measure are preferred, but does not provide guidance as to the shape of the evaluation measure's single dimensional value functions.

Appendix B presents the WAG 6 CERCLA value hierarchy and discusses the development of each of the 28 evaluation measures that were used to score the trains. A list of the 28 evaluation measures is provided in Table 3.4 below:

Table 3.4 WAG 6 CERCLA Criteria/Subcriteria \& Evaluation Measures

\begin{tabular}{|c|c|}
\hline WAG 6 Subcriteria & Evaluation Measure \\
\hline \multicolumn{2}{|c|}{ Long-Term Effectiveness \& Permanence } \\
\hline \multirow[t]{3}{*}{ 1. Magnitude of Residual Risk } & 1. HM Remaining in the Subsurface \\
\hline & 2. Percent of TCE Left in Subsurface \\
\hline & 3. Activity of Tc-99 in Ground Water \\
\hline 2. Adequacy and Reliability of Controls & Replacement of Technical Components \\
\hline WAG 6 Subcriteria & Evaluation Measure \\
\hline \multicolumn{2}{|c|}{ Reduction of Toxicity, Mobility, or Volume Through Treatment } \\
\hline 1. Treatment Process Used \& Materials & PCOCs Addressed in the Treatments \\
\hline \multirow{2}{*}{ 2. Amount of HM Destroyed, etc. } & 1. Percent of TCE Destroyed, etc. \\
\hline & 2. Percent of Tc-99 Destroyed, etc. \\
\hline
\end{tabular}




\begin{tabular}{|c|c|}
\hline \multirow{5}{*}{ 3. Expected Reduction in TMV } & 1. Reduction of Toxicity Through In-situ \\
\hline & 2. Reduction of Mobility for TCE \\
\hline & 3. Reduction of Mobility for Tc- 99 \\
\hline & 4. Reduction in Volume of TCE zone \\
\hline & 5. Reduction in Volume of Tc-99 zone \\
\hline \multirow[t]{2}{*}{ 4. Degree That Treatment is Irreversible } & 1. Percent of TCE Irreversibly treated.. \\
\hline & 2. Percent of Tc-99 Irreversibly treated.. \\
\hline \multicolumn{2}{|c|}{ Short-Term Effectiveness } \\
\hline 1. Impact on Community Protection & Community Protection \\
\hline 2. Impact on Worker Protection & Worker Protection \\
\hline \multirow[t]{2}{*}{ 3. Impact on the Environment } & 1. Surface Releases \\
\hline & 2. Subsurface Injection of Foreign Matls. \\
\hline 4. Time Until Protection is Achieved & Year Until Protection is Achieved \\
\hline \multicolumn{2}{|c|}{ Implementability } \\
\hline \multirow[t]{5}{*}{ 1. Technical Feasibility } & 1. Ability to Construct \\
\hline & 2. Number of System Equivalents \\
\hline & 3. Number of Successful Applications \\
\hline & 4. Effect/Impact on Future Remediation \\
\hline & 5. Exposure Risk from Unmonitored Path \\
\hline 2. Administrative Feasibility & Level of Effort to Obtain Permits \\
\hline \multirow[t]{2}{*}{ 3. Availability of Services \& Materials } & 1. Treatment/Storage/Disposal Options \\
\hline & 2. Minimum Number of Contractors/Sub \\
\hline \multicolumn{2}{|c|}{$\operatorname{cosT}$} \\
\hline Net Present Cost & Net Present Cost Dollars \\
\hline
\end{tabular}

Each train listed in Table 3.3 was evaluated against each of the above

evaluation measures using a scoring packet shown in Appendix D. Every technical

expert on the WAG 6 team was asked to score each train individually, then the group

of technical experts came together and discussed the scores until consensus was

reached. This procedure was repeated until each train was scored and the technical

experts were in agreement on the scores assigned. While the scoring was being 
conducted, the technical experts were not provided a copy of the corresponding value functions to avoid any bias in the scoring process. Only after all the scores were obtained, were they transformed into values through the appropriate single dimensional value functions.

Since CERCLA provided no direct guidance on the shape of the single dimensional value functions, the WAG 6 team determined an initial decision rule; single dimensional value functions would be linear across the possible range of values, which would, in their view, accurately reflect CERCLA's intentions for most of the evaluation measures. Thus, many of the single dimensional value functions are linear with either an increasing or decreasing slope, as appropriate. Appendix B describes the single dimensional value functions that were developed for each evaluation measure, and provides the rationale for their shape when they differ from the initial decision rule. These functions are critical as they convert evaluation measure scores into unitless values, which can be combined and compared as part of multiattribute preference theory described in Chapter 2. 


\subsection{Assessing Weights}

The WAG 6 team obtained weights for each tier of the value hierarchy to reflect the relative importance of each primary balancing criteria, subcriteria, and evaluation measures, through direct assessment. The weights at each level of the hierarchy must sum to one, and so the overall weight attributed to the CERCLA value must also be one, as explained previously in Chapter 2. CERCLA contributes the following guidance for balancing (weighting): "The balancing shall emphasize longterm effectiveness and reduction of toxicity, mobility, or volume through treatment." [40 CFR S300.430(f)(1)(ii)(E)]. The team interpreted this to mean that half the weight of the primary balancing criteria should be split between Long-Term Effectiveness and Permanence and Reduction of Toxicity, Mobility, or Volume Through Treatment (hence their weight of $1 / 4$ each). The remaining half of the weight was divided equally amongst the remaining three balancing criteria (hence their respective weights of 1/6 each), as shown below in Figure 3.5.

Unfortunately, CERCLA does not go on to distinguish or provide additional guidance for balancing/weighting the subcriteria. The WAG 6 team members asserted that since CERCLA accounted for no distinction, neither should they.

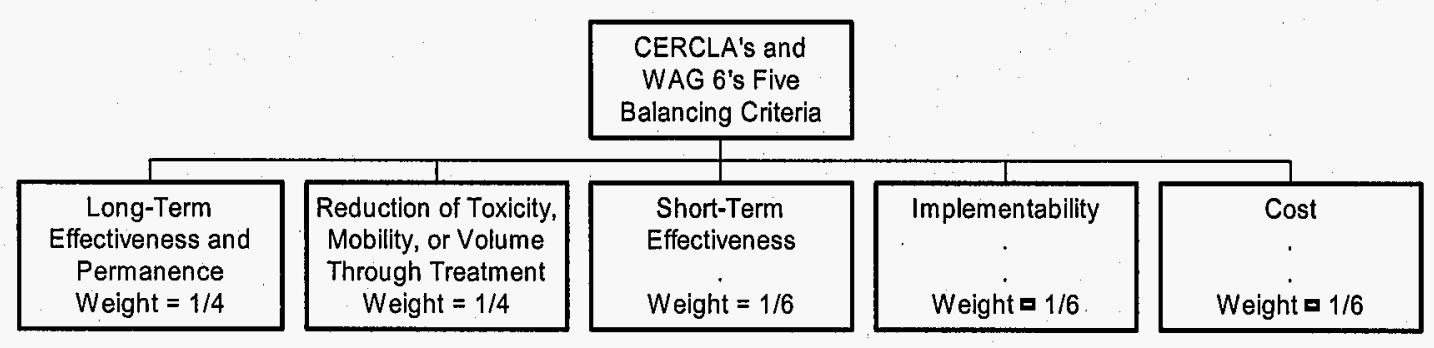

Figure 3.5 WAG 6 Hierarchy Showing Balancing Criteria Weights 
The remaining weights for the subcriteria level of the hierarchy, the solid lined boxes in Figure 3.6, are equally divided and still sum to one.

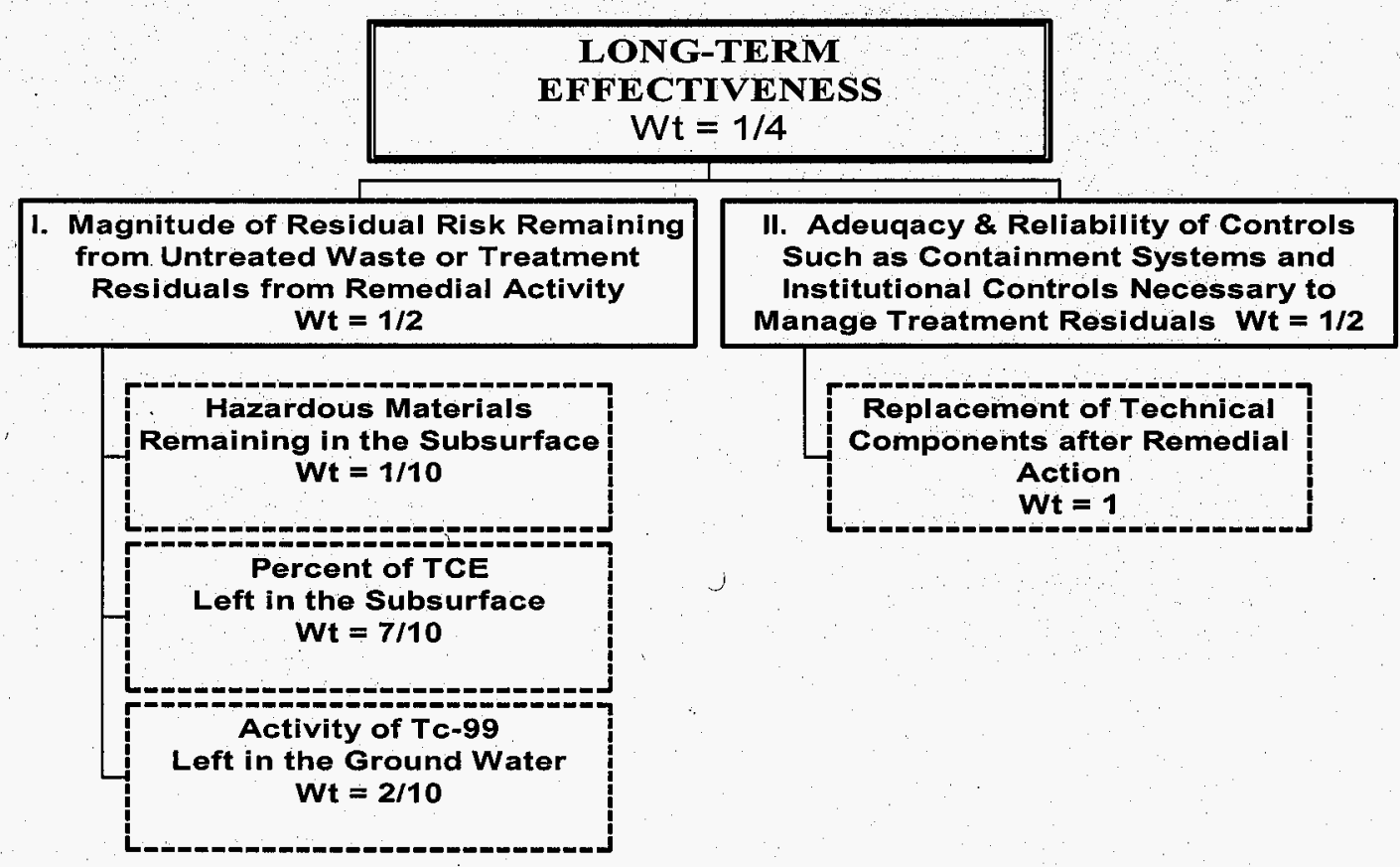

Figure 3.6 Long-Term Effectiveness Hierarchy and Weights

The next level of weights are those assigned to the evaluation measures, the dashed boxes in Figure 3.6. In the case where there is only one evaluation measure, the default weight is one (see Replacement of Technical Components after Remedial Action in Figure 3.6). Where there are several evaluation measures, the weight is again split equally, except where there is a distinction between TCE and Tc-99. Referencing CERCLA (40 CFR S300.430(f)(1)(ii)(E)), it goes on to say, "The balancing shall also consider the preference for treatment as a principal element and the bias against off-site land disposal of untreated waste." The WAG 6 team members interpreted this to mean that treating a waste was three times more valuable than disposing of it. Hence, TCE, which can be treated or destroyed, and does not 
need to be disposed of off-site in a landfill, weighs $7 / 10$ (over 3 times the weight for Tc-99). Tc-99 cannot be readily destroyed, however, and in high concentrations it must be landfilled so it receives a weight of $2 / 10$. The remaining weight of $1 / 10$ was then assigned to the evaluation measure for hazardous materials remaining in the subsurface.

Note that the overall weight for any evaluation measure is the weight assigned to that evaluation measure, multiplied by all the criterion weights above it in the CERCLA hierarchy. For example, to calculate the overall weight for the evaluation measure of the Percent of TCE Left in the Subsurface, simply multiply $7 / 10 * 1 / 2 *$ $1 / 4=7 / 80$ (see Figure 3.6)

\subsection{Application of Additive Value and Power-Additive Utility Functions}

Now that the evaluation measures, single dimensional value functions, weights, and scores are assessed, they must be combined into a single measure of the overall value for each alternative [Kirkwood, 1997:53]. As Grelk's work pointed out, the form of the overall value function must be easily understood by the decision maker, and allow extensive sensitivity analysis [Grelk 1997: 2-27]. The additive value function is merely a weighted average of the single dimensional value functions assigned to each evaluation measure and it is used extensively in practice [Kirkwood, 1997: 230]. It applies well in this decision opportunity because one of the primary assumptions made in the construction of the WAG 6 hierarchy was that the criteria and subcriteria are mutually preferentially independent. This assumption allows us to use the additive value function [Kirkwood, 1997: 230], presented as Equation 3.1. 


$$
\mathrm{v}(\mathrm{x})=\sum_{\mathrm{i}=1}^{\mathrm{n}} \lambda_{\mathrm{i}} \mathrm{v}_{\mathrm{i}}\left(\mathrm{x}_{\mathrm{i}}\right)
$$

where the total value calculated is represented by $\mathrm{v}(\mathrm{x})$, and $\mathrm{v}_{\mathrm{i}}\left(\mathrm{x}_{\mathrm{i}}\right)$ is the single dimensional value function for measure $i$, and $\lambda_{i}$ represents the weights for measure $i$.

It is assumed also that:

$$
\sum_{i=1}^{n} \lambda_{i}=1
$$

Mutual preferential independence was briefly introduced in 2.2.3.5, where it was defined by a decision maker's preference for one objective not impacting their preference for any other objectives. As an example of applying this concept to the WAG 6 hierarchy, the decision makers viewed the subcriteria: Amount of Hazardous Substances Destroyed (under Long-Term Effectiveness) and Magnitude of Residual Risk (under Reduction of TMV) as mutually preferentially independent, by creating unique definitions and bounds for each of these subcriteria. The Amount of Hazardous Substances Destroyed is interpreted to mean the volume of only the PCOCs that will be destroyed, treated, or recycled through use of the technology train [Appendix B; B-12]. The Magnitude of Residual Risk is defined as any hazardous material left within the subsurface, this includes treatment residuals, degradation products, or unreacted materials [Appendix B; B-5]. Although some of the evaluation measures developed for these two subcriteria may be similar, the objective that they are measuring is perceived to be unique and independent by the decision maker. 
Appendix B provides additional documentation on what the criteria and subcriteria were defined to be by the decision maker and how they were ultimately measured.

\subsubsection{Uncertainty}

The deterministic decision analysis models use the additive value function to produce a ranking of alternatives or trains that does not account for the uncertainty or risk associated with unknown contaminant volume. The power-additive utility function converts multiattribute values into utilities, which captures the decision maker's attitude toward risk through the use of a multiattribute risk tolerance factor $\left(\rho_{\mathrm{m}}\right)$. The power-additive utility function is expressed as [Kirkwood, 1997: 161]:

$u\left(x_{1}, x_{2}, \ldots, x_{n}\right)=\left[\begin{array}{rr}1-\exp p \\ \left.\left.x_{1}, \underline{x}_{2}, \ldots, x_{n}\right) / \rho_{m}\right], \\ 1-\exp \left(-10 / \rho_{m}\right) \\ v\left(x_{1}, x_{2}, \ldots, x_{n}\right), & \text { otherwise }\end{array}\right.$

where $u\left(x_{1}, x_{2}, \ldots, x_{n}\right)$ is the overall utility for the evaluation measures $x_{1}, x_{2}, \ldots, x_{n}$, $\mathrm{v}\left(\mathrm{x}_{1}, \mathrm{x}_{2}, \ldots, \mathrm{x}_{\mathrm{n}}\right)$ is an additive value function which calculates the overall value for evaluation measures $\mathrm{x}_{1}, \mathrm{x}_{2}, \ldots, \mathrm{x}_{\mathrm{n}}$, and $\rho_{\mathrm{m}}$ is the multiattribute risk tolerance factor.

For the deterministic analysis, the overall CERCLA values for each train are assessed at different spill volumes using the additive value function expressed as Equation 3.1, when modified to account for $\mathrm{s}$ different spill volumes becomes [Kloeber; 1997]: 


$$
\mathrm{v}_{\mathrm{s}}\left(\mathrm{x}_{\mathrm{j} s}\right) \sum_{\mathrm{i}=1}^{28} \lambda_{\mathrm{i}} \mathrm{v}_{\mathrm{i}}\left(\mathrm{x}_{\mathrm{ijs}}\right)
$$

where $s$ is either $50,100,200,300,400$, or 500 thousand gallons, $j=$ Train 1 through 23 , and $\mathrm{i}=1$ through the $28^{\text {th }}$ single dimensional value function. $\mathrm{v}_{\mathrm{i}}\left(\mathrm{x}_{\mathrm{ijs}}\right)$ are the values from each single dimensional value function at the corresponding spill volume, $\mathrm{s}$, for all trains. The values $\mathrm{v}_{\mathrm{s}}\left(\mathrm{x}_{\mathrm{ij}}\right)$ are actual outputs of the deterministic models described in section 3.8. These values are then combined using the discrete probabilities presented in Table 3.1, which accounts for the uncertainty associated with the TCE spill volume, to calculate a single expected value representing a train's ability to meet the overall, fundamental CERCLA objective. This combination is completed using the following generic equation [Kloeber, 1997]:

$$
\mathrm{V}\left(\mathrm{x}_{\mathrm{j}}\right)=\mathrm{E}\left[\mathrm{v}_{\mathrm{s}}\left(\mathrm{x}_{\mathrm{j} s}\right)\right]=\sum_{\mathrm{s}} \mathrm{p}_{\mathrm{s}} \mathrm{v}_{\mathrm{s}}\left(\mathrm{x}_{\mathrm{j} s}\right)
$$

where $\mathrm{j}$ ranges from Train 1 to Train $23, \mathrm{~V}\left(\mathrm{x}_{\mathrm{j}}\right)=$ the expected value of train $\mathrm{x}_{\mathrm{j}}$, $\mathrm{p}_{\mathrm{s}}=$ probability associated with a spill volume of $\mathrm{s}$ amount (from Table 3.1 ), and $\mathrm{v}_{\mathrm{s}}\left(\mathrm{x}_{\mathrm{js}}\right)$ is the CERCLA value of the train at that corresponding spill volume, $\mathrm{s}$ from Equation 3.3. Appendix E presents the spreadsheet used to calculate $\mathrm{V}\left(\mathrm{x}_{\mathrm{j}}\right)$ based on the data generated from the deterministic models.

Using the trains' expected values calculated above in Appendix E and the relationship established in Equation 3.2, the total utility of each train can be derived, provided the multiattribute risk tolerance factor, $\rho_{\mathrm{m}}$, is known. The multiattribute risk 
tolerance factor is a measure of the decision maker's aversion to risk. However, in the case of multiple decision makers, it is often difficult to assess risk aversion. Therefore, an analysis of the sensitivity of $\rho_{\mathrm{m}}$, can assist in determining whether it is necessary to ascertain an actual value for $\rho_{\mathrm{m}}$. Using the theory supplied by Kirkwood, where $\rho_{\mathrm{m}}$, varies between 0.2 and infinity, the trains' values are converted to utilities and ranked [Kirkwood, 1997: 161]. If the ranking changes at different values of $\rho_{\mathfrak{m}}$, then an attempt to quantify $\rho_{m}$ directly from the decision maker must be made. However, if the rankings do not change, then the value of $\rho_{\mathrm{m}}$ is inconsequential and it can be assumed that the decision maker is multiattribute risk neutral. Appendix F demonstrates the analysis performed on $\rho_{\mathrm{m}}$, which concludes that the value of $\rho_{\mathrm{m}}$ is irrelevant in this decision opportunity and so the train values generated from the decision models can also be interpreted as the train utilities.

\subsection{The Decision Models: Deterministic and Probabilistic}

Two different decision analysis software packages were used to model this decision opportunity: Logical Decisions ${ }^{\circledR}(\mathrm{LDW})$ and DPL ${ }^{\mathrm{TM}}$. LDW centers on value focused thinking concepts and allows the user to construct value hierarchies and enter data into a "familiar" spreadsheet format. LDW also produces numerous display options for deterministic results. DPL, utilizing decision trees and influence diagrams, handles uncertainty and probability better by allowing for sequential decisions and an unlimited number of key uncertainties and effects to be added. 
Grelk's work summarized the strengths and weaknesses of both software packages in his Table 3.4 [Grelk, 1997: 3-26].

Because of LDW's superiority in presenting deterministic results, $6 \mathrm{LDW}$ models were created, one specific to each of the spill volumes expressed in Table 3.1. This was possible because cost and time data were provided by MSE at the same spill volumes. Appendix $\mathrm{H}$ provides the LDW model used to evaluate the trains at a spill volume of 50,000 gallons, this model is similar to the other 5 models, only the evaluation measure scores in cost, performance and time were changed to reflect the impact of differing spill volumes.

LDW facilitates further analysis that delves deeper than just overall rank based on the overall train values. It will actually demonstrate how well each train performs against each evaluation measure so that a decision maker can consider tradeoffs. LDW also supports weight sensitivity analysis by allowing the user to vary any criterion weight from $0 \%$ to $100 \%$ and then automatically recalculates the other weights, in the same original proportion, providing the overall value of the train, based on this one weight change.

Based on the deterministic analysis, it is possible to screen down the number of trains to where a more detailed probabilistic analysis can be performed. Probabilistic analysis is better supported by DPL and so three separate models were constructed that addressed uncertainty in time, cost, and overall CERCLA value based on the initial uncertainty in TCE spill volume. The DPL models can be viewed in Appendix I. 


\subsubsection{DA Modeling Assumptions}

Because of the complexity of the decision opportunity, several assumptions were made in this research. The primary intent of the assumptions listed is to simplify the decision making and analysis; yet include enough information so that the analysis is objective, traceable and robust. The following list of assumptions were used in the development of the DA models:

1. The WAG 6 criteria and subcriteria are mutually preferentially independent. Section 3.7 addresses this assumption, which seems to be defensible because the criteria and subcriteria were constructed with this point in mind. Without this assumption, the additive value function would be invalid.

2. All alternatives or trains evaluated in this analysis meet CERCLA's Threshold criteria. Decision makers selected and reviewed the candidate trains to ensure that threshold criteria were met and that the technologies were aggressive, not purely containment focused.

3. The only uncertainty accounted for in this decision opportunity is volume of contaminant. Volume is not the only uncertainty, but it is a key technical uncertainty that impacts all trains and therefore must be addressed. Once the top trains have been identified in this effort, decision makers can determine where to focus additional resources to address other technical uncertainties; such as site constraints, technology performance, etc.

4. Removal efficiency for Tc-99 will be assessed by the aquifer technology, which assumes that the majority of Tc-99 is in the regional ground water aquifer. Since Tc- 
99 is soluble, this is a reasonable assumption. As additional information becomes available through the RI, it may be necessary to modify this assumption. However, the latest geological corings, indicate that the protective clay layer above the aquifer may be absent. If this is correct, then the Tc-99 has a direct conduit to the aquifer, which supports the original premise that the majority of Tc-99 is in the aquifer. Appendix $\mathrm{G}$ highlights the standard decay function used to determine the concentration of Tc-99 for the trains evaluated in this analysis.

5. All technology trains are evaluated at $90 \%$ removal efficiency of TCE. The only exception to this is when a train exceeds 30 years to reach the $90 \%$. Any train that requires more than thirty years is considered to add zero value with respect to time, as demonstrated by the single dimensional value function derived for time [Appendix B;

B-24]. For those trains that exceed 30 years (Trains 2, 3, 4, 10, 16 and 22), $90 \%$ removal efficiency for TCE is not assumed. Rather, using linear interpolation (the $60 \%$ efficiency, cost and time data is the lowest efficiency data provided by MSE), an efficiency is calculated for the thirty year point. Net Present Cost for these trains is assumed to be at the $60 \%$ efficiency level because linear interpolation is not applicable.

\subsubsection{Life Cycle Cost Modeling Assumptions}

The following list of assumptions were made by MSE in deriving the Net Present Cost and train performance data from the Life Cycle Cost (LCC) model. LCC Model outputs are provided in Appendix M. 
1. The unsaturated and saturated zones are fixed so that only the aquifer length is varied when addressing different TCE spill volumes. The technical expert considered the DNAPL in regards to the hydrogeologic model presented in Figure 3.2, and determined that this is a reasonable assumption [Davis, 1997].

2. Performance curves that are used to assess a trains' ability to remove or treat the contaminant are taken directly from the vendor. This assumes that the vendor, who is trying to sell the technology, is providing accurate information on the technology's performance.

3. Permeable Treatment Zones (PTZ) and In situ Redox times include the assumption that it takes one year for their installation. Their performance is assumed to be $0 \%$ at the time of installation and is then based on ground water flow, which is currently estimated at 22,400 gallons/day. These are thought to be the best technical assumptions that can be made in this situation.

4. Tc-99 is treated, using ion exchange, only by those trains that pull water out of the aquifer, such as pump and treat. All other trains assume a natural decay rate as shown in Appendix G.

5. Any technology that uses only a mechanical means of extraction from the aquifer, relies on dissolution calculations, which penalizes the technology with a longer time until remediation is achieved.

6. Cost estimates for technology trains (Trains 4-9) that incorporate the 2 Phase technology should be considered optimistic.

\subsection{Summary}


Figure 3.7 succinctly expresses the methodology followed in this effort, the roles of the key participants, and how the data was melded together. The WAG 6 team, comprised of AFIT/VCU and the decision makers, is responsible for the generation of the CERCLA hierarchy and weights (presented in detail in Appendix B). The team also provides the restraining hydrogeologic model which impacts the technology trains selected for evaluation. The LCC Model provides net present cost and performance information for each technology train evaluated. Finally, AFIT collects all the information generated and translates it into decision analysis software for complete evaluation as presented in Chapter 4.

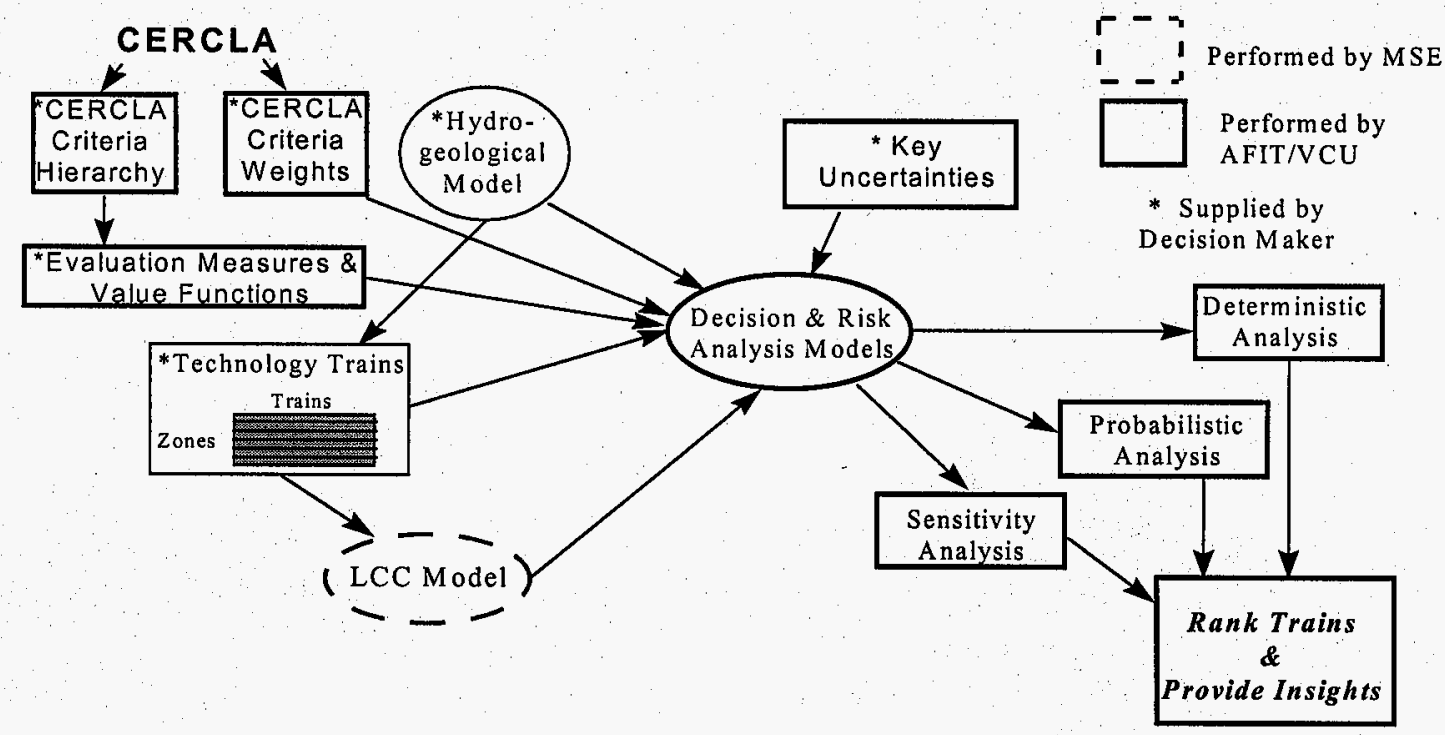

Figure 3.7 Decision and Risk Methodology Used for Train Selection 


\section{Results and Analysis}

\subsection{Introduction}

This chapter presents the results from the deterministic and probabilistic models developed in Chapter 3. First, the deterministic results are presented, which highlight the trains that best meet the CERCLA criteria for the various spill volumes identified in Table 3.1. This is followed by a discussion of required CERCLA analysis, sensitivity analysis of criteria weights, and a comparison of all the trains' rankings at the two spill volume extremes. From this deterministic analysis, the top four trains will be selected for further evaluation through probabilistic analysis,

The probabilistic analysis will present the results from the models that initially explore how the utility of the top four trains are affected by the uncertainty found in volume. Specifically, overall CERCLA utility, net present cost and time will be examined for the influence of uncertainty in volume.

\subsection{Deterministic Results}

Six models were built to account for the six different spill volumes associated with this site. In the figures that follow, it will be helpful to remember that Train 23 is the "No Action Alternative" and may be used as a reference point to compare against all other trains. Figure 4.1 demonstrates the train rankings for a TCE spill volume of 50,000 gallons, which represents the lower end of the spill distribution. Figure 4.1 also shows how well each train meets each of the five CERCLA balancing criteria. The maximum value a perfect train can achieve is a value of ten. 
Upon examining Figure 4.1, a few observations can be made. First, there is little difference in overall value for the top 4 trains. The highest rated train, Train $7=$ 7.709 , and the fourth ranked train, Train $1=7.576$, have a total difference of 0.133 . The top trains do equally well in the Reduction of Toxicity, Mobility, and Volume balancing criterion (TMV Reduction) and fairly equally in Long-Term Effectiveness and Permanence (Long-Term Effect). There is a more notable difference in Net Present Cost and Implementability criteria values, as demonstrated by Trains 7 and 21. Train 7 (2Phase \& Surfactants) receives a higher value in Implementability than Train 21, LASAGNA and Oxidation. However, Train 7 does not receive as much value in the Net Present Cost criterion, which indicates it costs more.

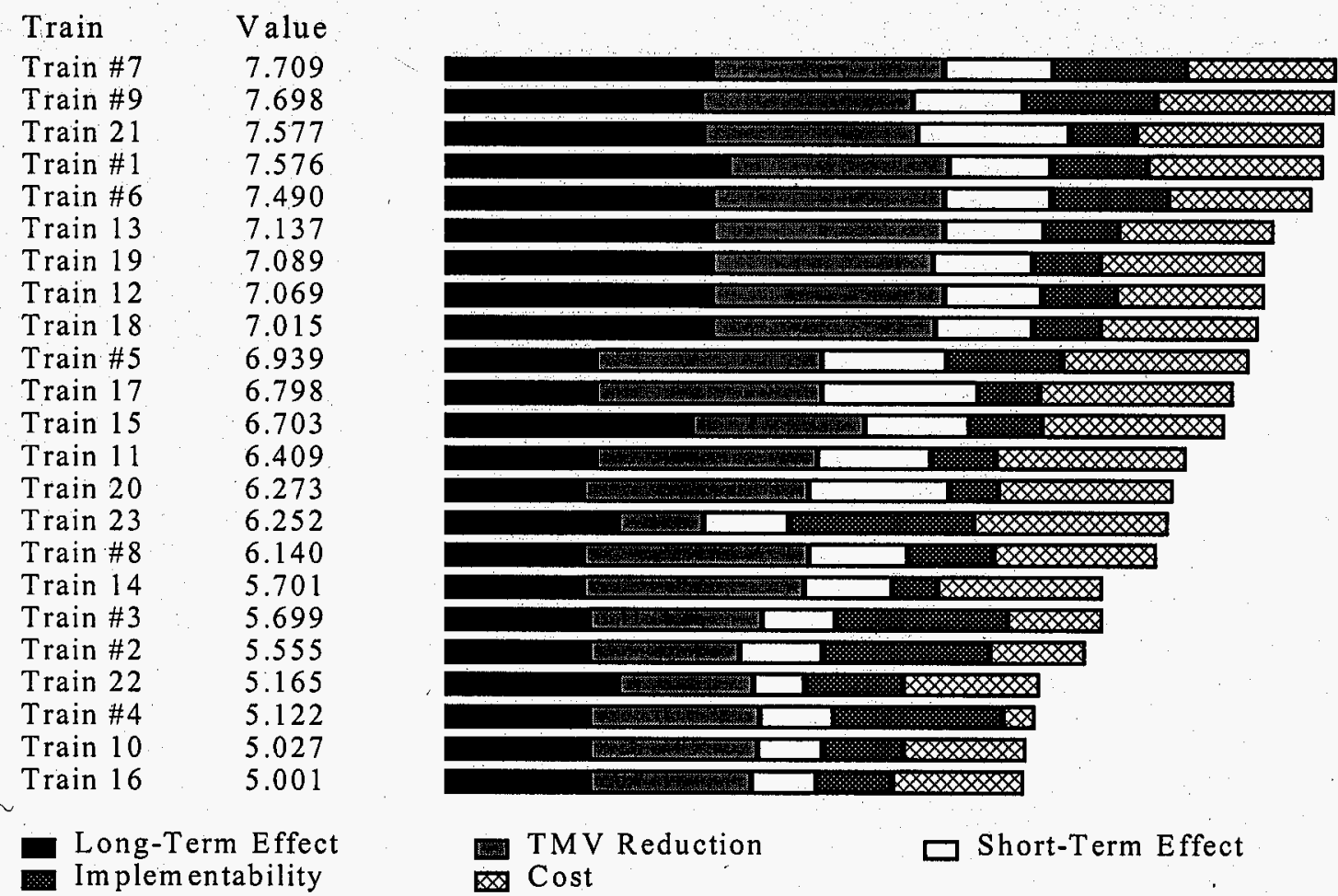

Figure 4.1 Overall CERCLA ranking for 50,000 gallon spill 
Appendix J provides further quantification of each trains' balancing criteria's

values at each different spill volume. Table 4.1 demonstrates this information for the 50,000 gallon spill scenario, the same information was used to create Figure 4.1. The maximum value a train can receive for any criterion is ten.

Table 4.1 Overall CERCLA and Balancing Criteria Values for Trains 1-23 at a $\mathbf{5 0 , 0 0 0}$ gallon spill site

\begin{tabular}{|c|c|c|c|c|c|c|}
\hline $\begin{array}{c}\text { Trains } \\
\text { Ranked } \\
\text { High to } \\
\text { Low }\end{array}$ & $\begin{array}{c}\text { CERCLA } \\
\text { Goal }\end{array}$ & $\begin{array}{c}\text { Long-Term } \\
\text { Effect Goal }\end{array}$ & $\begin{array}{c}\text { TMV } \\
\text { Reduction } \\
\text { Goal }\end{array}$ & $\begin{array}{c}\text { Short-Term } \\
\text { Effect Goal }\end{array}$ & $\begin{array}{c}\text { Implement- } \\
\text { ability } \\
\text { Goal }\end{array}$ & $\begin{array}{c}\text { Cost } \\
\text { Goal }\end{array}$ \\
\hline 7 & 7.709 & 9.231 & 7.958 & 5.625 & 7.003 & 7.828 \\
\hline 9 & 7.698 & 8.848 & 7.271 & 5.750 & 7.005 & 9.242 \\
\hline 21 & 7.577 & 8.897 & 7.334 & 7.843 & 3.541 & 9.679 \\
\hline 1 & 7.576 & 9.731 & 7.625 & 5.250 & 5.066 & 9.071 \\
\hline 6 & 7.490 & 9.231 & 7.979 & 5.500 & 6.097 & 7.510 \\
\hline 13 & 7.137 & 9.231 & 7.958 & 5.125 & 3.866 & 8.004 \\
\hline 19 & 7.089 & 9.231 & 7.625 & 5.125 & 3.625 & 8.457 \\
\hline 12 & 7.069 & 9.231 & 7.979 & 5.000 & 3.866 & 7.692 \\
\hline 18 & 7.015 & 9.231 & 7.646 & 5.000 & 3.539 & 8.191 \\
\hline 5 & 6.939 & 5.231 & 7.813 & 6.376 & 6.077 & 9.603 \\
\hline 17 & 6.899 & 8.444 & 5.891 & 5.250 & 5.265 & 9.351 \\
\hline 15 & 6.798 & 5.231 & 7.813 & 8.001 & 3.175 & 10.000 \\
\hline 11 & 6.703 & 8.487 & 5.945 & 5.375 & 3.782 & 9.371 \\
\hline 20 & 6.409 & 5.231 & 7.688 & 5.876 & 3.416 & 9.748 \\
\hline 23 & 6.273 & 4.731 & 7.813 & 7.249 & 2.590 & 8.937 \\
\hline 8 & 6.252 & 5.999 & 2.966 & 4.502 & 9.603 & 10.000 \\
\hline 14 & 6.14 & 4.731 & 7.813 & 5.124 & 4.546 & 8.332 \\
\hline 3 & 5.701 & 4.731 & 7.688 & 4.625 & 2.412 & 8.501 \\
\hline 2 & 5.699 & 5.000 & 5.999 & 3.877 & 8.931 & 4.925 \\
\hline 22 & 5.555 & 4.999 & 5.212 & 4.376 & 8.724 & 4.955 \\
\hline 4 & 5.122 & 5.000 & 5.928 & 3.877 & 8.864 & 1.644 \\
\hline 10 & 5.027 & 5.000 & 5.801 & 3.377 & 4.246 & 6.327 \\
\hline 16 & 5.001 & 5.000 & 5.570 & 3.377 & 3.999 & 6.758 \\
\hline
\end{tabular}

Figure 4.2 shows the variability of the ranking due to spill volume uncertainty by demonstrating the overall CERCLA ranking for a 500,000 gallon spill site. Not 
only do the overall train rankings change, but there is more variability among the top trains in Long-Term Effectiveness, Implementability and Net Present Cost criteria values. There is a larger difference in value between the top 4 trains as well. The first train, Train $1=7.474$, and the fourth ranked train, Train $17=6.798$, which results in a 0.676 difference in overall CERCLA value. In addition, notice that Train 4 receives no value for cost; its expected net present cost is approximately $\$ 32$ million, the most expensive of all trains at any spill volume (Appendix B; B-35).

$\begin{array}{ll}\text { Train } & \text { Value } \\ \text { Train \#1 } & 7.474 \\ \text { Train \#5 } & 6.939 \\ \text { Train \#7 } & 6.860 \\ \text { Train 17 } & 6.798 \\ \text { Train 21 } & 6.797 \\ \text { Train \#9 } & 6.777 \\ \text { Train 11 } & 6.409 \\ \text { Train \#6 } & 6.388 \\ \text { Train 19 } & 6.380 \\ \text { Train 13 } & 6.304 \\ \text { Train 20 } & 6.273 \\ \text { Train 23 } & 6.252 \\ \text { Train \#8 } & 6.140 \\ \text { Train 18 } & 6.094 \\ \text { Train 12 } & 5.987 \\ \text { Train 15 } & 5.843 \\ \text { Train 14 } & 5.701 \\ \text { Train \#3 } & 5.386 \\ \text { Train \#2 } & 5.247 \\ \text { Train 22 } & 4.951 \\ \text { Train 10 } & 4.902 \\ \text { Train 16 } & 4.896 \\ \text { Train \#4 } & 4.746 \\ \text { a Long-Term Effect } \\ \text { ara Implementability }\end{array}$

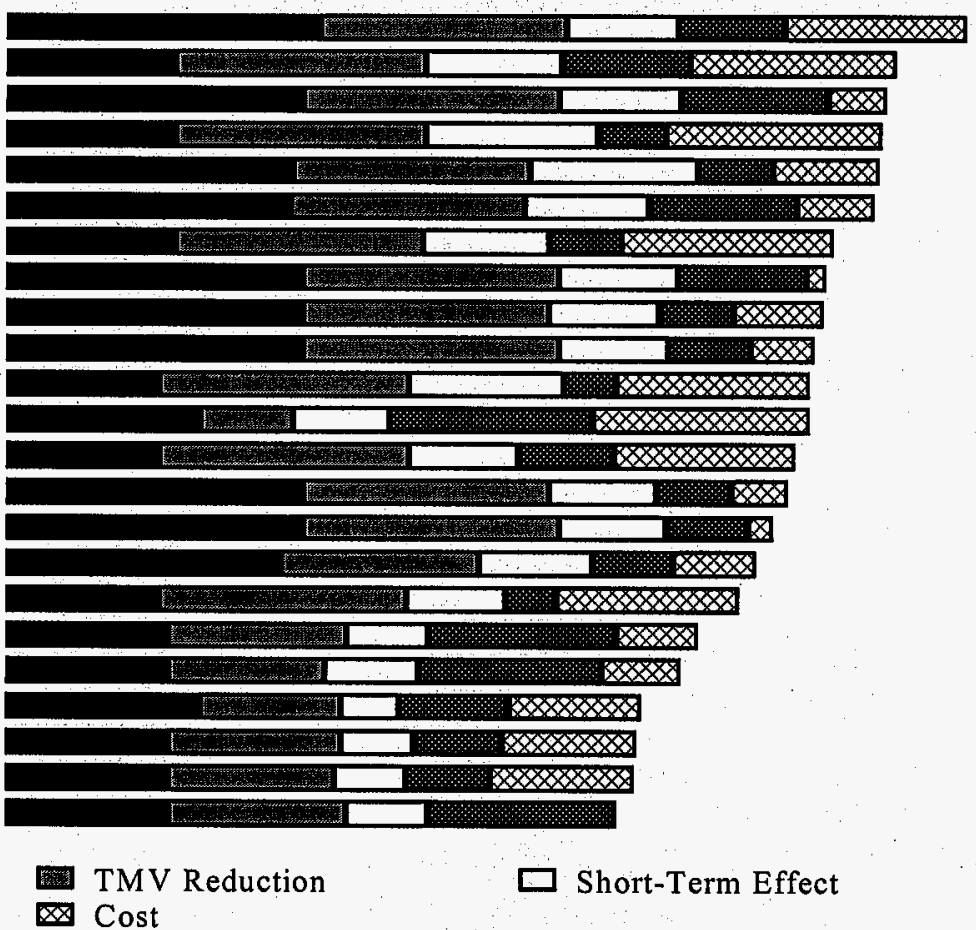

\section{Figure 4.2 Overall CERCLA ranking for 500,000 gallon spill}

At this point it becomes necessary to examine more closely each of the five balancing criteria to determine why the trains scored as they did. Since the spill volume is variable with the probability distribution discussed in Chapter 3 , the 
expected value of that distribution is closest to a spill volume of 100,000 gallons, hence this volume is selected for further analysis. Figure 4.3 shows the overall CERCLA rankings for a 100,000 gallon TCE spill. Notice that Figure 4.3 has different overall train rankings from Figures 4.1 and 4.2 , and has less variability among the top trains than Figure 4.2. There is also less of a difference in value among the top four trains compared to Figure 4.2. Train $9=7.596$ and $\operatorname{Train} 21=$ 7.49 , which is only a 0.106 difference.

$\begin{array}{ll}\text { Train } & \text { Value } \\ \text { Train \#9 } & 7.596 \\ \text { Train \#7 } & 7.557 \\ \text { Train \#1 } & 7.541 \\ \text { Train 21 } & 7.490 \\ \text { Train \#6 } & 7.313 \\ \text { Train 13 } & 6.988 \\ \text { Train 19 } & 6.963 \\ \text { Train \#5 } & 6.939 \\ \text { Train 12 } & 6.895 \\ \text { Train 18 } & 6.867 \\ \text { Train 17 } & 6.798 \\ \text { Train 15 } & 6.635 \\ \text { Train 11 } & 6.409 \\ \text { Train 20 } & 6.273 \\ \text { Train 23 } & 6.252 \\ \text { Train \#8 } & 6.140 \\ \text { Train 14 } & 5.701 \\ \text { Train \#3 } & 5.475 \\ \text { Train \#2 } & 5.380 \\ \text { Train 22 } & 5.131 \\ \text { Train 10 } & 5.064 \\ \text { Train 16 } & 5.043 \\ \text { Train \#4 } & 4.943 \\ \text { D Long-Term Effect } \\ \text { Tr Implem entability }\end{array}$

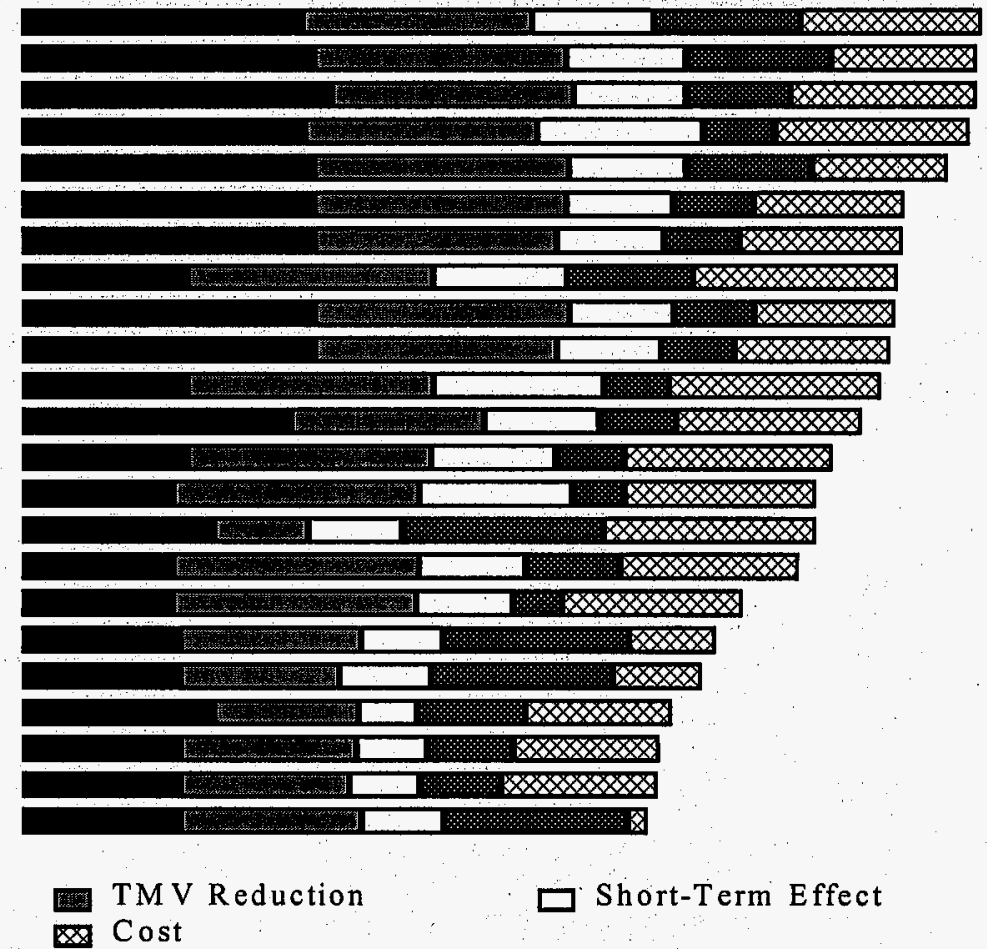

\section{Figure 4.3 Overall CERCLA ranking for 100,000 gallon spill}

It is possible to further decompose Figure 4.3 by looking at each of the balancing criteria and their related evaluation measures. Consider Figure 4.4, which demonstrates the ranking using only one evaluation measure, Net Present Cost at 
100,000 gallons (the same spill volume as in Figure 4.3). Train 17 receives the maximum value for cost because its expected net present cost is approximately $\$ 1.2$ million, the least expensive technology train. Although Train 23 (No Action Alternative) is assumed to have no additional cost, it is not considered a technology and therefore it cannot set the lower cost limit. Train 23 does receives a value of 10 , however, which is the maximum value it could achieve. Train 4, 2 Phase and Pump \& Treat, receives the lowest value because it is the most expensive train at this spill volume. Train 4 does not receive zero value, however, because it has not reached the most expensive cost, which was shown to occur at a volume of 500,000 gallons. The top four trains in Overall CERCLA value at this spill volume, that were shown in Figure 4.3, are denoted by an asterisk in Figures 4.4 and 4.5.

$\begin{array}{ll}\text { Train } & \text { Value } \\ \text { Train 17 } & 10.000 \\ \text { Train 23 } & 10.000 \\ \text { Train 11 } & 9.748 \\ \text { Train \#5 } & 9.603 \\ \text { * Train 21 } & 9.156 \\ \text { Train 20 } & 8.937 \\ \text { *Train \#1 } & 8.860 \\ \text { Train 15 } & 8.757 \\ \text { *Train \#9 } & 8.618 \\ \text { Train 14 } & 8.501 \\ \text { Train \#8 } & 8.332 \\ \text { Train 19 } & 7.698 \\ \text { Train 16 } & 7.322 \\ \text { Train 18 } & 7.305 \\ \text { Train 13 } & 7.113 \\ \text { *Train \#7 } & 6.921 \\ \text { Train 22 } & 6.896 \\ \text { Train 10 } & 6.885 \\ \text { Train 12 } & 6.652 \\ \text { Train \#6 } & 6.450 \\ \text { Train \#2 } & 4.112 \\ \text { Train \#3 } & 4.009 \\ \text { Train \#4 } & 0.916 \\ \text { T Net Present Cost }\end{array}$

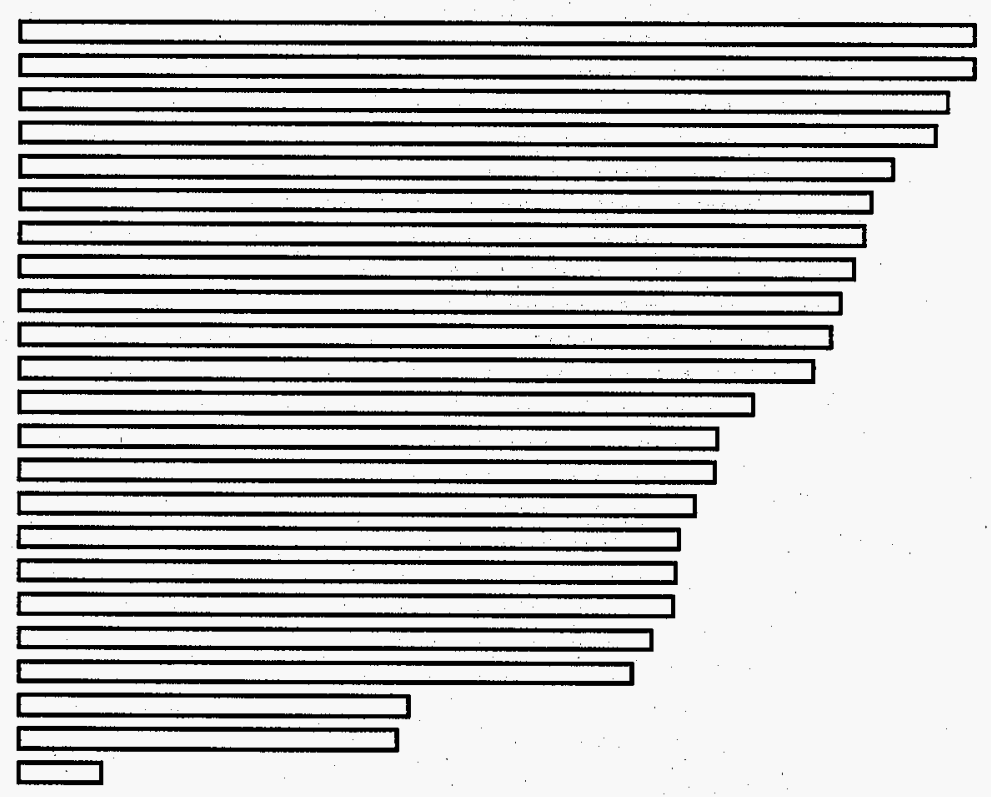

Figure 4.4 Net Present Cost Rankings Only - 100,000 gallon spill 
The Short-Term Effectiveness criteria also provides a great range in value among the trains and is depicted in Figure 4.5, for a 100,000 gallon spill. Again, the train rankings do not match those for the overall CERCLA value (which are asterisked), but provide further insight into how train values for short-term effectiveness compare. Train 20, LASAGNA and Redox, receives no value for subsurface injection, because it injects reagents into the aquifer, yet it ranks third in overall short term effectiveness because it maximizes the rest of the evaluation measures.

\begin{tabular}{ll} 
Train & Utility \\
Train 17 & 8.001 \\
*Train 21 & 7.835 \\
Train 20 & 7.249 \\
Train \#5 & 6.376 \\
Train 11 & 5.876 \\
*Train \#9 & 5.750 \\
*Train \#7 & 5.625 \\
Train \#6 & 5.500 \\
Train 15 & 5.375 \\
*Train \#1 & 5.250 \\
Train 13 & 5.125 \\
Train 19 & 5.125 \\
Train \#8 & 5.124 \\
Train 12 & 5.000 \\
Train 18 & 5.000 \\
Train 14 & 4.625 \\
Train 23 & 4.502 \\
Train \#2 & 4.376 \\
Train \#3 & 3.877 \\
Train \#4 & 3.877 \\
Train 10 & 3.377 \\
Train 16 & 3.377 \\
Train 22 & 2.751 \\
\hline
\end{tabular}

Community Protect Subsurface Inject

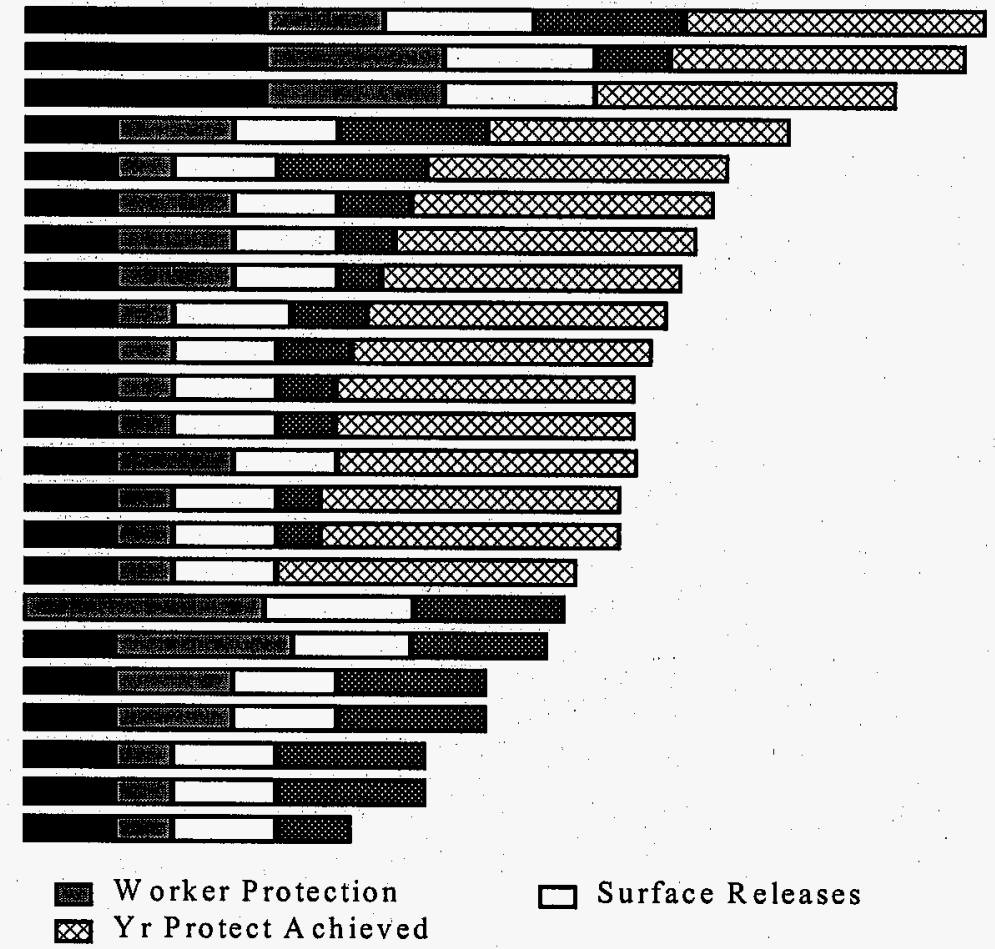

Figure 4.5 Short-Term Effectiveness Rankings Only $-100,000$ gallon spill

Similarly, each of the five balancing criteria can be examined to trace the advantages of each train, against each evaluation measure, in each balancing criteria. 
Appendix $J$ contains the remaining criteria of Long-Term Effectiveness and Permanence, Reduction of Toxicity, Mobility, and Volume, and Implementability for the 100,000 gallon spill scenario.

\subsection{Required CERCLA Analysis}

The bar graphs just presented relate how well the trains perform overall. They are useful in comparing trains against one criterion or specific evaluation measure. To more clearly demonstrate how trains compare when they are assessed against two or more criteria, scatter plots are used. Scatter plots demonstrate a train's performance on one criteria plotted against that same train's performance on another criteria. To maintain consistency with the bar graphs, the values from the $100 \mathrm{~K}$ gallon spill scenario will be used in this section.

CERCLA states that the remedial technology selected should be cost effective. It further defines "overall effectiveness" as the following three of the five primary balancing criteria: Long-Term Effectiveness and Permanence, Reduction of Toxicity, Mobility or Volume through Treatment, and Short-Term Effectiveness [40 CFR S300.430(f)(ii)(D)]. Using a scatter plot, Figure 4.6 compares the Overall Effectiveness of a train, as defined by CERCLA, to the train's Net Present Cost.

Trains that are in the upper left portion of Figure 4.6 represent those trains that have the lowest cost and the highest overall effectiveness value and thus are most desirable. The train that has the highest effectiveness value is Train 21, LASAGNA and Oxidation, but it does not have as low a cost as Train 17, LASAGNA and PTZ. From Figure 4.6, it is possible for the decision makers to understand the tradeoffs 
between cost and overall effectiveness. As a quick check, the train that costs the least and has the lowest effectiveness value is Train 23, the No Action Alternative. There are some expected costs associated with Train 23; such as obtaining regulator approvals, monitoring, reporting, etc.

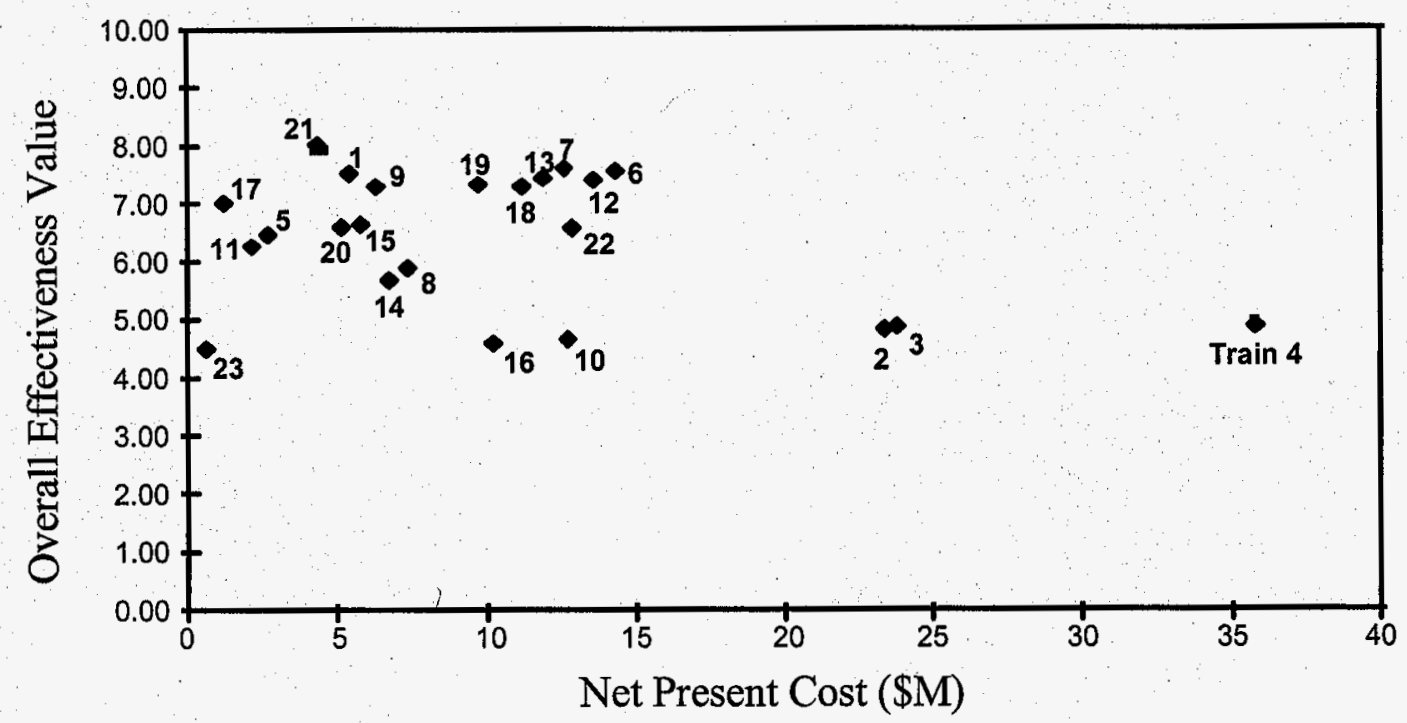

Figure 4.6 Net Present Cost vs. Overall Effectiveness Value (at 100,000 gals.)

Examining Figure 4.6 for deterministic dominance reveals that Trains 23,17 and 21 are nondominated. That is, based on the CERCLA value-focused thinking evaluation and its assumptions, no train has both a better overall effectiveness value and a lower cost than these trains. For example, "if" all the data was completely accurate, there would be no reason to select Trains 11 or 5 because Train 17 has a higher overall effectiveness value for a lower cost. Train 17 is said to deterministically dominate Trains 11 and 5 and all other trains that are to the right and lower. Similarly, Train 21 deterministically dominates Trains 9 and 1 and all other 
trains below and to the right of it. Of course, such conclusions depend on the precision of the data used.

A decision maker may also find it useful to understand the tradeoffs between the overall CERCLA value determined for each train and Net Present Cost, as shown in Figure 4.7. It should be noted that the overall CERCLA value in Figure 4.7 includes values from all the balancing criteria except for net present cost values.

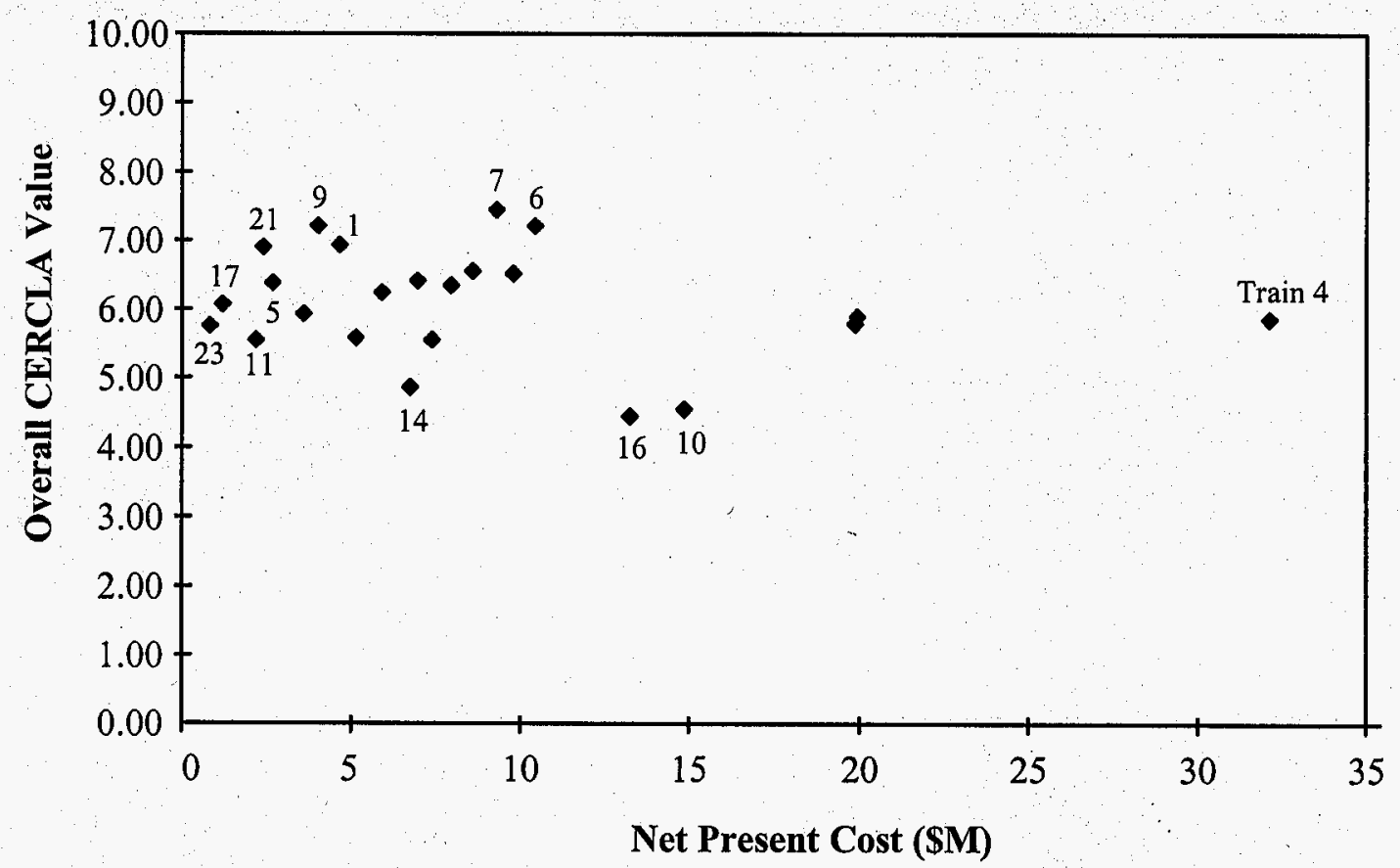

Figure 4.7 Net Present Cost vs. Overall CERCLA Value (at 100,000 gals.)

Figure 4.7 demonstrates that Trains $23,17,21,9$, and 7 are nondominated by the other trains when comparing cost to overall CERCLA value. No other train has both a larger overall CERCLA value and a lower cost than these trains. Train 9 has shifted over from being dominated in Figure 4.6, where overall effectiveness and net present cost were plotted, by Train 21 to being nondominated in Figure 4.7. The additional 
value received from the Implementability criterion within the overall CERCLA value (plotted in Figure 4.7) is enough to give Train 9 a higher overall CERCLA value than Train 21. Deterministically, one would normally choose a nondominated train.

\subsection{Criteria Weight Sensitivity Analysis}

Because CERCLA fails to specifically identify weights for the five primary balancing criteria, the assignment of weights and how they affect the overall CERCLA value and ranking of trains is an area of potential concern. Chapter 3 discusses the assumptions that are made in order to arrive at the initial set of weights depicted in Figure 4.8 and Table 4.2. However, suppose a decision maker interprets CERCLA as having no preference, unless a specific criterion is explicitly stated. It is possible to examine the influence any weight may have on the top ranked train by reviewing the sensitivity analysis results presented in Figure 4.8:

Percent of Total Weight

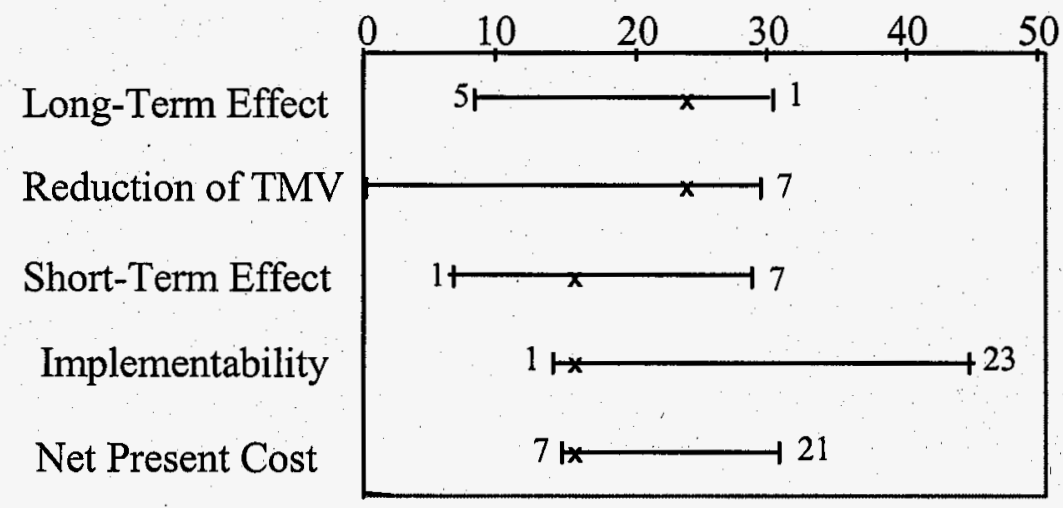

$\mathrm{x}=$ initial weights causing Train 9 to rank the best in Overall CERCLA Value

Figure 4.8 Weight Sensitivity Analysis at 100,000 gallons 
Figure 4.8 graphically demonstrates the range each weight can be varied for each criterion before changing the ranking of Train 9 to one of the other trains demonstrated at the ends of the lines. It is important to realize that as the weight for a criterion is adjusted, the other weights are changed proportionally and simultaneously for the other criteria, thus assuring that the criteria weights always total $100 \%$.

Table 4.2 also depicts how Train 9, which is the top ranked train under the current set of weights for a 100,000 gallon spill, is sensitive to adjustments in primary balancing criteria weights. The table lists the lowest and highest percentage that the particular criterion can be adjusted, before there is a change in the ranking of the top train. The train that replaces Train 9 in rank of overall CERCLA value is indicated by the bolded number in parentheses. For example, consider the Net Present Cost (NPC) criterion, where the lowest percentage weight for which the current ranking remains valid is $14.8 \%$ : At a lower weight for NPC, Train 9 is replaced by Train 7. Likewise, a weighting of NPC higher than $30.5 \%$ will change the overall ranking resulting in Train 21 having a higher CERCLA value.

Table 4.2 Sensitivity of Train 9 to Adjustments in Criteria Weights

\begin{tabular}{|c|c|c|c|}
\hline Criterion & $\begin{array}{l}\text { Lowest Percent } \\
\text { of Total Weight }\end{array}$ & $\begin{array}{c}\text { Initial Percent } \\
\text { of Total Weight }\end{array}$ & $\begin{array}{l}\text { Highest Percent } \\
\text { of Total Weight }\end{array}$ \\
\hline Long-Ten & $8.4 \quad(5)$ & $25.0 \quad(9)$ & $29.5 \quad(1)$ \\
\hline Reductio & 0 & $25.0 \quad(9)$ & $29.1 \quad(7)$ \\
\hline Short-Terr & $\begin{array}{ll}6.2 & (1) \\
\end{array}$ & $16.7 \quad(9)$ & $28.5 \quad(7)$ \\
\hline Imple & $14.0 \quad(1)$ & $16.7 \quad(9)$ & $45.0 \quad(23)$ \\
\hline Net Present Cost & $14.8 \quad(7)$ & $16.7 \quad(9)$ & $30.5 \quad(21)$ \\
\hline
\end{tabular}


Train 9 seems to be the most sensitive to lowering the weight for NPC criterion, allowing only a 1.9 percent decrease in weight before being usurped by Train 7 in the ranking. Decision makers may decided to increase the weight associated with NPC, stressing the importance of a cost effective solution. If this were the case then other criteria weights would be lowered accordingly making the criterion weight for Implementability most sensitive to change. Another interesting observation that can be made from Table 4.1 is that Train 9 is replaced the same number of times by both Train 7 and 1, averaging about a $6 \%$ change in any criterion weight. Appendix $\mathrm{K}$ contains the sensitivity graphs that support the derivation of Figure 4.8 and Table 4.2.

\subsection{Discussion of Train Rankings as Affected by Volume}

After reviewing the discussion of weight sensitivity, it might be asked how do variations in volume compare? Until now, the analysis has centered around the most probable spill volume of 100,000 gallons, and a deterministic analysis has been performed. Figure 4.9 portrays the impact of volume on the overall CERCLA value rankings of the 23 trains. The extreme points of the volume distribution were used to demonstrate the range of rankings a train will experience as volume is changed. From this chart it is possible to recognize the top performers by those that consistently rank high, and have little variation in rank, regardless of the spill volume.

After examining Figure 4.9 it is clear that the top four trains are: Trains 7, 9, 1, and 21. Although Trains 5 and 17 rank above the $5^{\text {th }}$ place ranking line for the largest spill volume, they perform poorly at smaller spill volumes. Considering smaller spill volumes have a higher probability of existing than larger spill volumes 
based on the information provided in Table 3.1, further consideration of Trains 5 and 17 would suggest accepting the risk of lower overall CERCLA values. However, as more accurate estimates of the spill volume become available, this would be a critical issue to reexamine.

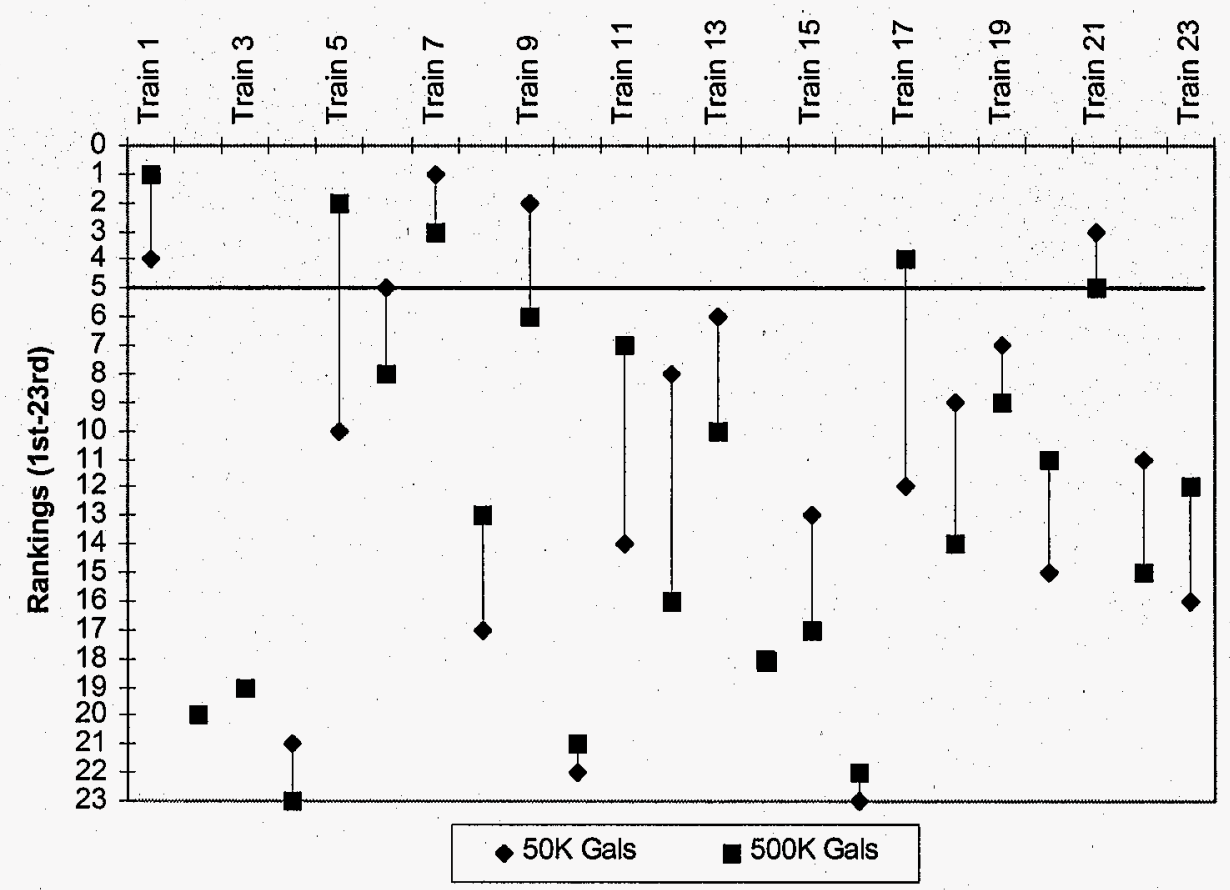

Figure 4.9 Train Rankings for Differing Spill Volumes

Appendix J contains a listing of all train rankings at all spill volumes.

Interestingly, these trains are predominantly the same trains that surfaced during the deterministic criteria weight sensitivity analysis for a 100,000 gallon spill site. With these top trains identified, a probabilistic analysis was performed which better demonstrates the consequences of uncertainty in spill volume.

\subsection{Probabilistic Analysis}


Chapter 3 provides support for the assumption that for this decision opportunity, the expected CERCLA values can also be interpreted as expected CERCLA utilities. Appendix E shows how the expected values/utilities for the trains are calculated.

Table 4.3 shows the expected utility and ranking for each train.

Table 4.3 Expected Utility of Trains

\begin{tabular}{|c|c|c|}
\hline Trains & Expected Utility & Train Ranking \\
\hline 7 & 7.61 & 1 \\
\hline 9 & 7.60 & 2 \\
\hline 1 & 7.56 & 3 \\
\hline 21 & 7.49 & 4 \\
\hline 6 & 7.36 & 5 \\
\hline 13 & 7.04 & 6 \\
\hline 19 & 7.00 & 7 \\
\hline 12 & 6.94 & 8 \\
\hline 5 & 6.94 & 9 \\
\hline 18 & 6.91 & 10 \\
\hline 22 & 6.81 & 11 \\
\hline 17 & 6.80 & 12 \\
\hline 15 & 6.61 & 13 \\
\hline 11 & 6.41 & 14 \\
\hline 20 & 6.27 & 15 \\
\hline 23 & 6.25 & 16 \\
\hline 8 & 6.14 & 17 \\
\hline 14 & 5.70 & 18 \\
\hline 3 & 5.63 & 19 \\
\hline 2 & 5.49 & 20 \\
\hline 16 & 5.13 & 21 \\
\hline 4 & 5.06 & 22 \\
\hline 10 & 5.01 & 23 \\
\hline & & \\
\hline
\end{tabular}

The top trains identified by expected utility are 7, 9, 1 and 21 . These are the same top four trains that surfaced in Figure 4.3, where the trains were ranked for a 100,000 
gallon spill. There is a difference in the order of the top four. Train 7 places first in expected utility but is second to Train 9 at the 100,000 gallons scenario. This implies that while Train 9 performs well at one spill volume, it is out performed by Train 7 at the other spill volumes.

When conducting a probabilistic analysis, it is common to use risk profiles, which are plots that demonstrate the risk involved with a particular alternative or train. In this analysis, the risk is associated with differing spill volumes and quantifying its impact on train performance in the areas of overall CERCLA value, Net Present Cost and time until protection is achieved. A cumulative risk profile is nothing more than the adding up of chances or probabilities of those individual outcomes [Clemen, 1996: 123]. Consider Figure 4.10 where risk profiles of the top four trains are presented for the total CERCLA utility. These plots show the CERCLA value at different probabilities, the same probabilities that represent the spill volumes.

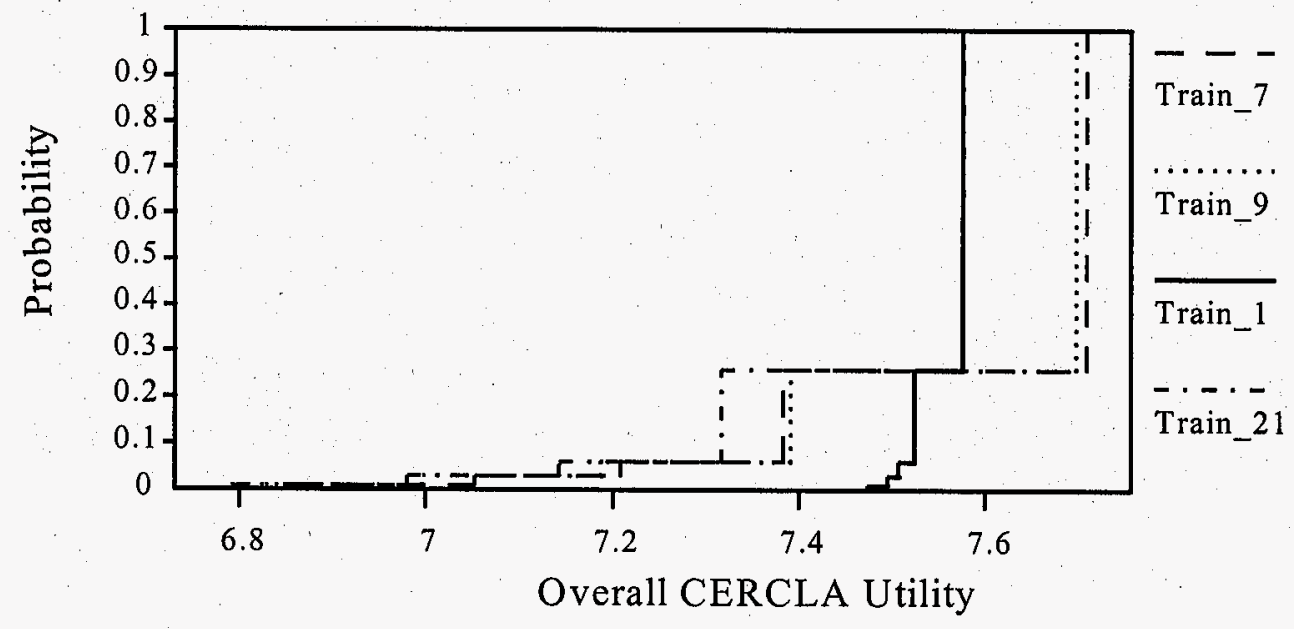




\section{Figure 4.10 Risk Profile of Overall CERCLA Utility}

The optimal train in Figure 4.10 would reach the highest CERCLA utility at the lowest possibility. Another way to interpret this figure is looking at Train 1 , there is a 0.35 probability that Train 1 will have an overall CERCLA utility of 7.58 or less.

Train 1 also exhibits a smaller range of utility compared to the other risk profiles, which means that uncertainty in volume changes the overall CERCLA utility very little. It is not difficult to reason then that Train 21 , the line always to left of the other profiles, would never be selected. Train 21 is said to be stochastically or probabilistically dominated by the other trains, because at any point, there is always another train that has the same if not greater overall utility.

Another interesting risk profile comparison can be made with Net Present Cost.

Figure 4.11 demonstrates how uncertainty in volume translates into uncertainty in cost. The interpretation of this figure is similar to Figure 4.10.

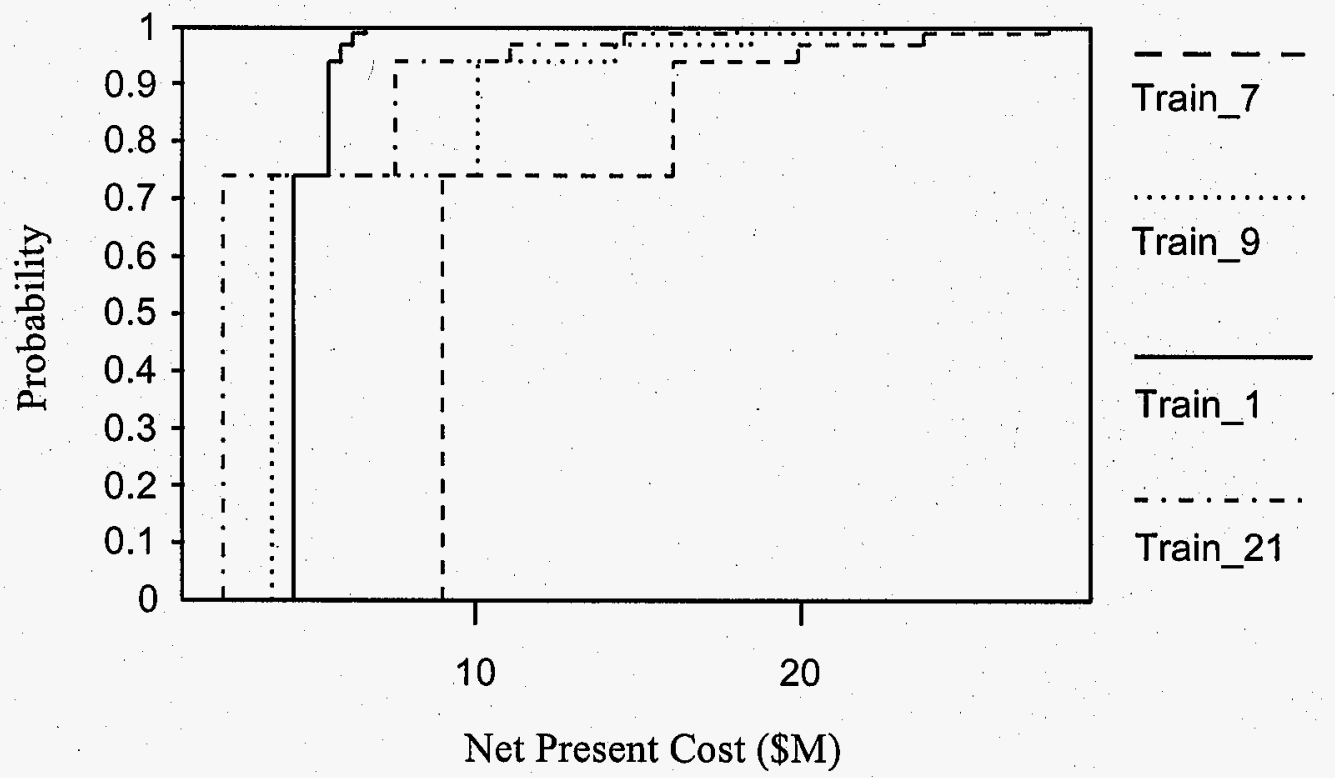




\section{Figure 4.11 Risk Profile of Net Present Cost}

Train 1 still exhibits little variance, but in this case its Net Present Cost does not seem to be affected by the uncertainty in volume. In addition, the most preferred profile will be one that has a high probability of low cost, or the profiles closest to the left, which differs from Figure 4.10. Therefore, Train 7 is the worst train in this case and is stochastically dominated by all the other trains. Additionally, Train 7 and Train 9 are stochastically dominated by Train 21 .

Based on this analysis, as a decision maker considering only Net Present Cost, you would select either Train 1,9 or 21. Train 1 seems to be the more likely choice, because there is a $74 \%$ chance of it costing $\$ 4.7$ million and a $26 \%$ chance of a higher cost. The most Train 1 would ever cost is only $\$ 6.9$ million, but its expected cost is $\$ 5$ million. Train 9 has a $74 \%$ chance of costing $\$ 4$ million and a $26 \%$ chance of a larger cost. Train 9 has an expected cost of $\$ 6.24$ million but could cost as much as $\$ 24.8$ million. Train 21 has a $74 \%$ chance of costing $\$ 2.4$ million with a $26 \%$ chance of a higher cost. The most Train 21 would ever cost is $\$ 19.8$ million, which seems a bit risky. However, the expected cost of Train 21 is only $\$ 4.3$ million. The decision maker is faced with deciding whether it is worth risking approximately $\$ 13$ million $(19.8-6.9)$ in order to save $\$ 700,000$ in expected costs. Of course, this analysis is dependent upon the accuracy of the assumptions made in the decision and life cycle cost models.

Finally, the issue of time until protection is achieved is addressed with the risk profile of time, shown in Figure 4.12. The most interesting point demonstrated by 
this figure is that, based on the current model assumptions, uncertainty in volume has very little impact on time. Train 1 takes the least amount of time and is unaffected by uncertainty. It can be said that Train 1 deterministically dominates all other trains because its risk profile reaches completion in 1.33 years, sooner than all the other profiles begin. The next closest train is Train 7 which deterministically dominates Trains 9 and 21, as it finishes in 5.7 years, before either Train 9 or 21 begin. Finally, it can also be said that Train 21 is deterministically dominated by all other trains. It takes the longest and all other trains have finished before Train 21 even begins. It seems surprising that volume has little impact on time to remediate for these top four trains. Based on the 10-year plan and assuming construction of the train would be complete by 2002 , any train taking 8 years or less would be considered extremely successful. Train 21 is the only train that does not meet that goal; it has an expected time of 8.3 years.

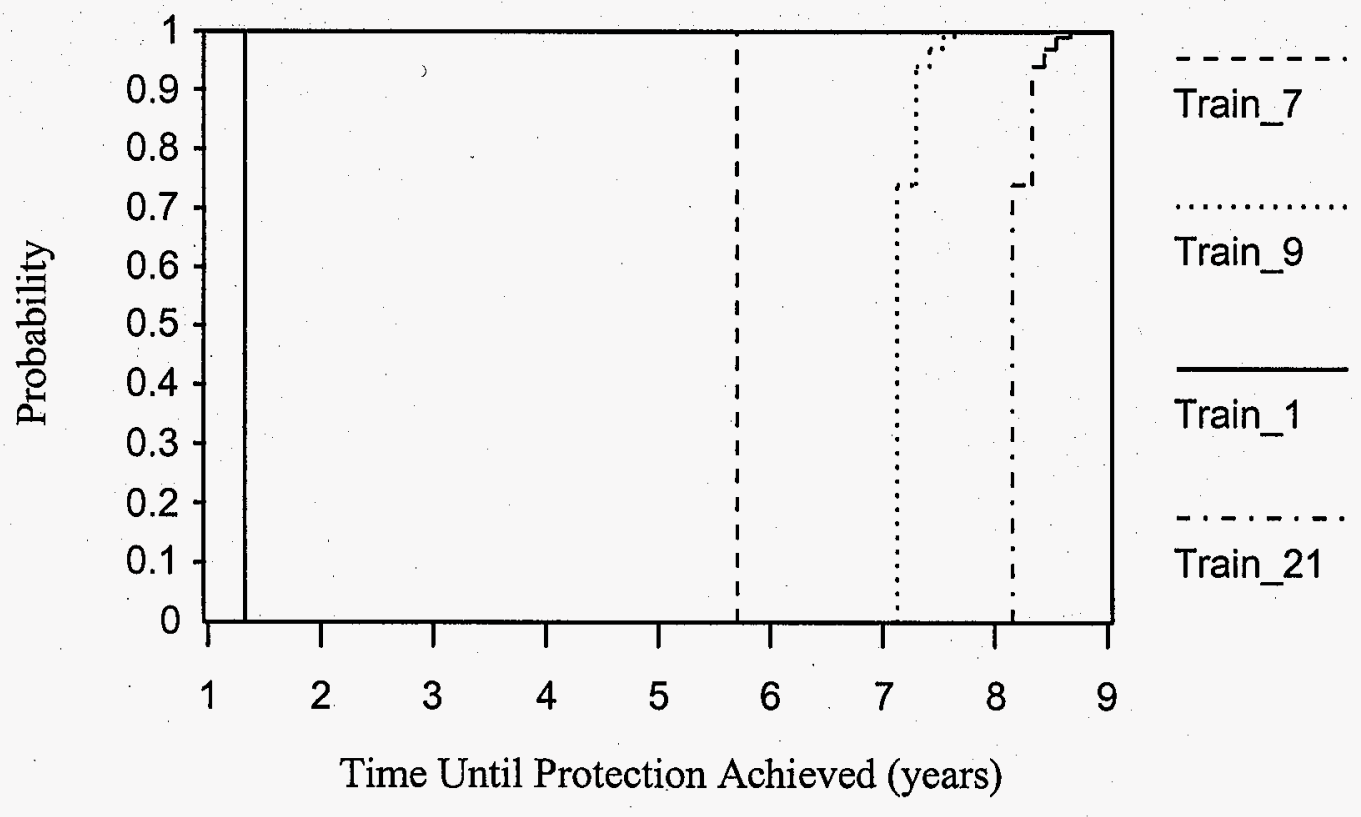


Figure 4.12 Risk Profile for Time

\subsection{Conclusions}

Through deterministic analysis, the 23 candidate trains were evaluated and screened by the use of bar graphs and scatter plots. The top four trains, those that best meet the CERCLA criteria at all spill volumes are:

* Train 7 - 2Phase and Surfactants

* Train 9 - 2Phase and Oxidation

* Train 1 - DUS

* Train 21 - LASAGNA and Oxidation

Further probabilistic analysis shows the impact of volume uncertainty on these trains with respect to overall CERCLA Utility, Net Present Cost and Time Until Protection is Achieved. Table 4.4 compares the top four trains against each other with respect to expected overall CERCLA Utility, expected Net Present Cost and expected Time Until Protection is Achieved by ranking the trains $1^{\text {st }}$ through $4^{\text {th }}$. Appendix L provides the actual values associated with these rankings. There was no train that ranked the highest consistently across all three categories as shown in Table 4.4 .

Table 4.4 Summary of Top Four Train Rankings

\begin{tabular}{|c|c|c|c|}
\hline Trains & $\begin{array}{c}\text { Expected Overall } \\
\text { CERCLA Utility }\end{array}$ & $\begin{array}{c}\text { Expected Net } \\
\text { Present Cost }\end{array}$ & $\begin{array}{c}\text { Expected Time Until } \\
\text { Protection Achieved }\end{array}$ \\
\hline Train 1 & 3 & 2 & 1 \\
\hline Train 7 & 1 & 4 & 2 \\
\hline Train 9 & 2 & 3 & 3 \\
\hline Train 21 & 4 & 1 & 4 \\
\hline
\end{tabular}


A risk seeking decision maker, strictly motivated by achieving the lowest expected cost, willing to accept the risks of a longer expected time to remediate and a lower expected CERCLA utility, would select Train 21. A risk averse decision maker would select Train 1 because although the expected cost is slightly higher then Train 21 , the expected variation in cost is less. In addition, Train 1 performs the quickest and has an expected CERCLA utility that is very close to Trains 9 and 7 . If the decision maker is risk seeking, from the aspect that costs are of no concern, then Train 7 is the best pick as it ranks highest in expected utility and second best with respect to time.

The analysis provided in this chapter is susceptible to the accuracy of the data and assumptions made in both the decision analysis models and life cycle cost model. This information should be used in concert with expert opinion and should complement the decision making process not supersede it. 


\section{Findings, Conclusions, and Recommendations}

\subsection{Summary of Analysis and Results}

Selecting a remediation technology for a CERCLA site is a very complicated process. Although guidance, such as the NCP within CERCLA and other related environmental regulations exists, it does not provide a lucid, traceable methodology for evaluating remediation technologies.

Utilizing the concepts of value-focused thinking and multiattribute preference theory and basing them in CERCLA, provides a defensible, transparent methodology to assist decision makers in structuring their analysis of remediation technologies (trains). Value-focused thinking requires decision makers to take a step back and examine their values in the decision opportunity. Identifying values assists in generating alternatives (or trains) that meet those values; trains that may not have been obvious otherwise. Multiattribute preference theory supports decision analysis modeling which quantifies the values and preferences of the decision maker; allowing trains to be ranked on their ability to meet those values. Quantification allows further sensitivity analysis on how rankings are subject to change through adjustments in model parameters; such as criteria weights and volume.

The trains selected for this analysis are limited to those that aggressively treat the PCOCs (TCE and Tc-99). There is one exception, the No Action Alternative, Train 23 , which is considered as a baseline. The decision analysis model has 28 evaluation measures that evaluate the five CERCLA balancing criteria. Of these 28 measures 
only 8 are impacted by uncertainty in PCOC volume, the remaining evaluation measures are constant throughout the analysis.

It is important to realize the context of this analysis. This research was conducted prior to the feasibility study, while remedial investigation data was still being collected. The analysis presented serves to demonstrate the type of data that could be generated and how it could be used in the RI/FS decision making process. The deterministic analysis focused on the performance of the trains and their ability to meet the CERCLA criteria at various spill volumes. This portion of the analysis showed how to screen down the initial trains to a smaller set of the most competitive trains shown in Table 5.1

Table 5.1 Description of the Top Four Trains

\begin{tabular}{|l|l|}
\hline Train & \multicolumn{1}{|c|}{ Description } \\
\hline Train 1 & $\begin{array}{l}\text { Dynamic Underground Stripping, addresses all three hydrologic zones } \\
\text { and includes ion exchange, working parallel in the aquifer }\end{array}$ \\
\hline Train 7 & $\begin{array}{l}\text { 2Phase in the Unsaturated and Saturated zones and Surfactants in the } \\
\text { aquifer, working in parallel with ion exchange }\end{array}$ \\
\hline Train 9 & $\begin{array}{l}\text { 2Phase in the Unsaturated and Saturated zones and Oxidation in the } \\
\text { aquifer, without ion exchange }\end{array}$ \\
\hline Train 21 & $\begin{array}{l}\text { LASAGNA in the Unsaturated and Saturated zones and Oxidation in the } \\
\text { aquifer, without ion exchange }\end{array}$ \\
\hline
\end{tabular}

These trains consistently placed in the top five for overall CERCLA value at all spill volumes, except for Train 9 which ranked $6^{\text {th }}$ at the 500,000 gallon spill volume. In addition, when expected CERCLA values/utilities are calculated, these trains again placed in the top four as shown in Table 5.2. Included in this table are the top 6 trains to demonstrate the difference in expected CERCLA value/utility. The second and 
third ranked trains vary by only hundredths in expected value/utility from the top train, but by the sixth ranked train, there is a 0.57 loss in expected CERCLA value/utility compared to the top train. These rankings depend upon the assumptions of the model and the precision of the scoring team in evaluating the technologies.

Table 5.2 Expected CERCLA Value/Utility of Top Trains

\begin{tabular}{|c|c|c|c|}
\hline Train Ranking & Train & $\begin{array}{c}\text { Expected CERCLA } \\
\text { Value/Utility }\end{array}$ & $\begin{array}{c}\text { Difference from } \\
\text { Top Train }\end{array}$ \\
\hline 1 & 7 & 7.61 & \\
\hline 2 & 9 & 7.60 & 0.01 \\
\hline 3 & 1 & 7.56 & 0.05 \\
\hline 4 & 21 & 7.49 & 0.12 \\
\hline 5 & 6 & 7.36 & 0.25 \\
\hline 6 & 13 & 7.04 & 0.57 \\
\hline
\end{tabular}

The top four trains were then subjected to probabilistic analysis demonstrating the impact of volume uncertainty on overall CERCLA utility, Net Present Cost, and Time Until Protection is Achieved. Based on the estimated probabilities provided, in the analysis for overall CERCLA utility, Train 21 is stochastically dominated by the other top four trains. This means that at least one of the other top four trains, at the same level of probability, has equal or greater overall utility. Examining Net Present Cost for dominance revealed that Trains 1 and 21 dominate Train 7, indicating that Trains 1 and 21 cost less than Train 7. Concerning Time Until Protection is Achieved, Train 1 dominates the other three trains by being the train quickest to remediate the site. 


\subsection{Conclusions}

In evaluating how well the top four trains attain overall CERCLA utility, which includes Net Present Cost and Time Until Protection is Achieved, the greatest expected utility achieved is 7.61 for Train 7. A decision maker who is risk neutral may select Train 7 because it does obtain the best overall CERCLA utility. However, a risk seeking decision maker motivated by potentially saving $\$ 700,000$ in expected costs, but at the same time willing to accept the risk of incurring a $\$ 13$ million cost, the loss of a little CERCLA utility and the risk of a longer expected time to remediate, may select Train 21. Conversely, if a risk averse decision maker is concerned about any variation in cost, wants the quickest Time Until Protection is Achieved, and is willing to pay an expected $\$ 700,000$ more, then Train 1 is the best alternative. These are some of the tradeoffs that ultimately must be faced by the decision maker. Again, it is important that these tradeoffs are considered within the context of the modeling assumptions and data accuracy.

\subsection{Recommendations}

The WAG 6 team should use the decision analysis methodology presented in this effort in the actual RJ/FS decision making process. The results and conclusion represented in this report support only the screening of 23 potential remediation alternatives down to four highly competitive alternatives. Although there is a temptation to base the technology selection on this analysis alone, there are serious constraints that must be realized. Quantitative models can not capture all the subtleties present in a complex decision. There is no substitute for expert judgment. 
However, expert judgment can be supported through sound quantitative modeling [Deckro, 1997].

The only technical uncertainty addressed in this analysis is volume. Before implementing any of these four technologies, the decision maker should consider investigating technological risks inherent to each of these top four trains that may impact the assumed $90 \%$ source recovery/destruction rate of TCE. For example, with Train 1 , DUS, the risk of hydroparalysis may limit recovery rates and lengthen time to remediate beyond what is expected. Also, consider oxidation, which is a part of Trains 9 and 21, just how much of a risk is there to unreacted material being left in the aquifer and what potential is there to produce toxic, partially degraded bi-products from this remediation process?

There are also other, potentially limiting, physical uncertainties surrounding the WAG 6 site; such as an operational building located on top of the site, which may impede some technologies' implementability as well as their performance. It may behoove the decision maker to further evaluate these limiting physical characteristics, especially once more RI data becomes available and it is possible to better characterize the geology and model the hydrologeology of the site.

Finally, assumptions made in generating the cost and performance data for the top technologies should be reviewed to determine whether any improvement to the Life Cycle Cost model can be made. In particular, as more field performance data become available to lessen the reliance on vendor performance curves, this data should be incorporated into the DA models. 